\title{
MALMQUIST-LUENBERGER PRODUCTIVITY INDEXES FOR DYNAMIC NETWORK DEA WITH UNDESIRABLE OUTPUTS AND NEGATIVE DATA
}

\author{
Pooja Bansal*ib And Aparna Mehra
}

\begin{abstract}
The data envelopment analysis (DEA) technique is well known for computing the Malmquist-Luenberger productivity index (MLPI) in measuring productivity change in the decisionmaking units (DMUs) over two consecutive periods. In this research, we detect infeasibility of the directional distance function (DDF) based DEA model of MLPI under the variable returns to scale technology when data takes on negative values. We address this problem by developing a novel DDFbased DEA model that computes an improved MLPI. We extend the DDF approach to the dynamic network structure and introduce the dynamic MLPI for analyzing the performance of DMUs over time. We also develop the dynamic sequential MLPI to detect shifts in the efficient frontiers due to random shocks or technological advancements over time. The dynamic network structure in the two indexes comprises multiple divisions in DMUs connected vertically by intermediate productivity links and horizontally over time by carryovers. The proposed models are feasible and bounded with undesirable features and negative and non-negative data values. Real data of 39 Indian commercial public and private banks from 2008 to 2019 used to illustrate the two indexes.
\end{abstract}

Mathematics Subject Classification. 90B10, 90C05, 90C08, 90C39, 90C90, 91B06.

Received July 7, 2021. Accepted February 7, 2022.

\section{INTRODUCTION}

Productivity improvement is essential for the long-run sustainability and well being of the firms. How well a firm stand in an environment of cut-throat competition hinges on how well the firm performs on the productivity front. Given the importance of productivity change, a large body of literature has emerged, aiming at measuring the productivity growth rates using a range of productivity measurement approaches. The earliest methodological developments is attributed to the work of Solow [66] who measured productivity growth using a growth accounting framework. Among the later methodological innovations that enticed a large number of practical applications are Malmquist productivity index (MPI) and Malmquist-Luenberger productivity index (MLPI). These indexes allow decomposing the productivity change into two distinct drivers: efficiency change (EC) and technical change (TC). Though both MPfI and MLPI have emerged as standard tools for computing productivity change, their computation using the non-parametric DEA-based framework attracted more attention both at methodological and application levels.

Keywords. Data envelopment analysis, directional distance function, dynamic network structure, productivity change, dynamic Malmquist-Luenberger productivity indexes.

Department of Mathematics, Indian Institute of Technology Delhi, Hauz Khas, New Delhi 110016, India.

*Corresponding author: pooja.jsm@gmail.com 
The parametric and non-parametric approaches co-exist to measure the efficiency and productivity of entities. However, the two approaches exhibit some advantages and limitations. While, on the one hand, the parametric methods (like stochastic frontier analysis) assume the functional form of the frontier and estimate the parameter in it, the non-parametric method avoids the same altogether. Moreover, unlike parametric techniques, which require parameter estimation in the regression model of the explanatory variables and the probability distribution of the error measure (or noise), the non-parametric methodology of DEA is deterministic. Hence, it does not suffer from estimation errors.

Our present research contributes to both the methodology and the applications. On the theoretical side, we discovered that in the case of negative data, the modified MLPI model in [18] is infeasible. Briec and Kerstens [7] pointed out that many of Malmquist productivity indices models are infeasible. In another work, Briec and Kerstens [8] highlighted the infeasibility of the directional distance function (DDF) based Luenberger productivity index model. It is thus natural to recommend a remedy for it. Taking a leaf from the work of Lin and Chen [46], we propose a novel DDF to build an upgraded MLPI model. We prove that the proposed model is feasible for any real data, thus fully resolving the MLPI DEA model's long-standing infeasibility issue.

Secondly, we note that the traditional MLPI model treats production technology as a black box, excluding intermediate goods or linking activities. We strive to delve deep and unlock the black box in this study in order to reveal the dynamic network structure's insight and complex function. In the dynamic network DEA framework, we propose the dynamic Malmquist-Luenberger productivity index (DMLPI) to assess productivity growth of a unit. However, we realized that, like MLPI, the DMLPI also suffers from the inconsistency issue pointed out by Aparicio et al. [2]. The inconsistency in MLPI referred to a situation when the numerical value did not measure the actual production frontier shifts properly. Aparicio et al. [2] put forward a new postulate, closely related to the notion of sequential frontiers, and showed that the models based on sequential frontiers provide a more reliable measure than the traditional model in computing MLPI. In the same spirit, we finally introduce the dynamic sequential MLPI (DSMLPI) in the dynamic network framework to evaluate the sequential productivity change across different periods and different divisions in the presence of desirable and undesirable outputs with negative data values. The DSMLPI overcomes the technical regress while computing productivity growth over consecutive periods in network dynamic DEA.

To the best of our knowledge, there is no research reported in the literature to cognate DMLPI and DSMLPI in the dynamic network structure under the variable returns to scale (VRS) technology in the presence of negative data-values. The proposed indexes capture the productivity growth or regress independently of the scale change under VRS. At the application level, we analyzed the data of Indian commercial banks from 2008 to 2019 to highlight the viability of DMLPI and DSMLPI.

The paper is structured as follows. In Section 2, we briefly review the relevant DEA literature including dynamic and network framework research, and models involving negative data values. We also present the literature on variants of Malmquist productivity indexes. Section 3 revisits the issue of infeasibility in MLPI in the presence of negative data values. We identify a new direction vector and apply it to formulate an improved MLPI to fix the specific case. Section 4 explains the dynamic network structure in the series. Section 5 introduces the DMLPI and formulates the DDF based DEA model to compute it. The model is shown to be feasible and bounded. Section 6 proposes the DSMLPI, utilizing the sequential DEA frontier composed by applying all data from the reference benchmark time. We also compare the two indexes on the synthetic data. Section 7 presents an application of the two proposed indexes in analyzing productivity change in 39 Indian commercial banks from 2008 to 2019. In Section 8, we present our findings as well as our plans for future research.

\section{LITERATURE REVIEW}

A relevant literature on network and dynamic DEA along with a quick overview of Malmquist productivity index are presented in this section. 


\section{Dynamic DEA models}

The dynamic DEA models study the efficiency change in a decision making unit (DMU) in the presence of inter-temporal dependence of input-output data over a multi-period scenario. The situations at which intertemporal dependence may occur can be divided into two cases. The first case is when the output level is affected by the change in the capital stock over various production periods. The capital stock is the plant, equipment, and other assets that help with production. Emrouznejad and Thanassoulis [20] presented the case of dynamic DEA where the inter-temporal dependence takes place by changing the capital stock among various production periods. Ghobadi [32] introduced a generalized DEA model to pursue such an inter-temporal dependence and extend the questions from inverse DEA to the dynamic DEA.

The second situation for inter-temporal dependency refers to the case in which some outputs produced in a period are utilized as inputs in the next period. Such variables are termed carryovers, which are transmitted over different periods to establish interdependence. The performance of a unit in a given period can be affected by its performance in previous periods. Färe and Grosskopf [25] designed a dynamic DEA model to count the effect of carryovers in efficiency analysis. Since then, there is a burgeoning research $[21,40,54,57]$, to quote a few, in developing models and highlighting applications of dynamic DEA. A survey by Mariz et al. [52] records the evolution of the literature on dynamic DEA models from 1996 to 2016. Tone and Tsutsui [68] introduced a dynamic DEA model applying the SBM approach and classified carryovers into four categories, namely, desirable, undesirable, discretionary, and non-discretionary carryovers. Desirable (undesirable) carryovers are treated as desirable (undesirable) outputs at period $t$ and desirable (undesirable) inputs to period $t+1$. Retained earnings, net earned surplus, carry forward losses, belated demands, non-performing loans, are a few examples of carryovers in different businesses.

\section{Network DEA models}

In the classical form, DEA treats the entire system as a single process black box and aggregate the data to evaluate the efficiency of DMU with no attention to the intermediate products linking the initial inputs to the final outputs. For instance, in an industrial plant composed of multiple independent divisions, a division can produce intermediate products for other divisions to use, giving rise to a network production system. A network DEA model allows investigating the structure and processes inside a DMU. The overall efficiency of the system in a network DEA model reflects the efficiency of divisions in contrast to the traditional DEA models. Charnes et al. [11] were the first to develop a two-stage network DEA model. Kao [41] developed the network DEA model with the classification of two-stage series and parallel structures. Subsequently several authors $[13,16,37]$ made contributions in developing models and highlighting applications of network DEA in a variety of domains under different types of data-sets. One can refer to the text by Kao [42] for more on network DEA.

Integrating the dynamic and network structures into one, Tone and Tsutsui [69] applied the SBM approach to propose a dynamic network DEA (DNDEA) model and called it by a dynamic network slack based model (DNSBM). In this non-radial DEA model, they introduced the carryovers to connect the divisions of a DMU in different periods. Tavana et al. [67] proposed the RDM based dynamic two-stage DEA model for handling negative input-intermediate-output data assuming both the desirable and undesirable carryovers between different periods. Fernández et al. [28] reviewed the applications of the DNDEA in diverse fields. Avkiran [6] applied a DNDEA model in commercial banking. One can refer to $[10,35,74]$, and references therein, for more insight on DNDEA.

\section{Productivity indexes}

The MPI, established by Caves et al. [9] after being introduced by Malmquist [51], analyses productivity change over time. This index is characterized via distance functions and defined as the geometric mean of indexes in two consecutive periods. Chen [12] extended MPI into a non-radial MPI in order to alleviate inefficiencies caused by the non-zero slacks. Some of the recent applications of MPI include studies by Falavigna et al. [24], Fernandez et al. [28], Walheer [71], Njuki et al. [55], and a few more. Conventional MPI fails to assess the actual productivity improvement in the presence of undesirable outputs and their influence on productivity 
(see, $[18,19])$. Chung et al. $[14]$ applied the DDF approach to define the MLPI to quantify productivity and environmental performance in the presence of undesirable outputs. Aparicio et al. [2] explored the issue of MLPI inconsistency and introduced a new postulate on undesirable outputs to fix it. Using their research, Aparicio et al. [4] examined the environmental performance of 39 nations from 1995 to 2007, concluding that technical advancement is the primary driver of productivity growth. Emrouznejad et al. [22] noted that the MLPI inherits the weakness of infeasibility while calculating the cross-period DDFs. Later on, Du et al. [18] raised the concern of infeasibility in computing MLPI and provided a modified variation that used the direction vectors described by Lin and Chen [45] to solve the long-standing problem.

Apart from these studies, Oh et al. [56] discussed inappropriate consideration of the technical features in MLPI. The MLPI operates on the synchronous DEA frontier which assumes that the efficiency frontier in each period envelops the observations from that period only and does not depend on the data of the previous periods. In other words, the efficiency analysis in the subsequent periods does not take into account the technology of the previous periods, and hence, the inward movement of the efficient frontier may indicate some technical regress. Kumar [44] observed technical regress while employing the conventional MLPI. Shestalova [65] argued that technology should be considered in the state of progress or at least remaining unchanged with the progress in time. The technical regress registered in MLPI is rather uncommon in the industrial sector except for some specific areas. Oh et al. [56] came up with an alternative measure for the environmentally sensitive productivity growth, liberated from factitious technical regress. The new measure named the sequential Malmquist-Luenberger productivity index (SMLPI) is the amalgamation of successive sequential reference production sets and the DDF. The notable advantage of SMLPI is that it is circular and operates with sequential DEA frontier, which, in a specific period, envelops all the data points observed up to that time, leaving no possibility of registering any technical regress. Due to the incorporation of past periods information, the SMLPI is less sensitive than MLPI to the presence or absence of a specific observation in the data.

\section{DEA models with negative data}

Scheel [62] suggested to treat negative inputs (outputs) as positive outputs (inputs) to measure efficiency. Seiford and Zhu [63] pointed out that such an arrangement alters the original input-output framework of the process. Ali and Seiford [1] applied data transformation approach using a shifted negative transformation $\psi(x)=-x+\tau, \tau>0$ (sufficiently large) to transform the data into positive values. This method is sensitive to the choice of the shift parameter $\tau$, and can result in inconsistent outcomes [73].

Subsequent years witnessed some research suggestions to tackle negative data values directly. Among all such studies, the range directional measures (RDM) [59], modified slack based measure (SBM) model [64], and semioriented radial measure (SORM) model [23] proved to be useful. Matin et al. [53] and Jahanshahloo and Piri [38] presented the modified SORM models. Lin and Liu [47] analyzed the conditions satisfied by the direction vectors so that the super-efficiency model remains feasible and yields bounded super-efficiency scores in the presence of negative data.

In this paper, we adopt the DDF approach to propose MLPI in a dynamic network DEA framework. We stick to the DDF based DEA modeling for two reasons. One, the DDF aims to increase the desirable outputs while concurrently reducing the undesirable outputs [14]. And two, the findings of Russell and Schworm [61] showed that all path-based indexes, including DDF, satisfy continuity property and violate indication property. Continuity property ensures that a minor error in measuring the input-output data results in only a small error in the efficiency score, and indication property provides that the index value is equal to some specified value if and only if the evaluated DMU is efficient.

Another essential component of our study is adopting variable returns to scale (VRS) in production technology. Coelli et al. [15] and Kourtzidis et al. [43] argued that due to a variety of variables like imperfect competition, budgetary constraints, the decision making units (DMUs) may be forced to operate at a scale that is not necessarily optimal, while constant returns to scale (CRS) measures results in optimal scale operation by all DMUs. Wheelock et al. [72] suggested to assume VRS for better capturing the effects of technical advances and regulatory changes amongst DMUs of various sizes. Färe et al. [27] pointed out that CRS technology is 
inconsistent in the presence of negative valued data, and thus advocated using the VRS technology in productivity analysis. Lovell [48] presented decomposition of Malmquist index under CRS and VRS production technology following the decomposition of Ray and Desli [60].

Zofio et al. [75] claimed that any Malmquist index under VRS would not be regarded as a productivity index. Earlier, Grifell-Tatje and Lovell [33] and Lovell et al. [49] raised an issue of elucidation of Malmquist-type indices under VRS. In response, Portela et al. [58] asserted that the Malmquist index under VRS captures the productivity change net of the scale economies. We follow this assertion, and consider the productivity change to be independent of the scale efficiency change factor.

\section{The MLPI AND INFEASIBILITY CONCERN}

In this section, we highlight the persistent issue of infeasibility in MLPI while computing the cross-period DDFs in the presence of negative data values. We design a new direction vector to resolve this issue.

We shall be using the following notations in this section.

$$
\begin{aligned}
& j \in\{1, \ldots, n\}: \text { the index set of } n \text { DMUs } \\
& i \in\{1, \ldots, m\}: \text { the index set of } m \text { inputs } \\
& r \in\{1, \ldots, s\}: \text { the index set of } s \text { desirable outputs } \\
& p \in\{1, \ldots, q\}: \text { the index set of } q \text { undesirable outputs } \\
& X_{j}^{t}=\left(x_{1 j}^{t}, \ldots, x_{m j}^{t}\right)^{\prime}: \text { the vector of inputs consumed by } \mathrm{DMU}_{j} \text { in period } t \\
& Y_{j}^{t}=\left(y_{1 j}^{t}, \ldots, y_{s j}^{t}\right)^{\prime}: \text { the vector of desirable outputs produced by } \mathrm{DMU}_{j} \text { in period } t \\
& U_{j}^{t}=\left(u_{1 j}^{t}, \ldots, u_{q j}^{t}\right)^{\prime}: \text { the vector of undesirable outputs produced by } \mathrm{DMU}_{j} \text { in period } t \\
& \lambda_{j}^{t}: \text { the intensity scalar of DMU } j \text { in period } t \\
& o: \text { the DMU under evaluation. }
\end{aligned}
$$

The MLPI measures the productivity change in two consecutive periods $t$ and $t+1$ by noting the most substantial increase in the desirable outputs compatible with the reduction in the undesirable outputs. Under the CRS assumption, Chung et al. [14] defined the production possibility set (PPS) of period $t$ considering the data of period $t+1$ as follows:

$$
P^{t}=\left\{\left(X^{t+1}, Y^{t+1}, U^{t+1}\right) \mid X^{t+1} \geq \sum_{j=1}^{n} \lambda_{j}^{t} X_{j}^{t}, Y^{t+1} \leq \sum_{j=1}^{n} \lambda_{j}^{t} Y_{j}^{t}, U^{t+1}=\sum_{j=1}^{n} \lambda_{j}^{t} U_{j}^{t}, \lambda_{j}^{t} \geq 0, j=1, \ldots, n\right\},
$$

where $X^{t+1}=\left(X_{1}^{t+1}, \ldots, X_{m}^{t+1}\right)^{\prime}, Y^{t+1}=\left(Y_{1}^{t+1}, \ldots, Y_{s}^{t+1}\right)^{\prime}, U^{t+1}=\left(U_{1}^{t+1}, \ldots, U_{q}^{t+1}\right)^{\prime}$, are respectively the input, desirable output, and undesirable output vectors in period $t+1$.

The DDF $D^{t}\left(X^{t+1}, Y^{t+1}, U^{t+1}\right)$ of $\mathrm{DMU}_{o}$ under CRS assumption is described as follows:

$$
\begin{array}{lll} 
& D^{t}\left(X^{t+1}, Y^{t+1}, U^{t+1}\right)=\max \beta_{o} & \\
\text { s.t. } & \sum_{j=1}^{n} \lambda_{j}^{t} y_{r j}^{t} \geq\left(1+\beta_{o}\right) y_{r o}^{t+1}, & r=1, \ldots, s, \\
& \sum_{j=1}^{n} \lambda_{j}^{t} x_{i j}^{t} \leq x_{i o}^{t+1}, & i=1, \ldots, m, \\
& \sum_{j=1}^{n} \lambda_{j}^{t} u_{p j}^{t}=\left(1-\beta_{o}\right) u_{p o}^{t+1}, & p=1, \ldots, q,
\end{array}
$$




$$
\beta_{o} \in \mathbb{R}, \quad \lambda_{j}^{t} \geq 0, \quad j=1, \ldots, n .
$$

The DDF $D^{t}\left(X^{t+1}, Y^{t+1}, U^{t+1}\right)$ can be viewed as the function that evaluates data of $\mathrm{DMU}_{o}$ from period $t+1$ with respect to the production technology of period $t$. An explanatory graphical illustration of MLPI in Section 8.4 in [42] depicts the DDF for a DMU consuming the data and production technology from different periods.

Following Caves et al. [9], Chung et al. [14] defined the DDF based MLPI under CRS assumption as the geometric mean of indexes of two consecutive periods $t$ and $t+1$ as follows:

$$
\mathrm{ML}^{(t, t+1)}=\left(\frac{1+D^{t}\left(X^{t}, Y^{t}, U^{t}\right)}{1+D^{t}\left(X^{t+1}, Y^{t+1}, U^{t+1}\right)} \times \frac{1+D^{t+1}\left(X^{t}, Y^{t}, U^{t}\right)}{1+D^{t+1}\left(X^{t+1}, Y^{t+1}, U^{t+1}\right)}\right)^{\frac{1}{2}} .
$$

Note that the PPS under VRS assumption is the same as $P^{t}$ with an additional constraint $\sum_{j=1}^{n} \lambda_{j}^{t}=1$ in (3.1).

Du et al. [18] observed infeasibility in (3.2) under both CRS and VRS assumptions while calculating the cross-period DDFs namely, $D^{t}\left(X^{t+1}, Y^{t+1}, U^{t+1}\right)$ and $D^{t+1}\left(X^{t}, Y^{t}, U^{t}\right)$. They proposed to replace the equality constraints in the undesirable outputs to the inequalities $U^{t+1} \geq \sum_{j=1}^{n} \lambda_{j}^{t} U_{j}^{t}$ in the PPS $P^{t}$ amounting to replacing the weak disposability by strong disposability in the undesirable outputs in (3.1). A different case is made under VRS assumption, where following Lin and Chen [45], Du et al. [18] chose $\left(-x_{i o}^{t+1}-\max _{1 \leq j \leq n}\left\{x_{i j}^{t}\right\}, y_{r o}^{t+1},-u_{p o}^{t+1}-\max _{1 \leq j \leq n}\left\{u_{p j}^{t}\right\}\right), i=1, \ldots, m, r=1, \ldots, s, p=1, \ldots, q$, as a reference bundle to calculate the DDF of $\mathrm{DMU}_{o}$ in period $t$ consuming the data of period $t+1$ as follows:

$$
\begin{aligned}
& D^{t}\left(X^{t+1}, Y^{t+1}, U^{t+1}\right)=\max \beta_{o} \\
& \text { s.t. } \sum_{j=1}^{n} \lambda_{j}^{t} y_{r j}^{t} \geq\left(1+\beta_{o}\right) y_{r o}^{t+1}, \quad r=1, \ldots, s, \\
& \sum_{j=1}^{n} \lambda_{j}^{t} x_{i j}^{t} \leq\left(1-\beta_{o}\right) x_{i o}^{t+1}-\beta_{o} \max _{1 \leq j \leq n}\left\{x_{i j}^{t}\right\}, \quad i=1, \ldots, m, \\
& \sum_{j=1}^{n} \lambda_{j}^{t} u_{p j}^{t} \leq\left(1-\beta_{o}\right) u_{p o}^{t+1}-\beta_{o} \max _{1 \leq j \leq n}\left\{u_{p j}^{t}\right\}, \quad p=1, \ldots, q, \\
& \sum_{j=1}^{n} \lambda_{j}^{t}=1 \\
& \beta_{o} \in \mathbb{R}, \lambda_{j}^{t} \geq 0, \quad j=1, \ldots, n .
\end{aligned}
$$

Model (M2) thoroughly addresses the infeasibility issue in MLPI except in one case when the data involves negative values. The following exhibit demonstrates this situation.

Illustration 3.1. Consider the dataset of 7 DMUs having one input, one desirable output, and one undesirable output, in two periods $t$ and $t+1$ as described in Table 1 . Columns 2 and 5 report the input, columns 3 and 6 present the desirable output, and columns 4 and 7 show the undesirable output in periods $t$ and $t+1$, respectively. Column 8 shows the cross-period efficiency score $D^{t}\left(X^{t+1}, Y^{t+1}, U^{t+1}\right)$ applying model (M2). The model corresponding to unit $G$ is observed to be infeasible.

Infeasibility limits the broader applications of MLPI in problems involving negative data values such as the return of investment, the profit in business, and so on. Silva Portela et al. [59] documented several drawbacks of data transformation and proposed a DDF based DEA model. Lin and Chen [46] proposed a modified DDF based super-efficiency model to overcome the infeasibility issue with negative data in the super-efficiency analysis. 
TABLE 1. The two period data of 7 DMUs and the cross-period efficiency scores by model (M2).

\begin{tabular}{llllllll}
\hline DMU & $X^{t}$ & $Y^{t}$ & $U^{t}$ & $X^{t+1}$ & $Y^{t+1}$ & $U^{t+1}$ & $D^{t}\left(X^{t+1}, Y^{t+1}, U^{t+1}\right)$ \\
\hline $\mathrm{A}$ & 2 & 4 & 4 & 0 & 2 & -2 & -0.0833 \\
$\mathrm{~B}$ & 4 & 8 & -3 & 2 & 7 & -6 & Infeasible \\
$\mathrm{C}$ & 0 & -4 & 2 & 5 & 4 & 1 & 0.1954 \\
$\mathrm{D}$ & 3 & 4 & -2 & 7 & 2 & 1 & 0.3554 \\
$\mathrm{E}$ & 10 & 8 & 1 & 8 & 5 & 5 & 0.2762 \\
$\mathrm{~F}$ & 5 & 7 & -3 & 6 & -6 & 2 & 0.3559 \\
$\mathrm{G}$ & 1 & 3 & -5 & 3 & 9 & -4 & -0.3889 \\
\hline
\end{tabular}

Taking motivation from their study, in this paper, we attempt to eliminate the infeasibility issue in MLPI by formulating the new direction vector.

Define the direction vectors $\mu^{t}=\left(\mu_{1}^{t}, \ldots, \mu_{m}^{t}\right)^{\prime}, \nu^{t}=\left(\nu_{1}^{t}, \ldots, \nu_{s}^{t}\right)^{\prime}$, and $\omega^{t}=\left(\omega_{1}^{t}, \ldots, \omega_{q}^{t}\right)^{\prime}$ with components

$$
\begin{aligned}
\mu_{i}^{t} & =\xi * \max _{1 \leq j \leq n}\left\{\left|x_{i j}^{t}\right|\right\}, & i & =1, \ldots, m, \\
\nu_{r}^{t} & =\min _{1 \leq j \leq n}\left\{y_{r j}^{t}\right\}-\pi, & r & =1, \ldots, s, \\
\omega_{p}^{t} & =\xi_{1} * \max _{1 \leq j \leq n}\left\{\left|u_{p j}^{t}\right|\right\}, & & p=1, \ldots, q,
\end{aligned}
$$

where $\pi, \xi, \xi_{1}$ are positive reals chosen such that the vectors $\left(X^{t+1}+\mu^{t}\right),\left(Y^{t+1}-\nu^{t}\right)$, and $\left(U^{t+1}+\omega^{t}\right)$ are strictly positive.

Based on these new reference directions, a DDF is obtained as follows:

$$
D^{t}\left(X^{t+1}, Y^{t+1}, U^{t+1}\right)=\max \left\{\beta \mid\left((1-\beta) X^{t+1}-\beta \mu^{t},(1+\beta) Y^{t+1}-\beta \nu^{t},(1-\beta) U^{t+1}-\beta \omega^{t}\right) \in P^{t}\right\}
$$

Here, $P^{t}$ is taken with strong disposability in the undesirable outputs and VRS condition in (3.1). We propose an improved VRS DEA model for calculating the DDF of $\mathrm{DMU}_{o}$ in period $t+1$ via the reference technology of period $t$ as follows:

$$
\begin{aligned}
& D^{t}\left(X^{t+1}, Y^{t+1}, U^{t+1}\right)=\max \beta_{o} \\
& \text { s.t. } \sum_{j=1}^{n} \lambda_{j}^{t} y_{r j}^{t} \geq y_{\text {ro }}^{t+1}+\beta_{o}\left(y_{r o}^{t+1}-\nu_{r}^{t}\right), \quad r=1, \ldots, s, \\
& \sum_{j=1}^{n} \lambda_{j}^{t} x_{i j}^{t} \leq x_{i o}^{t+1}-\beta_{o}\left(x_{i o}^{t+1}+\mu_{i}^{t}\right), \quad i=1, \ldots, m, \\
& \sum_{j=1}^{n} \lambda_{j}^{t} u_{p j}^{t} \leq u_{p o}^{t+1}-\beta_{o}\left(u_{p o}^{t+1}+\omega_{p}^{t}\right), \quad p=1, \ldots, q, \\
& \sum_{j=1}^{n} \lambda_{j}^{t}=1 \\
& \beta_{o} \in \mathbb{R}, \lambda_{j}^{t} \geq 0, \quad j=1, \ldots, n .
\end{aligned}
$$

To begin, we'll show that (3.3) is translation invariant. According to Aparicio et al. [3], a DDF is translation invariant if and only if the directional vector associated with the translated sample of units is equivalent to the one associated with the original DMUs. 
Assume that the outputs of all DMUs are translated to $y_{r j}^{t^{\prime}}=y_{r j}^{t}+\tau_{r}, r=1, \ldots, s, j=1, \ldots, n, t=1, \ldots, T$, where, $\tau_{r}, r=1, \ldots, s$, are arbitrary constants. The translated $\nu_{r}^{t^{\prime}}$ should be calculated by

$$
\nu_{r}^{t^{\prime}}=\min _{1 \leq j \leq n}\left\{y_{r j}^{t^{\prime}}\right\}-\pi=\min _{1 \leq j \leq n}\left\{y_{r j}^{t}+\tau_{r}\right\}-\pi=\min _{1 \leq j \leq n}\left\{y_{r j}^{t}\right\}+\tau_{r}-\pi=\nu_{r}^{t}+\tau_{r}
$$

Hence, the output directional vector of the translated DMUs $y_{r j}^{t+1^{\prime}}-\nu_{r}^{t^{\prime}}=y_{r j}^{t+1}+\tau_{r}-\nu_{r}^{t}-\tau_{r}=y_{r j}^{t+1}-\nu_{r}^{t}$, remain invariant.

If all the inputs of DMUs are translated to $x_{i j}^{t^{\prime}}=x_{i j}^{t}+\eta_{i}, i=1, \ldots, m, j=1, \ldots, n, t=1, \ldots, T$, where, $\eta_{i}, i=1, \ldots, m$, are arbitrary constants. The translated $\mu_{i}^{t^{\prime}}$ should be calculated by

$$
\mu_{i}^{t^{\prime}}=\xi * \max _{1 \leq j \leq n}\left\{\left|x_{i j}^{t^{\prime}}\right|\right\}=\xi * \max _{1 \leq j \leq n}\left\{\left|x_{i j}^{t}+\eta_{i}\right|\right\}=\xi * \max _{1 \leq j \leq n}\left\{\left|x_{i j}^{t}\right|\right\}-\eta_{i}=\mu_{i}^{t}-\eta_{i},
$$

note that, we translated $\mu_{i}^{t}$ by the opposite amount of the corresponding input translation to ensure translation invariance of the input directional vector, as specified by Lin and Chen [46]. Hence, the input directional vector of the translated DMUs $x_{i j}^{t+1^{\prime}}-\mu_{i}^{t^{\prime}}=x_{i j}^{t+1}+\eta_{i}-\mu_{i}^{t}-\eta_{i}=x_{i j}^{t+1}-\mu_{i}^{t}$, remain invariant.

On the similar lines, we can show that the directional vector of undesirable output is translation invariant. Hence, we conclude that the proposed DDF is tranlsation invariant.

Theorem 3.2. Model (M3) is feasible and bounded, and its optimal value $\beta_{o}^{*}>-1$.

Proof. The inequalities (3.4)-(3.6) can be written as follows:

$$
\begin{array}{ll}
\beta_{o} \leq \frac{\sum_{j=1}^{n} \lambda_{j}^{t} y_{r j}^{t}-y_{r o}^{t+1}}{y_{r o}^{t+1}-\nu_{r}^{t}}, & r=1, \ldots, s, \\
\beta_{o} \leq \frac{x_{i o}^{t+1}-\sum_{j=1}^{n} \lambda_{j}^{t} x_{i j}^{t}}{x_{i o}^{t+1}+\mu_{i}^{t}}, & i=1, \ldots, m, \\
\beta_{o} \leq \frac{u_{p o}^{t+1}-\sum_{j=1}^{n} \lambda_{j}^{t} u_{p j}^{t}}{u_{p o}^{t+1}+\omega_{p}^{t}}, & p=1, \ldots, q .
\end{array}
$$

For a non-negative vector $\lambda^{t}$ satisfying (3.7), we can choose $\beta_{o}$, as

$$
\beta_{o} \leq \min \left(\min _{1 \leq r \leq s}\left\{\frac{\sum_{j=1}^{n} \lambda_{j}^{t} y_{r j}^{t}-y_{r o}^{t+1}}{y_{r o}^{t+1}-\nu_{r}^{t}}\right\}, \min _{1 \leq i \leq m}\left\{\frac{x_{i o}^{t+1}-\sum_{j=1}^{n} \lambda_{j}^{t} x_{i j}^{t}}{x_{i o}^{t+1}+\mu_{i k}^{t}}\right\}, \min _{1 \leq p \leq q}\left\{\frac{u_{p o}^{t+1}-\sum_{j=1}^{n} \lambda_{j}^{t} u_{p j}^{t}}{u_{p o}^{t+1}+\omega_{p}^{t}}\right\}\right) .
$$

Therefore, we can find $\left(\lambda^{t}=\left(\lambda_{j}^{t}, j=1, \ldots, n\right), \beta_{o}\right)$ in the feasible set of (M3), ensuring that the model is feasible. Moreover, by (3.8), the model is bounded above, hence, optimal solution exists with a finite optimal value $\beta_{o}^{*}$.

We next prove that $\beta_{o}^{*}>-1$. We show that, for any non-negative vector $\lambda^{t}$ satisfying (3.7), we can find positive constants $\pi, \xi$, and $\xi_{1}$ such that each of the three ratios in (3.8) are strictly greater than -1 .

From (3.4), for any $\pi>0$,

$$
\frac{\sum_{j=1}^{n} \lambda_{j}^{t} y_{r j}^{t}-y_{r o}^{t+1}}{y_{r o}^{t+1}-\nu_{r}^{t}} \geq \frac{\min _{1 \leq j \leq n}\left\{y_{r j}^{t}\right\}-y_{r o}^{t+1}}{y_{r o}^{t+1}-\nu_{r}^{t}}>-1, \quad r=1, \ldots, s, k=1, \ldots, K .
$$

If we choose $\xi$ such that

$$
\xi>\max \left\{0, \max _{1 \leq i \leq m}\left\{-\frac{x_{i o}^{t+1}}{\max _{1 \leq j \leq n}\left\{\left|x_{i j}^{t}\right|\right\}}\right\}, \max _{1 \leq i \leq m}\left\{\frac{\max _{1 \leq j \leq n}\left\{x_{i j}^{t}\right\}-2 x_{i o}^{t+1}}{\max _{1 \leq j \leq n}\left\{\left|x_{i j}^{t}\right|\right\}}\right\}\right\},
$$


TABle 2. The cross-period efficiency scores by model (M3) on the data in Table 1, with $\pi=1, \xi=3, \xi_{1}=3$.

\begin{tabular}{ll}
\hline DMU & $D^{t}\left(X^{t+1}, Y^{t+1}, U^{t+1}\right)$ \\
\hline A & -0.0276 \\
B & -0.1884 \\
C & 0.0842 \\
D & 0.1602 \\
E & 0.1318 \\
F & 0.1561 \\
G & -0.0843 \\
\hline
\end{tabular}

then, $\xi>0$, and for all $i=1, \ldots, m$,

$$
\begin{aligned}
& \xi \max _{1 \leq j \leq n}\left\{\left|x_{i j}^{t}\right|\right\}>-x_{i o}^{t+1}, \\
& \xi \max _{1 \leq j \leq n}\left\{\left|x_{i j}^{t}\right|\right\}>\max _{1 \leq j \leq n}\left\{x_{i j}^{t}\right\}-2 x_{i o}^{t+1} \geq \sum_{j=1}^{n} \lambda_{j}^{t} x_{i j}^{t}-2 x_{i o}^{t+1} .
\end{aligned}
$$

From (3.9) and (3.10), we get that, for all $i=1, \ldots, m, \quad x_{i o}^{t+1}+\mu_{i}^{t}>0$, and $\frac{x_{i o}^{t+1}-\sum_{j=1}^{n} \lambda_{j}^{t} x_{i j}^{t}}{x_{i o}^{t+1}+\mu_{i}^{t}}>-1$. Consequently, $X^{t+1}+\mu^{t}>0$, and the second ratio in (3.8)

$$
\min _{1 \leq i \leq m} \frac{x_{i o}^{t+1}-\sum_{j=1}^{n} \lambda_{j}^{t} x_{i j}^{t}}{x_{i o}^{t+1}+\mu_{i}^{t}}>-1
$$

In a similar way, we can choose a constant $\xi_{1}>0$ such that $U^{t+1}+\omega^{t}>0$, and the third ratio in (3.8), corresponding to the undesirable outputs, is strictly greater than -1 .

Furthermore, at the optimal solution, there is at least one binding constraint in (3.4)-(3.6), else otherwise, we can apply (3.8) to find a feasible solution with $\beta_{o}$ lower than the optimal value $\beta_{o}^{*}$. Thus, $\beta_{o}^{*}>-1$.

The cross-period efficiency scores on the dataset described in Table 1 by model (M3) are reported in Table 2. The value of $D^{t}\left(X^{t+1}, Y^{t+1}, U^{t+1}\right)$ is less than the corresponding values in Table 1 indicating that, in comparison to model (M2), the DMUs at $t+1$ are closer to the efficient frontier at $t$ by our proposed model (M3) resulting in better target values for the DMUs.

We use the data in Table 1 to present the graphical interpretation of the direction vector in computing the cross-period DDFs, omitting the data of undesirable output for geometrical convenience. In Table 3, Column 2 records the $\beta$ value by model (M3). Columns 3 and 4 depict the input and output targets for DMUs in period $t+1$ when projected on the efficient frontier at a period $t$. The graphical representation of the efficient frontier at period $t$, data from period $t+1$, and their associated targets on the efficient frontier are shown in Figure 1.

DMUs B, C, E, and $\mathrm{G}$ are all efficient at $t$, forming an efficient frontier at $t$ (shown in blue in Fig. 1). Rest three units A, D, F (the blue dots in the PPS of $t$ ) are inefficient at $t$. The goal is to project the seven units to this efficient frontier at period $t+1$ (as indicated by the green dots). To compute $D^{t}\left(X^{t+1}, Y^{t+1}\right)$, we apply model (M3). We can observe that $D^{t}\left(X^{t+1}, Y^{t+1}\right)<0$ for units A, B and $\mathrm{G}$, because they are beyond the PPS of period $t$. To reach the efficient frontier at $t$, these three must raise their inputs and decrease their outputs at $t+1$. Our reasoning is supported by the results in columns 3 and 4 . The remaining units $\mathrm{C}, \mathrm{D}, \mathrm{E}$, and $\mathrm{F}$ are located within the PPS of period $t$ and can meet their objectives as usual (by increasing output and reducing input). In Figure 1, the direction vectors for the DMUs at period $t+1$ to attain the efficient frontier at period $t$ are red lines. 
TABle 3. Projections of $t+1$ period input-output data to the $t$ th period efficient frontier, where $D^{t}\left(X^{t+1}, Y^{t+1}\right)$, computed using model (M3) with $\pi=1$ and $\xi=3$.

\begin{tabular}{llll}
\hline DMUs & $D^{t}\left(X^{t+1}, Y^{t+1}\right)$ & $X_{t}^{t+1}$ & $Y_{t}^{t+1}$ \\
\hline A & -0.0276 & 0.8295 & 1.8065 \\
B & -0.0357 & 3.1429 & 6.5714 \\
C & 0.0842 & 2.0545 & 4.7574 \\
D & 0.1602 & 1.0728 & 3.1214 \\
E & 0.1318 & 2.9909 & 6.3182 \\
F & 0.1667 & 0 & -6.1667 \\
G & -0.0714 & 5.3571 & 8 \\
\hline
\end{tabular}

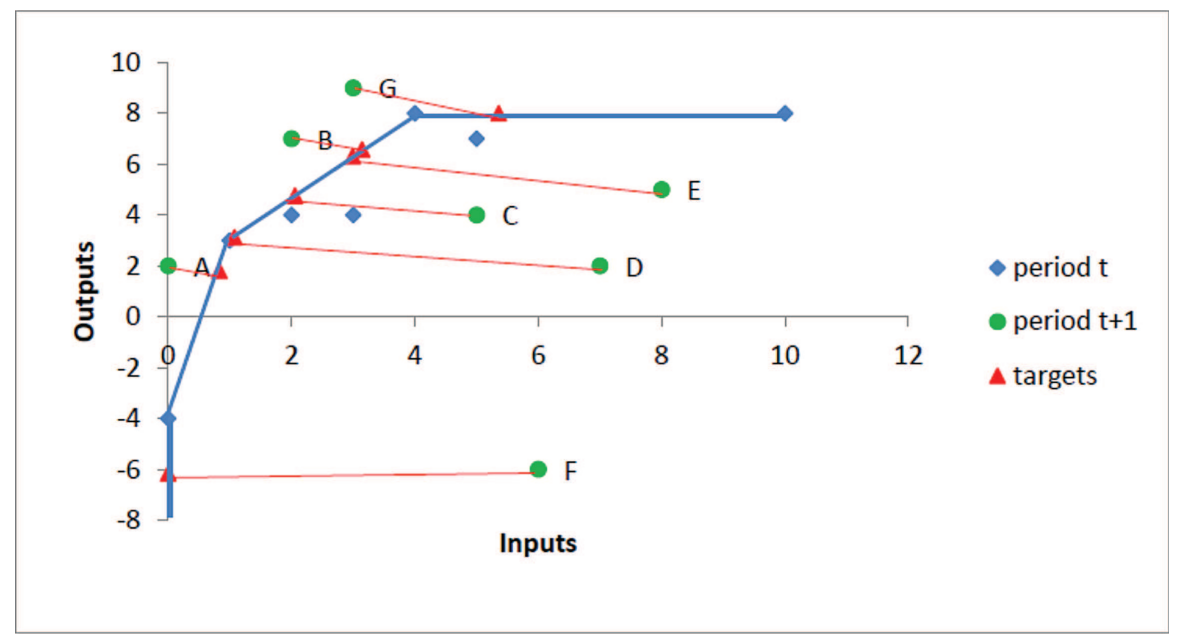

Figure 1. Projections of DMUs data at $t+1$ to the efficient frontier formed by the data of the DMUs at period $t$. The efficient frontier at $t$ is depicted in blue, the green dots represent the data of DMUs at $t+1$, and projections of $t+1$ data on the efficient frontier at $t$ along the proposed direction vectors are in red.

Model (M3) projects all units at $t+1$ on the efficient frontier at $t$; however, the projections are not necessarily strong efficient. For example, at $t+1$, units $\mathrm{F}$ and $\mathrm{G}$ are projected onto the weak efficient frontier at $t$. Our findings are consistent with those published by Portela et al. [59].

We are now in a position to introduce the improved MLPI as the geometric mean of two-period indexes as follows:

$$
\begin{aligned}
\mathrm{ML}^{(t, t+1)} & =\left(\frac{1+D^{t}\left(X^{t}, Y^{t}, U^{t}\right)}{1+D^{t}\left(X^{t+1}, Y^{t+1}, U^{t+1}\right)} \times \frac{1+D^{t+1}\left(X^{t}, Y^{t}, U^{t}\right)}{1+D^{t+1}\left(X^{t+1}, Y^{t+1}, U^{t+1}\right)}\right)^{\frac{1}{2}} \\
& =\left(\frac{1+D^{t}\left(X^{t}, Y^{t}, U^{t}\right)}{1+D^{t+1}\left(X^{t+1}, Y^{t+1}, U^{t+1}\right)}\right) \times\left(\frac{1+D^{t+1}\left(X^{t+1}, Y^{t+1}, U^{t+1}\right)}{1+D^{t}\left(X^{t+1}, Y^{t+1}, U^{t+1}\right)} \times \frac{1+D^{t+1}\left(X^{t}, Y^{t}, U^{t}\right)}{1+D^{t}\left(X^{t}, Y^{t}, U^{t}\right)}\right)^{\frac{1}{2}} .
\end{aligned}
$$

The term in the first bracket from the left depicts efficiency change or shift in the DMU from the efficient frontier over the period. The term in second bracket measures the technical change, which itself is the product of two factors measuring the frontier shift in the DMU at periods $t+1$ and $t$, respectively. Note, $\mathrm{ML}^{(t, t+1)}>1$ 


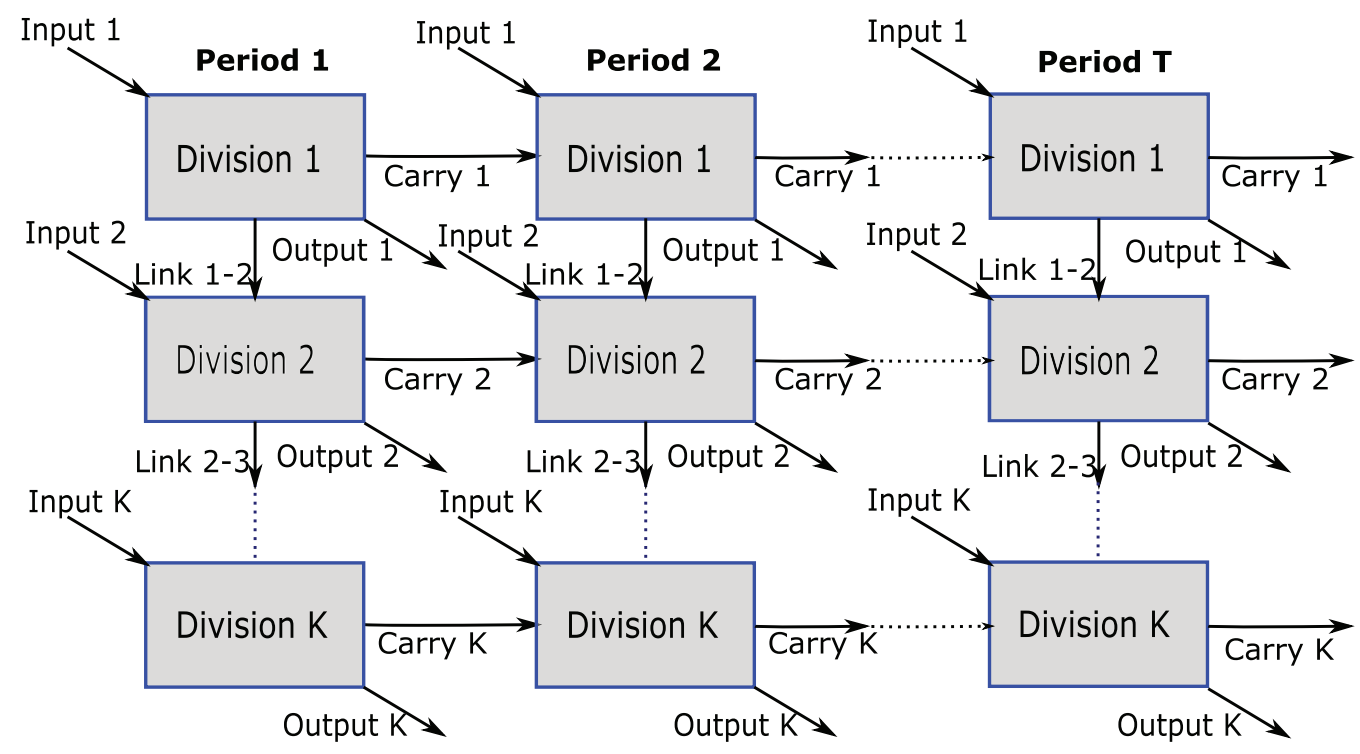

Figure 2. The dynamic network series structure with $K$ divisions and $T$ period of analysis. The divisions are connected vertically through intermediate links and horizontally across time by the carryover activities.

implies improvement in productivity while $\mathrm{ML}^{(t, t+1)}<1$ indicates productivity regress due to its components, efficiency change and technical change, not subject to the scale change from period $t$ to $t+1$.

\section{DynAmic Network DEA structure}

The dynamic network DEA considers the internal network structure of a DMU over the period. In this paper, we assume that the DEA network possesses a series structure in which each DMU comprises of $K$ divisions linked in series. Besides producing its outputs, the division also produces the intermediate products used by the next succeeding division to produce its outputs. We assume that the outputs of each division are different from their intermediate products. We also assume that each division is supplied with the exogenous inputs along with the intermediate inputs received from the former division. The multiple divisions of a DMU are connected vertically via the intermediate products and horizontally across the consecutive periods through the carryover activities. Figure 2 presents the architect of the dynamic network DEA for a DMU.

We shall be using the following notations for dynamic network DEA models in the discussion to follow.

$\Gamma$ : time horizon of study

$j \in\{1, \ldots, n\}$ : the index set of $n$ DMUs

$k \in\{1, \ldots, K\}:$ the index set of $K$ divisions

$t \in\{1, \ldots, T\}$ : the index set of $T$ periods

$i \in\{1, \ldots, m\}:$ the index set of $m$ inputs

$r \in\{1, \ldots, s\}:$ the index set of $s$ desirable outputs

$p \in\{1, \ldots, q\}$ : the index set of $q$ undesirable outputs 
$\ell_{1} \in\{1, \ldots$, ngood $\}:$ the index set of ngood desirable carryover

$\ell_{2} \in\{1, \ldots, n b a d\}$ : the index set of nbad undesirable carryover

$g \in\{1, \ldots, h\}:$ the index set of $h$ intermediate products

$o$ : a DMU under evaluation

$X_{j k}^{t}=\left(x_{1 j k}^{t}, \ldots, x_{m j k}^{t}\right)^{\prime}$ : the vector of inputs consumed by $\mathrm{DMU}_{j}$ for division $k$ in period $t$

$Y_{j k}^{t}=\left(y_{1 j k}^{t}, \ldots, y_{s j k}^{t}\right)^{\prime}$ : the vector of desirable outputs produced by $\mathrm{DMU}_{j}$ for divission $k$ in period $t$

$U_{j k}^{t}=\left(u_{1 j k}^{t}, \ldots, u_{q j k}^{t}\right)^{\prime}:$ the vector of undesirable outputs produced by $\mathrm{DMU}_{j}$ for division $k$ in period $t$

$C_{j k}^{d t}=\left(c_{1 j k}^{d t}, \ldots, c_{n g o o d j k}^{d t}\right)^{\prime}:$ the vector of desirable carryovers produced by $\mathrm{DMU}_{j}$ from period

$t$ to $t+1$ for division $k$

$C_{j k}^{u t}=\left(c_{1 j k}^{u t}, \ldots, c_{n b a d j k}^{u t}\right)^{\prime}:$ the vector of undesirable carryovers produced by $\mathrm{DMU}_{j}$ from period

$t$ to $t+1$ for division $k$

$Z_{j k}^{t}=\left(z_{1 j k}^{t}, \ldots, z_{h j k}^{t}\right)^{\prime}:$ the vector of intermediate products by $\mathrm{DMU}_{j}$ from division $k$ to $k+1$

in period $t$

$\lambda_{j k}^{t}$ : the intensity scalar of $\mathrm{DMU}_{j}$ for division $k$ in period $t$.

Tone et al. [69] classify the carryover activities into four categories namely, desirable, undesirable, discretionary, and non-discretionary. We have included only the desirable and undesirable carryover activities constraints in our present study; the remaining two could be added easily following the same procedure. Furthermore, Tone et al. [69] presented four cases of the linking constraints namely, free and non-discretionary, both as input and output links. Below, we explain the formulation of constraints corresponding to the input-output links connecting the divisions vertically.

Consider two divisions $k$ and $k+1$ in succession. The linking activities are outputs from division $k$ and hence a larger amount is considered favorable, so

$$
\sum_{j=1}^{n} \lambda_{j k}^{t} z_{g j k}^{t} \geq z_{g o k}^{t}, \quad g=1, \ldots, h, t=1, \ldots, T .
$$

The linking activities are inputs to the division $k+1$ and hence a smaller amount is regarded favorable, so

$$
\sum_{j=1}^{n} \lambda_{j k+1}^{t} z_{g j k}^{t} \leq z_{g o k}^{t}, \quad g=1, \ldots, h, t=1, \ldots, T .
$$

From (4.1) and (4.2), we have

$$
\sum_{j=1}^{n} \lambda_{j k}^{t} z_{g j k}^{t} \geq \sum_{j=1}^{n} \lambda_{j k+1}^{t} z_{g j k}^{t}, \quad g=1, \ldots, h, t=1, \ldots, T .
$$

The constraints in (4.3) will be imposed as the equality constraint to ensure that there is no loss and no new creation of intermediate products while passing from division $k$ to division $k+1, k=1, \ldots, K-1$.

\section{Dynamic ML PRoductivity index}

The dynamic network DEA models generate relative period efficiency scores based on efficiency frontiers in each period, but they do not capture each frontier's absolute position in the study's time horizon. In this 
section, we propose a dynamic MLPI of DMUs. The proposed model is shown to be feasible in evaluating the cross-period DDFs in the presence of undesirable and desirable features taking negative and non-negative data values.

To measure the productivity change, liberated from scale change between two consecutive periods $t$ and $t+1$, the dynamic network PPS in period $t$ consuming the data of period $t+1$ under the VRS assumption is defined as follows:

$$
\begin{aligned}
P^{\prime t}= & \left\{\left(X_{k}^{t+1}, Y_{k}^{t+1}, U_{k}^{t+1}, C_{k}^{d t+1}, C_{k}^{u t+1}\right) \mid X_{k}^{t+1} \geq \sum_{j=1}^{n} \lambda_{j k}^{t} X_{j k}^{t}, Y_{k}^{t+1} \leq \sum_{j=1}^{n} \lambda_{j k}^{t} Y_{j k}^{t}, U_{k}^{t+1} \geq \sum_{j=1}^{n} \lambda_{j k}^{t} U_{j k}^{t},\right. \\
& C_{k}^{d t+1} \leq \sum_{j=1}^{n} \lambda_{j k}^{t} C_{j k}^{d t}, C_{k}^{d t} \geq \sum_{j=1}^{n} \lambda_{j k}^{t} C_{j k}^{d t-1}, C_{k}^{u t+1} \geq \sum_{j=1}^{n} \lambda_{j k}^{t} C_{j k}^{u t}, C_{k}^{u t} \leq \sum_{j=1}^{n} \lambda_{j k}^{t} C_{j k}^{u t-1}, k=1, \ldots, K, \\
& \left.\sum_{j=1}^{n} \lambda_{j k}^{t} Z_{j k}^{t}=\sum_{j=1}^{n} \lambda_{j k+1}^{t} Z_{j k}^{t}, k=1, \ldots, K-1, \sum_{j=1}^{n} \lambda_{j k}^{t}=1, \lambda_{j k}^{t} \geq 0, j=1, \ldots, n, k=1, \ldots, K\right\},
\end{aligned}
$$

where $X_{k}^{t}=\left(X_{1 k}^{t}, \ldots, X_{m k}^{t}\right)^{\prime}, Y_{k}^{t}=\left(Y_{1 k}^{t}, \ldots, Y_{s k}^{t}\right)^{\prime}, U_{k}^{t}=\left(U_{1 k}^{t}, \ldots, U_{q k}^{t}\right)^{\prime}, C_{k}^{d t}=\left(C_{1 k}^{d t}, \ldots, C_{n g o o d k}^{d t}\right)^{\prime}, C_{k}^{u t}=$ $\left(C_{1 k}^{u t}, \ldots, C_{n b a d k}^{u t}\right)^{\prime}$, are respectively the input, desirable output, undesirable output, desirable carryover, and undesirable carryover vectors for division $k$ at time $t$, and $\lambda_{j k}^{t}$ are the intensity scalars.

For $t=1, \ldots, T, \quad k=1, \ldots, K$, define vectors $\mu_{k}^{t}=\left(\mu_{1 k}^{t}, \ldots, \mu_{m k}^{t}\right)^{\prime}, \nu_{k}^{t}=\left(\nu_{1 k}^{t}, \ldots, \nu_{s k}^{t}\right)^{\prime}, \omega_{k}^{t}=$ $\left(\omega_{1 k}^{t}, \ldots, \omega_{q k}^{t}\right)^{\prime}, \gamma_{k}^{t}=\left(\gamma_{1 k}^{t}, \ldots, \gamma_{n g o o d k}^{t}\right)^{\prime} \sigma_{k}^{t}=\left(\sigma_{1 k}^{t}, \ldots, \sigma_{n b a d k}^{t}\right)^{\prime}, \alpha_{k}^{t}=\left(\alpha_{1 k}^{t}, \ldots, \alpha_{n g o o d k}^{t}\right)^{\prime}$, and $\rho_{k}^{t}=$ $\left(\rho_{1 k}^{t}, \ldots, \rho_{\text {nbad } k}^{t}\right)^{\prime}$, with components as follows:

$$
\begin{aligned}
\mu_{i k}^{t} & =\xi * \max _{1 \leq j \leq n}\left\{\left|x_{i j k}^{t}\right|\right\}, & & i=1, \ldots, m, \\
\nu_{r k}^{t} & =\min _{1 \leq j \leq n}\left\{y_{r j k}^{t}\right\}-\pi, & & r=1, \ldots, s, \\
\omega_{p k}^{t} & =\xi^{\prime} * \max _{1 \leq j \leq n}\left\{\left|u_{p j k}^{t}\right|\right\}, & & p=1, \ldots, q, \\
\gamma_{\ell_{1} k}^{t} & =\min _{1 \leq j \leq n}\left\{c_{\ell_{1} j k}^{d t}\right\}-\pi^{\prime}, & & \ell_{1}=1, \ldots, \text { ngood }, \\
\sigma_{\ell_{2} k}^{t} & =\xi^{\prime \prime} * \max _{1 \leq j \leq n}\left\{\left|c_{\ell_{2} j k}^{u t}\right|\right\}, & & \ell_{2}=1, \ldots, \text { nbad }, \\
\alpha_{\ell_{1} k}^{t} & =\xi^{\prime \prime \prime} * \max _{1 \leq j \leq n}\left\{c_{\ell_{1} j k}^{d t}\right\}, & & \ell_{1}=1, \ldots, \text { ngood }, \\
\rho_{\ell_{2} k}^{t} & =\min _{1 \leq j \leq n}\left\{\left|c_{\ell_{2} j k}^{u t}\right|\right\}-\pi^{\prime \prime}, & & \ell_{2}=1, \ldots, \text { nbad } .
\end{aligned}
$$

The direction vectors for $\mathrm{DMU}_{o}$, corresponding to the division $k, k=1, \ldots, K$, are defined as $\left(X_{k}^{t+1}+\mu_{k}^{t}, Y_{k}^{t+1}-\right.$ $\left.\nu_{k}^{t}, U_{k}^{t+1}+\omega_{k}^{t}, C_{k}^{d t+1}-\gamma_{k}^{t}, C_{k}^{u t+1}+\sigma_{k}^{t}, C_{k}^{d t}+\alpha_{k}^{t-1}, C_{k}^{u t}-\rho_{k}^{t-1}\right)$, where $t$ and $t+1$ correspond to the periods of production technology and data under observation, respectively.

Using these direction vectors, the DDFs for $\mathrm{DMU}_{o}$ in period $t$ consuming the data of period $t+1$ is defined as follows:

$$
\begin{aligned}
& D^{t}\left(X^{t+1}, Y^{t+1}, U^{t+1}, C^{d t+1}, C^{u t+1}\right)=\max \left\{\beta_{o} \mid\left(X_{k}^{t+1}-\beta_{o}\left(X_{k}^{t+1}-\mu_{k}^{t}\right), Y_{k}^{t+1}+\beta_{o}\left(Y_{k}^{t+1}-\nu_{k}^{t}\right),\right.\right. \\
& \quad U_{k}^{t+1}-\beta_{o}\left(U_{k}^{t+1}-\omega_{k}^{t}\right), C_{k}^{d t+1}+\beta_{o}\left(C_{k}^{d t+1}-\gamma_{k}^{t}\right), C_{k}^{u t+1}-\beta_{o}\left(C_{k}^{u t+1}-\sigma_{k}^{t}\right), C_{k}^{d t}-\beta_{o}\left(C_{k}^{d t}-\alpha_{k}^{t-1}\right), \\
& \left.\left.\quad C_{k}^{u t}+\beta_{o}\left(C_{k}^{u t}-\rho_{k}^{t-1}\right)\right) \in P^{\prime}, k=1, \ldots, K\right\} .
\end{aligned}
$$


Our new VRS model for evaluating the DDF $D^{t+a}\left(X^{t+b}, Y^{t+b}, U^{t+b}, C^{d t+b}, C^{u t+b}\right), a, b \in\{0,1\}$, for $\mathrm{DMU}_{o}$ is described as follows:

$(\mathrm{M} 4)_{a, b}$

$$
\begin{aligned}
& D^{t+a}\left(X^{t+b}, Y^{t+b}, U^{t+b}, C^{d t+b}, C^{u t+b}\right)=\max \beta_{o}^{a, b} \\
& \text { s.t. } \sum_{j=1}^{n} \lambda_{j k}^{t+a} y_{r j k}^{t+a} \geq y_{r o k}^{t+b}+\beta_{o}^{a, b}\left(y_{r o k}^{t+b}-\nu_{r k}^{t+a}\right), \quad r=1, \ldots, s, k=1, \ldots, K, \\
& \sum_{j=1}^{n} \lambda_{j k}^{t+a} x_{i j k}^{t+a} \leq x_{i o k}^{t+b}-\beta_{o}^{a, b}\left(x_{i o k}^{t+b}+\mu_{i k}^{t+a}\right), \quad i=1, \ldots, m, k=1, \ldots, K, \\
& \sum_{j=1}^{n} \lambda_{j k}^{t+a} u_{p j k}^{t+a} \leq u_{p o k}^{t+b}-\beta_{o}^{a, b}\left(u_{p o k}^{t+b}+\omega_{p k}^{t+a}\right), \quad \quad p=1, \ldots, q, k=1, \ldots, K, \\
& \sum_{j=1}^{n} \lambda_{j k}^{t+a} c_{\ell_{1} j k}^{d t+a} \geq c_{\ell_{1} o k}^{d t+b}+\beta_{o}^{a, b}\left(c_{\ell_{1} o k}^{d t+b}-\gamma_{\ell_{1} k}^{t+a}\right), \quad \ell_{1}=1, \ldots, \text { ngood, } k=1, \ldots, K, \\
& \sum_{j=1}^{n} \lambda_{j k}^{t+a} c_{\ell_{1} j k}^{d t+a-1} \leq c_{\ell_{1} o k}^{d t+b-1}-\beta_{o}^{a, b}\left(c_{\ell_{1} o k}^{d t+b-1}+\alpha_{\ell_{1} k}^{t+a-1}\right), \quad \ell_{1}=1, \ldots, \text { ngood }, k=1, \ldots, K, \\
& \sum_{j=1}^{n} \lambda_{j k}^{t+a} c_{\ell_{2} j k}^{u t+a} \leq c_{\ell_{2} o k}^{u t+b}-\beta_{o}^{a, b}\left(c_{\ell_{2} o k}^{u t+b}+\sigma_{\ell_{2} k}^{t+a}\right), \quad \ell_{2}=1, \ldots, n b a d, k=1, \ldots, K, \\
& \sum_{j=1}^{n} \lambda_{j k}^{t+a} c_{\ell_{2} j k}^{u t+a-1} \geq c_{\ell_{2} o k}^{u t+b-1}+\beta_{o}^{a, b}\left(c_{\ell_{2} o k}^{u t+b-1}-\rho_{\ell_{2} k}^{t+a-1}\right), \quad \ell_{2}=1, \ldots, n b a d, k=1, \ldots, K, \\
& \sum_{j=1}^{n} \lambda_{j k}^{t+a} z_{g j k}^{t+a}=\sum_{j=1}^{n} \lambda_{j, k+1}^{t+a} z_{g j k}^{t+a}, \quad g=1, \ldots, h, k=1, \ldots, K-1, \\
& \sum_{j=1}^{n} \lambda_{j k}^{t+a}=1, \quad k=1, \ldots, K, \\
& \beta_{o}^{a, b} \in \mathbb{R}, \lambda_{j k}^{t} \geq 0, \quad j=1, \ldots, n, k=1, \ldots, K, t=1, \ldots, T,
\end{aligned}
$$

where $X^{t+1}=\left(X_{1}^{t+1}, \ldots, X_{K}^{t+1}\right)^{\prime}, Y^{t+1}=\left(Y_{1}^{t+1}, \ldots, Y_{K}^{t+1}\right)^{\prime}, U^{t+1}=\left(U_{1}^{t+1}, \ldots, U_{K}^{t+1}\right)^{\prime}, C^{d t+1}=$ $\left(C_{1}^{d t+1}, \ldots, C_{K}^{d t+1}\right)^{\prime}, C^{u t+1}=\left(C_{1}^{u t+1}, \ldots, C_{K}^{u t+1}\right)^{\prime}$, are respectively the input, desirable output, undesirable output, desirable carryover, and undesirable carryover vectors at time $t+1$. Note that while evaluating the cross- period DDFs $D^{t+a}\left(X^{t+b}, Y^{t+b}, U^{t+b}, C^{d t+b}, C^{u t+b}\right), a \neq b, a, b \in\{0,1\}$, the constants $\pi, \pi^{\prime}, \pi^{\prime \prime}, \xi, \xi^{\prime}, \xi^{\prime \prime}, \xi^{\prime \prime \prime}$ are chosen such that $\left(y_{r o k}^{t+b}-\nu_{r k}^{t+a}\right),\left(x_{i o k}^{t+b}+\mu_{i k}^{t+a}\right),\left(u_{p o k}^{t+b}+\omega_{p k}^{t+a}\right),\left(c_{\ell_{1} o k}^{d+b}-\gamma_{\ell_{1} k}^{t+a}\right)$, $\left(c_{\ell_{1} o k}^{d t+b-1}+\alpha_{\ell_{1} k}^{t+a-1}\right),\left(c_{\ell_{2} o k}^{u t+b}+\sigma_{\ell_{2} k}^{t+a}\right),\left(c_{\ell_{2} o k}^{u t+b-1}-\rho_{\ell_{2} k}^{t+a-1}\right)$ are positive for all $i, r, p, \ell_{1}, \ell_{2}, k, t$. We can prove the translation invariance of these direction vectors in the same way we did in Section 3. The DMLPI in period $t$ to $t+1$ is defined as follows:

$$
\operatorname{DML}^{(t, t+1)}=\left(\frac{1+D^{t}\left(X^{t}, Y^{t}, U^{t}, C^{d t}, C^{u t}\right)}{1+D^{t}\left(X^{t+1}, Y^{t+1}, U^{t+1}, C^{d t+1}, C^{u t+1}\right)} \times \frac{1+D^{t+1}\left(X^{t}, Y^{t}, U^{t}, C^{d t}, C^{u t}\right)}{1+D^{t+1}\left(X^{t+1}, Y^{t+1}, U^{t+1}, C^{d t+1}, C^{u t+1}\right)}\right)^{\frac{1}{2}} .
$$

Recalling that the CRS technology assumption is not compatible with the negative data [26], it is not appropriate to decompose DMLPI into the factors consisting of scale efficiency change factor as in [22]. The decomposition of DMLPI, independent of scale efficiency change, is described as follows:

$$
\operatorname{DML}^{(t, t+1)}=\left(\frac{1+D^{t}\left(X^{t}, Y^{t}, U^{t}, C^{d t}, C^{u t}\right)}{1+D^{t+1}\left(X^{t+1}, Y^{t+1}, U^{t+1}, C^{d t+1}, C^{u t+1}\right)}\right)
$$




$$
\begin{aligned}
& \times\left(\frac{1+D^{t+1}\left(X^{t+1}, Y^{t+1}, U^{t+1}, C^{d t+1}, C^{u t+1}\right)}{1+D^{t}\left(X^{t+1}, Y^{t+1}, U^{t+1}, C^{d t+1}, C^{u t+1}\right)} \times \frac{1+D^{t+1}\left(X^{t}, Y^{t}, U^{t}, C^{d t}, C^{u t}\right)}{1+D^{t}\left(X^{t}, Y^{t}, U^{t}, C^{d t}, C^{u t}\right)}\right)^{\frac{1}{2}} \\
= & \mathrm{EC}^{(t, t+1)} \times \mathrm{TC}^{(t, t+1)}
\end{aligned}
$$

where efficiency change component $\mathrm{EC}^{(t, t+1)}$ represents the movement of a DMU towards the best practice frontier and technical change component $\mathrm{TC}^{(t, t+1)}$ measures the shift in the efficient frontier composed by all divisions in period $t$ to $t+1$. $\mathrm{DML}^{(t, t+1)}=1$ indicates no change in productivity over the two consecutive periods, while $\mathrm{DML}^{(t, t+1)}>1$ and $\mathrm{DML}^{(t, t+1)}<1$ indicate improvement and regress respectively in productivity in all the divisions of $\mathrm{DMU}_{o}$ from period $t$ to $t+1$.

We need to solve linear problems (M4) $)_{a, b}$, for $a, b \in\{0,1\}$, to compute the DMLPI of DMU $\mathrm{D}_{o}$ between periods $t$ and $t+1$.

Theorem 5.1. For $a, b \in\{0,1\}$, model $(\mathrm{M} 4)_{a, b}$ is feasible and bounded, and its optimal value $\beta_{o}^{* a, b}>-1$.

Proof. If $a=b$, then model (M4) $)_{a, b}$ is feasible by taking $\beta_{o}^{a, b}=0, \lambda_{o k}^{t+a}=\lambda_{o k+1}^{t+a}=1$ and $\lambda_{j k}^{t+a}=\lambda_{j k+1}^{t+a}=0$, $\forall j=1, \ldots, n, j \neq o$. Let $a \neq b$. The inequalities (5.2)-(5.8) can be written as follows:

$$
\begin{aligned}
& \beta_{o}^{a, b} \leq \frac{\sum_{j=1}^{n} \lambda_{j k}^{t+a} y_{r j k}^{t+a}-y_{r o k}^{t+b}}{y_{r o k}^{t+b}-\nu_{r k}^{t+a}}, \quad \quad r=1, \ldots, s, \\
& \beta_{o}^{a, b} \leq \frac{x_{i o k}^{t+b}-\sum_{j=1}^{n} \lambda_{j k}^{t+a} x_{i j k}^{t+a}}{x_{i o k}^{t+b}+\mu_{i k}^{t+a}}, \quad i=1, \ldots, m, \\
& \beta_{o}^{a, b} \leq \frac{u_{p o k}^{t+b}-\sum_{j=1}^{n} \lambda_{j k}^{t+a} u_{p j k}^{t+a}}{u_{p o k}^{t+b}+\omega_{p k}^{t+a}}, \quad \quad p=1, \ldots, q, \\
& \beta_{o}^{a, b} \leq \frac{\sum_{j=1}^{n} \lambda_{j k}^{t+a} c_{\ell_{1 j}}^{d+a}-c_{\ell_{1} o k}^{d t+b}}{c_{\ell_{1} o k}^{d+b}-\gamma_{\ell_{1} k}^{t+a}}, \quad \ell_{1}=1, \ldots, \text { ngood }, \\
& \beta_{o}^{a, b} \leq \frac{c_{\ell_{2} o k}^{u t+b}-\sum_{j=1}^{n} \lambda_{j k}^{t+a} c_{\ell_{2} j k}^{u t+a}}{c_{\ell_{2} o k}^{u+b}+\sigma_{\ell_{2} k}^{t+a}}, \quad \ell_{2}=1, \ldots, \text { nbad. } \\
& \beta_{o}^{a, b} \leq \frac{c_{\ell_{1} o k}^{d t+b-1}-\sum_{j=1}^{n} \lambda_{j k}^{t+a} c_{\ell_{1} j k}^{d+a-1}}{c_{\ell_{1} o k}^{d+b-1}+\alpha_{\ell_{1} k}^{t+a-1}}, \quad \ell_{1}=1, \ldots, \text { ngood, } \\
& \beta_{o}^{a, b} \leq \frac{\sum_{j=1}^{n} \lambda_{j k}^{t+a} c_{\ell_{2} j k}^{u t+1}-c_{\ell_{2} o k}^{u t+b-1}}{c_{\ell_{2} o k}^{u+b-1}-\rho_{\ell_{2}}^{t+a-1}}, \quad \ell_{2}=1, \ldots, n b a d .
\end{aligned}
$$

We firstly intend to show that by choosing the six positive constants $\pi, \pi^{\prime}, \pi^{\prime \prime}, \xi, \xi^{\prime}, \xi^{\prime \prime}, \xi^{\prime \prime \prime}$ appropriately, the seven ratios in block (A) are greater than -1 .

From (5.2), for any $\pi>0$,

$$
\frac{\sum_{j=1}^{n} \lambda_{j k}^{t+a} y_{r j k}^{t+a}-y_{r o k}^{t+b}}{y_{r o k}^{t+b}-\nu_{r k}^{t+a}} \geq \frac{\min _{1 \leq j \leq n}\left\{y_{r j k}^{t+a}\right\}-y_{r o k}^{t+b}}{y_{r o k}^{t+b}-\nu_{r k}^{t+a}}>-1, \quad r=1, \ldots, s, k=1, \ldots, K .
$$

Similarly, for any $\pi^{\prime}>0$ and $\pi^{\prime \prime}>0$,

$$
\frac{\sum_{j=1}^{n} \lambda_{j k}^{t+a} c_{\ell_{1} j k}^{d t+a}-c_{\ell_{1} o k}^{d t+b}}{c_{\ell_{1} o k}^{d t+b}-\gamma_{\ell_{1} k}^{t+a}}>-1, \quad \frac{\sum_{j=1}^{n} \lambda_{j k}^{t+a} c_{\ell_{2} j k}^{u t+a-1}-c_{\ell_{2} o k}^{u t+b-1}}{c_{\ell_{2} o k}^{u t+b-1}-\rho_{\ell_{2} k}^{t+a-1}}>-1 .
$$

Next, consider the ratio in the second inequality in block (A). If we choose

$$
\xi>\max \left\{0, \max _{1 \leq i \leq m, 1 \leq k \leq K}\left\{-\frac{x_{i o k}^{t+b}}{\max _{1 \leq j \leq n}\left\{\left|x_{i j k}^{t+a}\right|\right\}}\right\}, \max _{1 \leq i \leq m, 1 \leq k \leq K}\left\{\frac{\max _{1 \leq j \leq n}\left\{x_{i j k}^{t+a}\right\}-2 x_{i o k}^{t+b}}{\max _{1 \leq j \leq n}\left\{\left|x_{i j k}^{t+a}\right|\right\}}\right\}\right\},
$$


then, $\xi>0$, and

$$
\begin{aligned}
& \xi \max _{1 \leq j \leq n}\left\{\left|x_{i j k}^{t+a}\right|\right\}>-x_{i o k}^{t+b}, \\
& \xi \max _{1 \leq j \leq n}\left\{\left|x_{i j k}^{t+a}\right|\right\}>\max _{1 \leq j \leq n}\left\{x_{i j k}^{t+a}\right\}-2 x_{i o k}^{t+b} \geq \sum_{j=1}^{n} \lambda_{j k}^{t+a} x_{i j k}^{t+a}-2 x_{i o k}^{t+b} .
\end{aligned}
$$

Hence, $x_{i o k}^{t+b}+\mu_{i k}^{t+a}>0$, and $\frac{x_{i o k}^{t+b}-\sum_{j=1}^{n} \lambda_{j k}^{t+a} x_{i j k}^{t+a}}{x_{i o k}^{t+b}+\mu_{i k}^{t+a}}>-1$.

By the similar arguments, we can choose $\xi^{\prime}, \xi^{\prime \prime}$, and $\xi^{\prime \prime \prime}$ to ensure that the other three ratios in third, fifth, and sixth inequalities in block (A) are greater than -1 .

\section{Feasibility of the model}

To evaluate the feasible region of model $(\mathrm{M} 4)_{a, b}$, we are required to find $\beta_{o}^{a, b}$ and $\lambda_{j k}^{t}, j=1, \ldots, n, k=$ $1, \ldots, K, t=1, \ldots, T$, which simultaneously satisfy (5.9), (5.10), and the inequalities in block (A). Note that the subsystem (5.9) and (5.10) is always feasible. Hence, for one such feasible vector $\lambda$, we can choose $\beta_{o}^{a, b}$, as

$$
\begin{aligned}
&-1<\beta_{o}^{a, b} \leq \min \left(\min _{1 \leq r \leq s}\left\{\frac{\sum_{j=1}^{n} \lambda_{j k}^{t+a} y_{r j k}^{t+a}-y_{r o k}^{t+b}}{y_{r o k}^{t+b}-\nu_{r k}^{t+a}}\right\}, \min _{1 \leq i \leq m}\left\{\frac{x_{i o k}^{t+b}-\sum_{j=1}^{n} \lambda_{j k}^{t+a} x_{i j k}^{t+a}}{x_{i o k}^{t+b}+\mu_{i k}^{t+a}}\right\},\right. \\
& \min _{1 \leq p \leq q}\left\{\frac{u_{p o k}^{t+b}-\sum_{j=1}^{n} \lambda_{j k}^{t+a} u_{p j k}^{t+a}}{u_{p o k}^{t+b}+\omega_{p k}^{t+a}}\right\}, \min _{1 \leq \ell_{1} \leq n g o o d}\left\{\frac{\sum_{j=1}^{n} \lambda_{j k}^{t+a} c_{\ell_{1} j k}^{d t+a}-c_{\ell_{1} o k}^{d t+b}}{c_{\ell_{1} o k}^{d t+b}-\gamma_{\ell_{1} k}^{t+a}}\right\}, \\
& \min _{1 \leq \ell_{1} \leq n g o o d}\left\{\frac{c_{\ell_{1} o k}^{d t+b-1}-\sum_{j=1}^{n} \lambda_{j k}^{t+a} c_{\ell_{1} j k}^{d t+a-1}}{c_{\ell_{1} o k}^{d t+b-1}+\alpha_{\ell_{1} k}^{t+a-1}}\right\}, \min _{1 \leq \ell_{2} \leq n b a d}\left\{\frac{c_{\ell_{2} o k}^{u t+b}-\sum_{j=1}^{n} \lambda_{j k}^{t+a} c_{\ell_{2} j k}^{u t+a}}{c_{\ell_{2} o k}^{u t+b}+\sigma_{\ell_{2} k}^{t+a}}\right\}, \\
&\left.\min _{1 \leq \ell_{2} \leq n b a d}\left\{\frac{\sum_{j=1}^{n} \lambda_{j k}^{t+a} c_{\ell_{2} j k}^{u t+a-1}-c_{\ell_{2} o k}^{u t+b-1}}{c_{\ell_{2} o k}^{u t+b-1}-\rho_{\ell_{2} k}^{t+a-1}}\right\}\right) .
\end{aligned}
$$

From (5.12), it is clear that the feasible set of $(\mathrm{M} 4)_{a, b}$ is bounded above, and the optimal value $\beta_{o}^{* a, b}>-1$.

Illustration 5.2. For testing and validation purposes, we consider the synthetic dataset of 30 DMUs for three periods; each DMU comprises two divisions connected in the series. There are two inputs, one desirable output and one undesirable output in division 1 , and one input and one desirable output in division 2 . There is one intermediate link between divisions and one desirable carryover in each division and each period. Figure 3 shows the dynamic network structure of a DMU for three periods. Tables 4 and 5 present the randomly generated data for three periods from a uniform distribution in the intervals given in the last row of the Table 4 . We apply the proposed models $(\mathrm{M} 4)_{a, b}$, for $a, b \in\{0,1\}$, to evaluate DMLPI and its components efficiency change and technical change for $t=1$ to $t=3$ in consecutive periods and the results are reported in Table 6 .

In Table 6 , columns 2 and 5 depict the efficiency change between $t=1 \& 2$, and $t=2 \& 3$, respectively. We observe that 6 DMUs namely $\{1,10,14,17,18,20\}$ show no change in their efficiency scores and hence remain efficient in the entire period of analysis. Out of the remaining 25 DMUs, 9 units show improvement and 15 units exhibit regress in efficiency while moving from $t=1 \& 2$ to $t=2 \& 3$.

Columns 3 and 6 in Table 6 report the technical change measured by the shift of an efficient frontier between two consecutive periods. We observe that 13 units report technical regress both in periods $t=1 \& 2$ and $t=2 \& 3$.

Columns 4 and 7 display the DMLPI of DMUs represented by equation (5.11) as a product of efficiency change and technical change. We found that 18 units show productivity gain and 12 units show productivity 


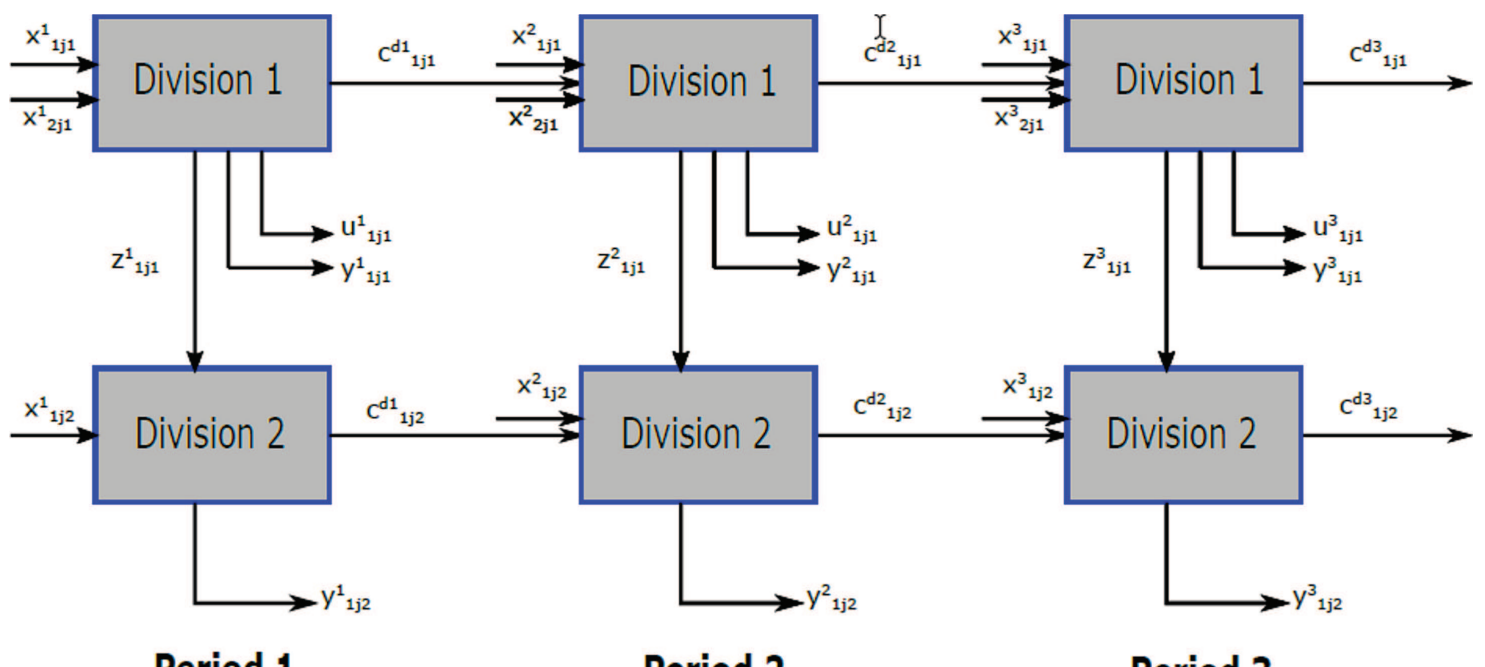

Period 1

Period 2

Period 3

Figure 3. The dynamic network structure of a DMU with 2 divisions and 3 periods of analysis.

loss in period $t=1 \& 2$ whereas 15 units record productivity gain and 15 record productivity loss in period $t=2 \& 3$. Note that the productivity change captured by DMLPI is independent of the scale efficiency change factor.

From Figure 4, we observe that several DMUs report technical regress between two consecutive periods under consideration. The reason for it can be attributed to the fact that while computing $D^{t}\left(X^{f}, Y^{f}, U^{f}, C^{d f}, C^{u f}\right)$, $f=t, t+1$, the technology considered is only of period $t$ and does not include the existing technology from the previous periods. In other words, the earlier periods' technology becomes unworkable in the subsequent periods leading to a technical regress, a situation uncommon in the industrial sector. The DMLPI thus fails to integrate the technology feature in it correctly. The sequential frontier analysis in DEA [70] provides an alternative to overcome the limitation of DMLPI.

\section{Dynamic SeQuential ML PRoductivity index}

In this section, we introduce the dynamic sequential ML productivity index.

The sequential PPS at $t$ establishes a reference production set formed by all the DMUs upto time t. It is defined by $\overline{P^{t}}=c o\left(P^{1} \cup P^{2} \cup \ldots \cup P^{t}\right), t=1, \ldots, T$, that is, it assumes that the technology of all the preceding periods are available in period $t$. Here, $c o(\cdot)$ denotes the convex hull. The sequential production technology frontier for the dynamic DEA with network structures is described as follows:

$$
\begin{gathered}
\overline{P^{t}=\{}\left(X_{k}^{t}, Y_{k}^{t}, U_{k}^{t}, C_{\ell_{1}}^{d t}, C_{\ell_{2}}^{u t}, Z_{k}^{t}\right) \mid X_{k}^{t} \geq \sum_{\tau=1}^{t} \sum_{j=1}^{n} \lambda_{j k}^{\tau} X_{j k}^{\tau}, Y_{k}^{t} \leq \sum_{\tau=1}^{t} \sum_{j=1}^{n} \lambda_{j k}^{\tau} Y_{j k}^{\tau}, U_{k}^{t} \geq \sum_{\tau=1}^{t} \sum_{j=1}^{n} \lambda_{j k}^{\tau} U_{j k}^{\tau}, \\
C_{k}^{d t} \leq \sum_{\tau=1}^{t} \sum_{j=1}^{n} \lambda_{j k}^{\tau} C_{j k}^{d \tau}, C_{k}^{d t-1} \geq \sum_{\tau=1}^{t} \sum_{j=1}^{n} \lambda_{j k}^{\tau} C_{j k}^{d \tau-1}, C_{k}^{u t} \geq \sum_{\tau=1}^{t} \sum_{j=1}^{n} \lambda_{j k}^{\tau} C_{j k}^{u \tau}, \\
C_{k}^{u t-1} \leq \sum_{\tau=1}^{t} \sum_{j=1}^{n} \lambda_{j k}^{\tau} C_{j k}^{u \tau-1}, k=1, \ldots, K, \sum_{j=1}^{n} \lambda_{j k}^{t} Z_{j}^{t}=\sum_{j=1}^{n} \lambda_{j k+1}^{t} Z_{j}^{t}, k=1, \ldots, K-1,
\end{gathered}
$$


TABLE 4. Synthetic data set 30 DMUs for period $t=1$, and divisions $k=1,2$.

\begin{tabular}{|c|c|c|c|c|c|c|c|c|c|}
\hline $\mathrm{DMU}_{j}$ & $x_{1 j 1}^{1}$ & $x_{2 j 1}^{1}$ & $c_{1 j 1}^{d 1}$ & $y_{1 j 1}^{1}$ & $u_{1 j 1}^{1}$ & $z_{1 j 1}^{1}$ & $x_{1 j 2}^{1}$ & $y_{1 j 2}^{1}$ & $c_{1 j 2}^{d 1}$ \\
\hline 1 & 46 & -5 & 51 & 22 & 19 & 44 & 16 & 92 & 10 \\
\hline 2 & 40 & -10 & 32 & 10 & 17 & 70 & 12 & 88 & 7 \\
\hline 3 & 35 & -4 & 31 & 40 & 17 & 46 & 20 & 118 & 37 \\
\hline 4 & 20 & 15 & 24 & 46 & 8 & 70 & 6 & 138 & 4 \\
\hline 5 & 10 & 3 & 48 & 45 & 12 & 65 & 12 & 110 & 40 \\
\hline 6 & 44 & -5 & 37 & 1 & 2 & 48 & 8 & 55 & -3 \\
\hline 7 & 34 & -10 & 36 & 29 & 19 & 35 & 20 & 66 & -1 \\
\hline 8 & 45 & 9 & 34 & 37 & 18 & 46 & 12 & 97 & 3 \\
\hline 9 & 45 & 11 & 36 & 45 & 19 & 51 & 18 & 116 & 0 \\
\hline 10 & 37 & -13 & 22 & 12 & 18 & 32 & 6 & 97 & 10 \\
\hline 11 & 37 & 0 & 28 & 9 & 13 & 77 & 20 & 139 & 17 \\
\hline 12 & 26 & 15 & 31 & 29 & 10 & 68 & 5 & 63 & 27 \\
\hline 13 & 38 & 5 & 52 & 17 & 18 & 50 & 15 & 132 & 16 \\
\hline 14 & 14 & -9 & 30 & 35 & 13 & 63 & 8 & 125 & 18 \\
\hline 15 & 49 & 5 & 34 & 8 & 18 & 40 & 8 & 69 & 22 \\
\hline 16 & 69 & 4 & 48 & 45 & 20 & 30 & 5 & 75 & 34 \\
\hline 17 & 31 & 11 & 41 & 48 & 0 & 31 & 20 & 82 & 19 \\
\hline 18 & 40 & -13 & 20 & 19 & 18 & 71 & 20 & 136 & 25 \\
\hline 19 & 54 & 16 & 32 & 20 & 6 & 61 & 19 & 83 & 36 \\
\hline 20 & 55 & 15 & 59 & 24 & 6 & 42 & 14 & 136 & 15 \\
\hline 21 & 19 & 0 & 46 & 16 & 1 & 61 & 11 & 109 & 12 \\
\hline 22 & 26 & 18 & 43 & 31 & 13 & 75 & 6 & 102 & 13 \\
\hline 23 & 36 & -6 & 37 & 49 & 11 & 65 & 11 & 80 & 34 \\
\hline 24 & 51 & -4 & 27 & 18 & 17 & 45 & 16 & 91 & -1 \\
\hline 25 & 64 & 0 & 28 & 15 & 20 & 76 & 19 & 118 & 5 \\
\hline 26 & 54 & 12 & 23 & 47 & 13 & 75 & 13 & 101 & -4 \\
\hline 27 & 33 & 18 & 17 & 16 & 18 & 73 & 16 & 101 & 5 \\
\hline 28 & 35 & 12 & 29 & 34 & 10 & 75 & 11 & 114 & 1 \\
\hline 29 & 62 & -5 & 28 & 11 & 7 & 80 & 15 & 58 & 30 \\
\hline \multirow[t]{2}{*}{30} & 24 & 18 & 24 & 50 & 4 & 60 & 15 & 84 & -3 \\
\hline & {$[10,70]$} & {$[-15,20]$} & {$[15,60]$} & {$[0,50]$} & {$[0,20]$} & {$[30,80]$} & {$[5,20]$} & {$[50,140]$} & {$[-5,40]$} \\
\hline
\end{tabular}

$$
\left.\sum_{\tau=1}^{t} \sum_{j=1}^{n} \lambda_{j k}^{\tau}=1, \lambda_{j k}^{t} \geq 0, j=1, \ldots, n, k=1, \ldots, K, t=1, \ldots, T\right\}
$$

where $X_{k}^{t}=\left(X_{1 k}^{t}, \ldots, X_{m k}^{t}\right)^{\prime}, Y_{k}^{t}=\left(Y_{1 k}^{t}, \ldots, Y_{s k}^{t}\right)^{\prime}, U_{k}^{t}=\left(U_{1 k}^{t}, \ldots, U_{q k}^{t}\right)^{\prime}, C_{k}^{d t}=\left(C_{1 k}^{d t}, \ldots, C_{n g o o d k}^{d t}\right)^{\prime}, C_{k}^{u t}=$ $\left(C_{1 k}^{u t}, \ldots, C_{n b a d k}^{u t}\right)^{\prime}$, are respectively the input, desirable output, undesirable output, desirable carryover, and undesirable carryover vectors for division $k$ in period $t$.

Compared to the sequential PPS defined by Oh et al. [56] for the conventional DEA models, our proposed definition includes the carryover activities between $t$ and $t+1$ and also the intermediate products in the vertical links between different divisions.

For $k=1, \ldots, K$ and $t=1, \ldots, T$, there exist constants $\eta_{1}, \eta_{1}^{\prime}, \eta_{1}^{\prime \prime}, \eta_{1}^{\prime \prime \prime}, \delta_{1}, \delta_{1}^{\prime}, \delta_{1}^{\prime \prime}$ to define the vectors $\mu_{k}^{t}=$ $\left(\mu_{1 k}^{t}, \ldots, \mu_{m k}^{t}\right)^{\prime}, \nu_{k}^{t}=\left(\nu_{1 k}^{t}, \ldots, \nu_{s k}^{t}\right)^{\prime}, \omega_{k}^{t}=\left(\omega_{1 k}^{t}, \ldots, \omega_{q k}^{t}\right)^{\prime}, \gamma_{k}^{t}=\left(\gamma_{1 k}^{t}, \ldots, \gamma_{n g o o d}^{t}\right)^{\prime}, \sigma_{k}^{t}=\left(\sigma_{1 k}^{t}, \ldots, \sigma_{\text {nbad } k}^{t}\right)^{\prime}$, 
TABLE 5. Synthetic data set of 30 DMUs for period $t=2,3$, and divisions $k=1,2$.

\begin{tabular}{|c|c|c|c|c|c|c|c|c|c|c|c|c|c|c|c|c|c|c|}
\hline $\mathrm{MU}_{j}$ & $x_{1 j 1}^{2}$ & $x_{2 j 1}^{2}$ & $c_{1 j 1}^{d 2}$ & $y_{1 j 1}^{2}$ & $u_{1 j 1}^{2}$ & $z_{1 j 1}^{2}$ & $x_{1 j 2}^{2}$ & $y_{1 j 2}^{2}$ & $c_{1 j 2}^{d 2}$ & $x_{1 j 1}^{3}$ & $x_{2 j 1}^{3}$ & $c_{1 j 1}^{d 3}$ & $y_{1 j 1}^{3}$ & $u_{1 j 1}^{3}$ & $z_{1 j 1}^{3}$ & $x_{1 j 2}^{3}$ & $y_{1 j 2}^{3}$ & $c_{1 j 2}^{d 3}$ \\
\hline 1 & 10 & 4 & 34 & 9 & 13 & 80 & 8 & 135 & 10 & 70 & 12 & 39 & 47 & 6 & 41 & 18 & 125 & 30 \\
\hline 2 & 60 & 16 & 21 & 20 & 1 & 38 & 13 & 86 & 18 & 11 & -10 & 23 & 25 & 13 & 56 & 20 & 72 & 11 \\
\hline 3 & 65 & -3 & 32 & 41 & 16 & 66 & 13 & 79 & 5 & 66 & 15 & 55 & 45 & 2 & 72 & 7 & 80 & 10 \\
\hline 4 & 46 & -10 & 29 & 30 & 14 & 64 & 13 & 71 & 29 & 17 & 3 & 16 & 9 & 8 & 51 & 7 & 108 & 26 \\
\hline 5 & 48 & -6 & 53 & 50 & 18 & 32 & 18 & 107 & 27 & 46 & 20 & 30 & 8 & 12 & 71 & 12 & 96 & -2 \\
\hline 6 & 64 & 17 & 41 & 33 & 17 & 32 & 11 & 79 & -5 & 68 & -12 & 48 & 9 & 8 & 64 & 13 & 57 & 3 \\
\hline 7 & 21 & -8 & 19 & 4 & 17 & 73 & 16 & 76 & 23 & 13 & -11 & 37 & 30 & 0 & 30 & 17 & 105 & 14 \\
\hline 8 & 65 & 1 & 20 & 38 & 19 & 64 & 7 & 138 & 9 & 65 & 13 & 21 & 41 & 3 & 57 & 10 & 87 & 38 \\
\hline 9 & 20 & 16 & 58 & 12 & 2 & 69 & 18 & 88 & 10 & 18 & -4 & 38 & 28 & 12 & 46 & 10 & 66 & 13 \\
\hline 10 & 42 & -14 & 16 & 44 & 1 & 42 & 17 & 97 & 10 & 37 & 1 & 27 & 17 & 8 & 50 & 14 & 69 & 26 \\
\hline 11 & 37 & 17 & 18 & 20 & 13 & 74 & 12 & 52 & 4 & 15 & 17 & 24 & 30 & 15 & 55 & 6 & 87 & 8 \\
\hline 12 & 39 & 19 & 29 & 42 & 6 & 64 & 6 & 52 & 22 & 49 & 16 & 34 & 20 & 11 & 31 & 13 & 95 & 6 \\
\hline 13 & 64 & 18 & 60 & 35 & 17 & 38 & 11 & 64 & 17 & 12 & -9 & 27 & 26 & 1 & 42 & 16 & 64 & 1 \\
\hline 14 & 69 & 7 & 32 & 47 & 2 & 79 & 8 & 87 & 33 & 68 & -3 & 36 & 23 & 1 & 51 & 5 & 129 & 2 \\
\hline 15 & 66 & 20 & 41 & 14 & 17 & 60 & 7 & 95 & 4 & 25 & -6 & 21 & 20 & 19 & 59 & 8 & 100 & 6 \\
\hline 16 & 29 & -1 & 49 & 23 & 13 & 67 & 16 & 60 & 5 & 46 & 8 & 53 & 15 & 5 & 54 & 20 & 132 & 25 \\
\hline 17 & 53 & -14 & 55 & 26 & 10 & 35 & 19 & 108 & 1 & 45 & 14 & 44 & 41 & 9 & 55 & 18 & 107 & 38 \\
\hline 18 & 41 & 16 & 32 & 48 & 11 & 60 & 13 & 128 & 7 & 12 & 20 & 25 & 49 & 16 & 47 & 12 & 137 & 38 \\
\hline 19 & 63 & 9 & 43 & 30 & 18 & 65 & 6 & 72 & 26 & 15 & 8 & 23 & 11 & 7 & 34 & 16 & 70 & -4 \\
\hline 20 & 67 & -8 & 60 & 30 & 5 & 73 & 15 & 123 & 35 & 42 & 7 & 39 & 11 & 8 & 72 & 5 & 100 & 25 \\
\hline 21 & 30 & -5 & 39 & 11 & 0 & 56 & 13 & 90 & 3 & 45 & 3 & 23 & 32 & 13 & 48 & 16 & 64 & 4 \\
\hline 22 & 41 & 16 & 34 & 14 & 10 & 33 & 15 & 65 & 37 & 51 & -13 & 20 & 27 & 14 & 63 & 5 & 135 & 38 \\
\hline 23 & 30 & -4 & 46 & 4 & 19 & 62 & 16 & 102 & 14 & 64 & -6 & 15 & 3 & 20 & 78 & 17 & 114 & 35 \\
\hline 24 & 59 & 18 & 25 & 1 & 15 & 38 & 6 & 81 & 22 & 49 & 11 & 55 & 41 & 6 & 49 & 10 & 52 & 27 \\
\hline 25 & 18 & 0 & 40 & 37 & 2 & 57 & 19 & 88 & 12 & 68 & -9 & 58 & 30 & 11 & 55 & 17 & 50 & 17 \\
\hline 26 & 18 & 19 & 48 & 33 & 16 & 73 & 14 & 134 & 0 & 51 & -6 & 56 & 30 & 2 & 60 & 18 & 57 & 18 \\
\hline 27 & 25 & -13 & 21 & 41 & 13 & 58 & 14 & 70 & 26 & 35 & 12 & 28 & 27 & 16 & 48 & 15 & 105 & 14 \\
\hline 28 & 43 & -9 & 25 & 24 & 5 & 55 & 19 & 96 & 27 & 46 & 18 & 32 & 2 & 11 & 70 & 12 & 52 & 25 \\
\hline 29 & 24 & 1 & 24 & 1 & 15 & 78 & 11 & 67 & 12 & 61 & -8 & 16 & 43 & 16 & 37 & 17 & 63 & -3 \\
\hline 30 & 19 & -6 & 52 & 9 & 13 & 69 & 17 & 125 & 5 & 27 & -2 & 33 & 32 & 7 & 54 & 11 & 65 & 2 \\
\hline
\end{tabular}

$\alpha_{k}^{t}=\left(\alpha_{1 k}^{t}, \ldots, \alpha_{n g o o d k}^{t}\right)^{\prime}$, and $\rho_{k}^{t}=\left(\rho_{1 k}^{t}, \ldots, \rho_{\text {nbad } k}^{t}\right)^{\prime}$, with components

$$
\begin{aligned}
\mu_{i k}^{t} & =\eta_{1} * \max _{1 \leq j \leq n, 1 \leq \tau \leq t}\left\{\left|x_{i j k}^{\tau}\right|\right\}, & & i=1, \ldots, m, k=1, \ldots, K, \\
\nu_{r k}^{t} & =\min _{1 \leq j \leq n, 1 \leq \tau \leq t}\left\{y_{r j k}^{\tau}\right\}-\delta_{1}, & & r=1, \ldots, s, k=1, \ldots, K, \\
\omega_{p k}^{t} & =\eta_{1}^{\prime} * \max _{1 \leq j \leq n, 1 \leq \tau \leq t}\left\{\left|u_{p j k}^{\tau}\right|\right\}, & & p=1, \ldots, q, k=1, \ldots, K, \\
\gamma_{\ell_{1} k}^{t} & =\min _{1 \leq j \leq n, 1 \leq \tau \leq t}\left\{c_{\ell_{1} j k}^{d \tau}\right\}-\delta_{1}^{\prime}, & & \ell_{1}=1, \ldots, \text { ngood, } k=1, \ldots, K, \\
\sigma_{\ell_{2} k}^{t} & =\eta_{1}^{\prime \prime} * \max _{1 \leq j \leq n, 1 \leq \tau \leq t}\left\{\left|c_{\ell_{2} j k}^{u \tau}\right|\right\}, & & \ell_{2}=1, \ldots, n b a d, k=1, \ldots, K, \\
\alpha_{\ell_{1} k}^{t} & =\eta_{1}^{\prime \prime \prime} * \max _{1 \leq j \leq n, 1 \leq \tau \leq t}\left\{c_{\ell_{1} j k}^{d \tau}\right\}, & & \ell_{1}=1, \ldots, \text { ngood }, k=1, \ldots, K, \\
\rho_{\ell_{2} k}^{t} & =\min _{1 \leq j \leq n, 1 \leq \tau \leq t}\left\{\left|c_{\ell_{2} j k}^{u \tau}\right|\right\}-\delta_{1}^{\prime \prime}, & & \ell_{2}=1, \ldots, n b a d, k=1, \ldots, K .
\end{aligned}
$$


TABLE 6. The DMLPI and its components for 30 DMUs on the synthetic data setting parameters $\xi=\xi^{\prime}=\xi^{\prime \prime}=\xi^{\prime \prime \prime}=3$, and $\pi=\pi^{\prime}=\pi^{\prime \prime}=1$.

\begin{tabular}{lllllll}
\hline $\mathrm{DMU}$ & $\mathrm{EC}^{(1,2)}$ & $\mathrm{TC}^{(1,2)}$ & $\mathrm{DML}^{(1,2)}$ & $\mathrm{EC}^{(2,3)}$ & $\mathrm{TC}^{(2,3)}$ & $\mathrm{DML}^{(2,3)}$ \\
\hline 1 & 1 & 1.0259 & 1.0259 & 1 & 0.9946 & 0.9946 \\
2 & 0.9931 & 1.0160 & 1.0090 & 1.0062 & 1.0275 & 1.0339 \\
3 & 0.9122 & 0.9925 & 0.9054 & 1.0302 & 1.0424 & 1.0739 \\
4 & 0.9513 & 1.0008 & 0.9521 & 0.9781 & 1.0240 & 1.0015 \\
5 & 1 & 1.0303 & 1.0303 & 0.9187 & 0.9074 & 0.8336 \\
6 & 0.9315 & 1.0081 & 0.9391 & 1 & 1.0003 & 1.0003 \\
7 & 0.9985 & 0.9985 & 0.9970 & 1 & 1.0413 & 1.0413 \\
8 & 1.0915 & 1.0052 & 1.0971 & 1 & 0.9978 & 0.9978 \\
9 & 1.0708 & 1.0230 & 1.0954 & 0.9892 & 0.9502 & 0.9400 \\
10 & 1 & 1.0917 & 1.0917 & 1 & 0.9403 & 0.9403 \\
11 & 0.92 & 0.9698 & 0.8922 & 1.0434 & 1.0141 & 1.0582 \\
12 & 1 & 0.9835 & 0.9835 & 0.9517 & 1.0122 & 0.9634 \\
13 & 1.0111 & 1.0642 & 1.0761 & 1 & 1.0007 & 1.0007 \\
14 & 1 & 0.9854 & 0.9854 & 1 & 0.9917 & 0.9917 \\
15 & 1.0321 & 0.9872 & 1.0188 & 1.0116 & 0.9975 & 1.0092 \\
16 & 0.9787 & 0.9798 & 0.9589 & 1.0218 & 0.9952 & 1.0169 \\
17 & 1 & 1.0670 & 1.0670 & 1 & 1.0039 & 1.0039 \\
18 & 1 & 0.9496 & 0.9496 & 1 & 1.0556 & 1.0556 \\
19 & 1.0727 & 0.9625 & 1.0325 & 0.9854 & 1.0134 & 0.9986 \\
20 & 1 & 1.0918 & 1.0918 & 1 & 0.9895 & 0.9895 \\
21 & 1 & 1.0088 & 1.0088 & 0.9487 & 0.9995 & 0.9482 \\
22 & 1.0086 & 0.9678 & 0.9761 & 1 & 1.0916 & 1.0916 \\
23 & 0.9572 & 1.0081 & 0.9650 & 0.9852 & 1.0064 & 0.9915 \\
24 & 1.0879 & 0.9996 & 1.0874 & 1 & 1.0160 & 1.0160 \\
25 & 1.1395 & 1.0197 & 1.1620 & 1 & 1.0031 & 1.0031 \\
26 & 1.0553 & 0.9757 & 1.0296 & 1 & 0.9764 & 0.9764 \\
27 & 1.0919 & 1.0521 & 1.1487 & 0.9847 & 0.9609 & 0.9462 \\
28 & 1.0349 & 1.0389 & 1.0751 & 0.9656 & 1.0132 & 0.9783 \\
29 & 0.9866 & 1.0161 & 1.0025 & 1.0216 & 1.0020 & 1.0236 \\
30 & 1 & 0.9993 & 0.9993 & 0.9654 & 0.9627 & 0.9294 \\
\hline & & & & & &
\end{tabular}

The real numbers $\eta_{1}, \eta_{1}^{\prime}, \eta_{1}^{\prime \prime}, \eta_{1}^{\prime \prime \prime}, \delta_{1}, \delta_{1}^{\prime}, \delta_{1}^{\prime \prime}$, are chosen such that all direction vectors are positive and $\mu_{i k}^{t+1}<\mu_{i k}^{t}, \omega_{p k}^{t+1}<\omega_{p k}^{t}, \alpha_{\ell_{1} k}^{t+1}<\alpha_{\ell_{1} k}^{t}, \sigma_{\ell_{2} k}^{t+1}<\sigma_{\ell_{2} k}^{t}, \nu_{r k}^{t+1}>\nu_{r k}^{t}, \gamma_{\ell_{1} k}^{t+1}>\gamma_{\ell_{1} k}^{t}, \rho_{\ell_{2} k}^{t+1}>\rho_{\ell_{2} k}^{t}$, to preserve $\bar{D}^{t+1}\left(X^{f}, Y^{f}, U^{f}, C^{d f}, C^{u f}\right)>\bar{D}^{t}\left(X^{f}, Y^{f}, U^{f}, C^{d f}, C^{u f}\right), f=t, t+1$.

The direction vector for $\mathrm{DMU}_{o}$ corresponding to division $k$ applying the production technology of period $t+a$ to the data of period $t+b, a, b \in\{0,1\}$, is defined by $\left(X_{o k}^{t+b}+\mu_{k}^{t+a}, Y_{o k}^{t+b}-\nu_{k}^{t+a}, U_{o k}^{t+b}+\omega_{k}^{t+a}, C_{o k}^{d t+b}-\right.$ $\left.\gamma_{k}^{t+a}, C_{o k}^{u t+b}-\sigma_{k}^{t+a}, C_{o k}^{d t+b-1}+\alpha_{k}^{t+a-1}, C_{o k}^{u t+b-1}-\rho_{k}^{t+a-1}\right)$. For $a, b \in\{0,1\}$, the dynamic sequential DDFs are obtained by solving the following four linear problems.

$$
\begin{array}{rlr}
(\mathrm{M} 5)_{a, b} & \bar{D}^{t+a}\left(X^{t+b}, Y^{t+b}, U^{t+b}, C^{d t+b}, C^{u t+b}\right)=\max \beta_{o}^{a, b} & \\
\text { s.t. } & \sum_{\tau=1}^{t+a} \sum_{j=1}^{n} \lambda_{j k}^{\tau} y_{r j k}^{\tau} \geq y_{r o k}^{t+b}+\beta_{o}^{a, b}\left(y_{r o k}^{t+b}-\nu_{r k}^{t+a}\right), & r=1, \ldots, s, k=1, \ldots, K, \\
& \sum_{\tau=1}^{t+a} \sum_{j=1}^{n} \lambda_{j k}^{\tau} x_{i j k}^{\tau} \leq x_{i o k}^{t+b}-\beta_{o}^{a, b}\left(x_{i o k}^{t+b}+\mu_{i k}^{t+a}\right), & i=1, \ldots, m, k=1, \ldots, K,
\end{array}
$$




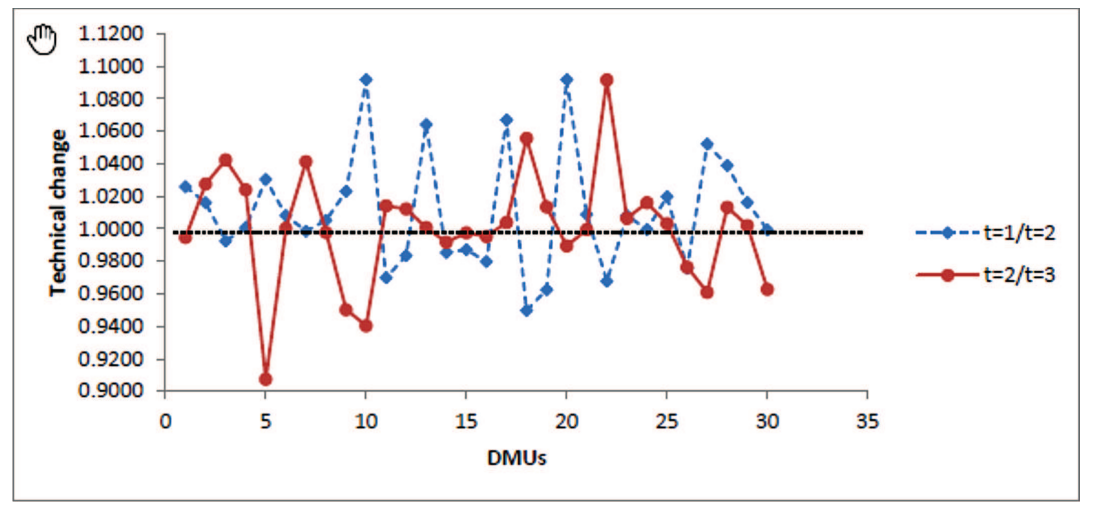

Figure 4. The technical change in DMLPI of 30 DMUs in two consecutive periods.

$$
\begin{array}{ll}
\sum_{\tau=1}^{t+a} \sum_{j=1}^{n} \lambda_{j k}^{\tau} u_{p j k}^{\tau} \leq u_{p o k}^{t+b}-\beta_{o}^{a, b}\left(u_{p o k}^{t+b}+\omega_{p k}^{t+a}\right), & p=1, \ldots, q, k=1, \ldots, K, \\
\sum_{\tau=1}^{t+a} \sum_{j=1}^{n} \lambda_{j k}^{\tau} c_{\ell_{1} j k}^{d \tau} \geq c_{\ell_{1} o k}^{d t+b}+\beta_{o}^{a, b}\left(c_{\ell_{1} o k}^{d t+b}-\gamma_{\ell_{1} k}^{t+a}\right), & \ell_{1}=1, \ldots, n g o o d, k=1, \ldots, K, \\
\sum_{\tau=1}^{t+a} \sum_{j=1}^{n} \lambda_{j k}^{\tau} c_{\ell_{1} j k}^{d \tau-1} \leq c_{\ell_{1} o k}^{d t+b-1}-\beta_{o}^{a, b}\left(c_{\ell_{1} o k}^{d t+b-1}+\alpha_{\ell_{1} k}^{t+a-1}\right), & \ell_{1}=1, \ldots, n g o o d, k=1, \ldots, K, \\
\sum_{\tau=1}^{t+a} \sum_{j=1}^{n} \lambda_{j k}^{\tau} c_{\ell_{2} j k}^{u \tau} \leq c_{\ell_{2} o k}^{u t+b}-\beta_{o}^{a, b}\left(c_{\ell_{2} o k}^{u t+b}+\sigma_{\ell_{2} k}^{t+a}\right), & \ell_{2}=1, \ldots, n b a d, k=1, \ldots, K, \\
\sum_{\tau=1}^{t+a} \sum_{j=1}^{n} \lambda_{j k}^{\tau} c_{\ell_{2} j k}^{u \tau-1} \geq c_{\ell_{2} o k}^{u t+b-1}+\beta_{o}^{a, b}\left(c_{\ell_{2} o k}^{u t+b-1}-\rho_{\ell_{2} k}^{t+a-1}\right), & \ell_{2}=1, \ldots, n b a d, k=1, \ldots, K, \\
\sum_{j=1}^{n} \lambda_{j k}^{t+a} z_{g j k}^{t+a}=\sum_{j=1}^{n} \lambda_{j, k+1}^{t+a} z_{g j k}^{t+a}, & g=1, \ldots, h, k=1, \ldots, K-1, \\
\sum_{\tau=1}^{t+a} \sum_{j=1}^{n} \lambda_{j k}^{\tau}=1, k=1, \ldots, K, & \\
\beta_{o}^{a, b} \in \mathbb{R}, \lambda_{j k}^{t} \geq 0, & \\
\end{array}
$$

where $X^{t+1}=\left(X_{1}^{t+}, \ldots, X_{K}^{t+1}\right)^{\prime}, Y^{t+1}=\left(Y_{1}^{t+1}, \ldots, Y_{K}^{t+1}\right)^{\prime}, U^{t+1}=\left(U_{1}^{t+1}, \ldots, U_{K}^{t+1}\right)^{\prime}, C^{d t+1}=$ $\left(C_{1}^{d t+1}, \ldots, C_{K}^{d t+1}\right)^{\prime}, C^{u t+1}=\left(C_{1}^{u t+1}, \ldots, C_{K}^{u t+1}\right)^{\prime}$, are respectively the input, desirable output, undesirable output, desirable carryover, and undesirable carryover vectors at time $t+1$.

The DSMLPI between periods $t$ and $t+1$ is defined by

$$
\operatorname{DSML}^{(t, t+1)}=\left(\frac{1+\bar{D}^{t}\left(X^{t}, Y^{t}, U^{t}, C^{d t}, C^{u t}\right)}{1+\bar{D}^{t}\left(X^{t+1}, Y^{t+1}, U^{t+1}, C^{d t+1}, C^{u t+1}\right)} \times \frac{1+\bar{D}^{t+1}\left(X^{t}, Y^{t}, U^{t}, C^{d t}, C^{u t}\right)}{1+\bar{D}^{t+1}\left(X^{t+1}, Y^{t+1}, U^{t+1}, C^{d t+1}, C^{u t+1}\right)}\right)^{\frac{1}{2}} .
$$

Unlike DMLPI, there is no feasibility concern in DSMLPI under both the CRS and VRS technology assumptions in the presence of the undesirable output feature, but it is the negative data values which debar us from using the CRS technology [26], and hence the scale efficiency change factor [22] is not defined. We therefore decompose 
DSMLPI into the efficiency change and technical change factors, independent of the scale efficiency change factor, as follows:

$$
\begin{aligned}
\operatorname{DSML}^{(t, t+1)}= & \left(\frac{1+\bar{D}^{t}\left(X^{t}, Y^{t}, U^{t}, C^{d t}, C^{u t}\right)}{1+\bar{D}^{t+1}\left(X^{t+1}, Y^{t+1}, U^{t+1}, C^{d t+1}, C^{u t+1}\right)}\right) \\
& \times\left(\frac{1+\bar{D}^{t+1}\left(X^{t+1}, Y^{t+1}, U^{t+1}, C^{d t+1}, C^{u t+1}\right)}{1+\bar{D}^{t}\left(X^{t+1}, Y^{t+1}, U^{t+1}, C^{d t+1}, C^{u t+1}\right)} \times \frac{1+\bar{D}^{t+1}\left(X^{t}, Y^{t}, U^{t}, C^{d t}, C^{u t}\right)}{1+\bar{D}^{t}\left(X^{t}, Y^{t}, U^{t}, C^{d t}, C^{u t}\right)}\right)^{\frac{1}{2}} \\
= & \overline{\mathrm{EC}}^{(t, t+1)} \times \overline{\mathrm{TC}}^{(t, t+1)} .
\end{aligned}
$$

Here, $\mathrm{DSML}^{(t, t+1)}=1$ indicates no productivity change over two periods; $\mathrm{DSML}^{(t, t+1)}>1$ depicts productivity growth while $\mathrm{DSML}^{(t, t+1)}<1$ indicates productivity regress from period $t$ to $t+1$.

Also, $\overline{\mathrm{EC}}^{(t, t+1)}$ captures efficiency change between periods $t$ and $t+1 ; \overline{\mathrm{EC}}^{(t, t+1)}>1$ means that $\mathrm{DMU}_{o}$ is closer to the efficient frontier in period $t+1$ than in period $t, \overline{\mathrm{EC}}^{(t, t+1)}<1$ depicts that $\mathrm{DMU}_{o}$ is a distance away from the efficient frontier in period $t+1$ than in $t$, while $\overline{\mathrm{EC}}^{(t, t+1)}=1$ means no efficiency change is observed in $\mathrm{DMU}_{o}$ between the two periods.

The term $\overline{\mathrm{TC}}^{(t, t+1)}$ captures the technical change in form of a shift in the efficient frontier between two periods. Within $\overline{\mathrm{TC}}^{(t, t+1)}$ in (6.11), the first ratio evaluates the frontier shift of the data observed at period $t+1$ while the second ratio evaluates the frontier shift of the data in period $t ; \overline{\mathrm{TC}}^{(t, t+1)}>1$ implies technical progress while $\overline{\mathrm{TC}}^{(t, t+1)}=1$ exhibits a neutral state of technical change from period $t$ to $t+1$. Notice that, since $\bar{D}^{t+1}\left(X^{f}, Y^{f}, U^{f}, C^{d f}, C^{u f}\right)>\bar{D}^{t}\left(X^{f}, Y^{f}, U^{f}, C^{d f}, C^{u f}\right), f=t, t+1$, it is not possible to have $\overline{\mathrm{TC}}^{(t, t+1)}<1$. Thus, DSML ${ }^{(t, t+1)}$ never encounters technical regress.

Further, if $P^{t} \subset P^{t+1}, t=1, \ldots, T-1$, then $\mathrm{DSML}^{(t, t+1)}=\mathrm{DML}^{(t, t+1)}$ [56]. Hence, $\mathrm{DML}^{(t, t+1)}$ can be considered as a special case of $\operatorname{DSML}^{(t, t+1)}$.

Theorem 6.1. For $a, b \in\{0,1\}$, model $(\mathrm{M} 5)_{a, b}$ is feasible and bounded, and its optimal value $\beta_{o}^{* a, b}>-1$.

Proof. If $a=b$, then model is feasible by taking $\beta_{o}^{a, b}=0, \lambda_{o k}^{t+a}=\lambda_{o k+1}^{t+a}=1$, and $\lambda_{j k}^{t+a}=\lambda_{j k+1}^{t+a}=0, j=$ $1, \ldots, n, j \neq o, k=1, \ldots, K-1$.

For $a \neq b$, the inequalities (6.2)-(6.8), can be rewritten as follows:

$$
\begin{aligned}
& \beta_{o}^{a, b} \leq \frac{\sum_{\tau=1}^{t+a} \sum_{j=1}^{n} \lambda_{j k}^{\tau} y_{r j k}^{\tau}-y_{r o k}^{t+b}}{y_{r o k}^{t+b}-\nu_{r k}^{t+a}}, \quad r=1, \ldots, s, \\
& \beta_{o}^{a, b} \leq \frac{x_{i o k}^{t+b}-\sum_{\tau=1}^{t+a} \sum_{j=1}^{n} \lambda_{j k}^{\tau} x_{i j k}^{\tau}}{x_{i o k}^{t+b}+\mu_{i k}^{t+a}}, \quad i=1, \ldots, m, \\
& \beta_{o}^{a, b} \leq \frac{u_{p o k}^{t+b}-\sum_{\tau=1}^{t+a} \sum_{j=1}^{n} \lambda_{j k}^{\tau} u_{p j k}^{\tau}}{u_{p o k}^{t+b}+\omega_{p k}^{t+a}}, \quad p=1, \ldots, q,
\end{aligned}
$$

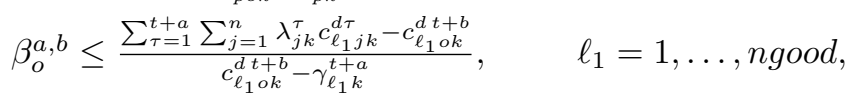

$$
\begin{aligned}
& \beta_{o}^{a, b} \leq \frac{c_{\ell_{1} o k}^{d+b-1}-\sum_{\tau=1}^{t+a} \sum_{j=1}^{n} \lambda_{j k}^{\tau} c_{\ell_{1} j k}^{d \tau-1}}{c_{\ell_{1} o k}^{d+b-1}+\alpha_{\ell_{1} k}^{t+a-1}}, \quad \ell_{1}=1, \ldots, \text { ngood }, \\
& \beta_{o}^{a, b} \leq \frac{c_{\ell_{2} \circ k}^{u t+b}-\sum_{\tau=1}^{t+a} \sum_{j=1}^{n} \lambda_{j k}^{\tau} c_{\ell_{2} j k}^{u \tau}}{c_{\ell_{2} \circ k}^{u+b}+\sigma_{\ell_{2} k}^{t+a}}, \quad \ell_{2}=1, \ldots, n b a d, \\
& \beta_{o}^{a, b} \leq \frac{\sum_{\tau=1}^{t+a} \sum_{j=1}^{n} \lambda_{j k}^{\tau} c_{\ell_{2} j k}^{u j-1}-c_{\ell_{2} o k}^{u t+b-1}}{c_{\ell_{2} o k}^{u t+b-1}-\rho_{\ell_{2} k}^{t+a-1}}, \quad \ell_{2}=1, \ldots, \text { nbad. }
\end{aligned}
$$

We firstly intend to show that by choosing the six positive constants $\pi, \pi^{\prime}, \pi^{\prime \prime}, \xi, \xi^{\prime}, \xi^{\prime \prime}, \xi^{\prime \prime \prime}$ appropriately, the seven ratios in block (B) are greater than -1 . 
From (6.2), for any $\pi>0$,

$$
\frac{\sum_{\tau=1}^{t+a} \sum_{j=1}^{n} \lambda_{j k}^{\tau} y_{r j k}^{\tau}-y_{r o k}^{t+b}}{y_{r o k}^{t+b}-\nu_{r k}^{t+a}} \geq \frac{\min _{1 \leq j \leq n, 1 \leq \tau \leq t+a}\left\{y_{r j k}^{\tau}\right\}-y_{r o k}^{t+b}}{y_{r o k}^{t+b}-\nu_{r k}^{t+a}}>-1, \quad \ell=1, \ldots, \zeta, k=1, \ldots, K .
$$

Similarly, for any $\pi^{\prime}>0$ and $\pi^{\prime \prime}>0$,

$$
\frac{\sum_{\tau=1}^{t+a} \sum_{j=1}^{n} \lambda_{j k}^{t+a} c_{\ell_{1} j k}^{d t+a}-c_{\ell_{1} o k}^{d t+b}}{c_{\ell_{1} o k}^{d t+b}-\gamma_{\ell_{1} k}^{t+a}}>-1, \quad \frac{\sum_{\tau=1}^{t+a} \sum_{j=1}^{n} \lambda_{j k}^{t+a} c_{\ell_{2} j k}^{u t+a-1}-c_{\ell_{2} o k}^{u t+b-1}}{c_{\ell_{2} o k}^{u t+b-1}-\rho_{\ell_{2} k}^{t+a-1}}>-1 .
$$

Next, consider the ratio in the second inequality in block (A).

We choose

$$
\left.\xi>\max \left\{0, \max _{1 \leq i \leq m, 1 \leq k \leq K}\left\{-\frac{x_{i o k}^{t+b}}{\max _{1 \leq j \leq n, 1 \leq \tau \leq t+a}\left\{\left|x_{i j k}^{t+a}\right|\right.}\right\}\right\}, \max _{1 \leq i \leq m, 1 \leq k \leq K}\left\{\frac{\max _{1 \leq j \leq n, 1 \leq \tau \leq t+a}\left\{x_{i j k}^{t+a}\right\}-2 x_{i o k}^{t+b}}{\max _{1 \leq j \leq n, 1 \leq \tau \leq t+a}\left\{\left|x_{i j k}^{t+a}\right|\right\}}\right\}\right\} .
$$

It yields that $\xi>0$, and

$$
\begin{aligned}
& \xi_{1 \leq j \leq n, 1 \leq \tau \leq t+a}\left\{\left|x_{i j k}^{t+a}\right|\right\}>-x_{i o k}^{t+b}, \\
& \xi_{1 \leq j \leq n, 1 \leq \tau \leq t+a}\left\{\left|x_{i j k}^{t+a}\right|\right\}>\max _{1 \leq j \leq n, 1 \leq \tau \leq t+a}\left\{x_{i j k}^{t+a}\right\}-2 x_{i o k}^{t+b} \geq \sum_{\tau=1}^{t+a} \sum_{j=1}^{n} \lambda_{j k}^{t+a} x_{i j k}^{t+a}-2 x_{i o k}^{t+b} .
\end{aligned}
$$

Thus, $x_{i o k}^{t+b}+\mu_{i k}^{t+a}>0$, and $\frac{x_{i o k}^{t+b}-\sum_{\tau=1}^{t+a} \sum_{j=1}^{n} \lambda_{j k}^{t+a} x_{i j k}^{t+a}}{x_{i o k}^{t+b}+\mu_{i k}^{t+a}}>-1$.

By the similar arguments, we can choose $\xi^{\prime}, \xi^{\prime \prime}$, and $\xi^{\prime \prime \prime}$ to ensure that the other three ratios in third, fifth, and sixth inequalities in block (B) are greater than -1 .

\section{Feasibility of the model}

To evaluate the feasible region of model $(\mathrm{M} 5)_{a, b}$, we are required to find $\lambda_{j k}^{t}, j=1, \ldots, n, k=1, \ldots, K, t=$ $1, \ldots, T$, and $\beta_{o}^{a, b}$ which simultaneously satisfy $(6.7),(6.8)$, and inequalities in the block (B). The equivalent expression of inequalities in block (B) is as follows:

$$
\begin{aligned}
&-1<\beta_{o}^{a, b} \leq \min \left(\min _{1 \leq r \leq s, 1 \leq k \leq K}\left\{\frac{\sum_{\tau=1}^{t+a} \sum_{j=1}^{n} \lambda_{j k}^{\tau} y_{r j k}^{\tau}-y_{r o k}^{t+b}}{y_{r o k}^{t+b}-\nu_{r k}^{a}}\right\}, \min _{1 \leq i \leq m, 1 \leq k \leq K}\left\{\frac{x_{i o k}^{t+b}-\sum_{\tau=1}^{t+a} \sum_{j=1}^{n} \lambda_{j k}^{\tau} x_{i j k}^{\tau}}{x_{i o k}^{t+b}+\mu_{i k}^{t+a}}\right\},\right. \\
& \min _{1 \leq p \leq q, 1 \leq k \leq K}\left\{\frac{u_{p o k}^{t+b}-\sum_{\tau=1}^{t+a} \sum_{j=1}^{n} \lambda_{j k}^{\tau} u_{p j k}^{\tau}}{u_{p o k}^{t+b}+\omega_{p k}^{t+a}}\right\}, \min _{1 \leq \ell_{1} \leq n g o o d, 1 \leq k \leq K}\left\{\frac{\sum_{\tau=1}^{t+a} \sum_{j=1}^{n} \lambda_{j k}^{\tau} c_{\ell_{1} j k}^{d \tau}-c_{\ell_{1} o k}^{d t+b}}{c_{\ell_{1} o k}^{d t+b}-\gamma_{\ell_{1} k}^{t+a}}\right\}, \\
& \min _{1 \leq \ell_{1} \leq n g o o d, 1 \leq k \leq K}\left\{\frac{c_{\ell_{1} o k}^{d t+b-1}-\sum_{\tau=1}^{t+a} \sum_{j=1}^{n} \lambda_{j k}^{\tau} c_{\ell_{1} j k}^{d \tau-1}}{c_{\ell_{1} o k}^{d t+b-1}+\alpha_{\ell_{1}}^{t+a-1}}\right\}, \\
& \min _{1 \leq \ell_{2} \leq n b a d, 1 \leq k \leq K}\left\{\frac{c_{\ell_{2} o k}^{u t+b}-\sum_{\tau=1}^{t+a} \sum_{j=1}^{n} \lambda_{j k}^{\tau} c_{\ell_{2} j k}^{u \tau}}{c_{\ell_{2} o k}^{u t+b}+\sigma_{\ell_{2} k}^{t+a}}\right\}, \\
&\left.\min _{1 \leq \ell_{2} \leq n b a d, 1 \leq k \leq K}\left\{\frac{\sum_{\tau=1}^{t+a} \sum_{j=1}^{n} \lambda_{j k}^{\tau} c_{\ell_{2} j k}^{u \tau-1}-c_{\ell_{2} o k}^{u t+b-1}}{c_{\ell_{2} o k}^{u t+b-1}-\rho_{\ell_{2} k}^{t+a-1}}\right\}\right) .
\end{aligned}
$$

It follows from (6.12) that the feasible set of $(\mathrm{M} 5)_{a, b}$ is non-empty and bounded above yielding the finite optimal value of the model and its optimal value $\beta_{o}^{* a, b}>-1$. 
TABLE 7. The DSMLPI and its components on synthetic dataset in Tables 4 and 5 setting parameters $\eta_{1}=\eta_{1}^{\prime}=\eta_{1}^{\prime \prime}=\eta_{1}^{\prime \prime \prime}=3, \delta_{1}=\delta_{1}^{\prime}=\delta_{1}^{\prime \prime}=1$ for period $t$, and $\eta_{1}=\eta_{1}^{\prime}=\eta_{1}^{\prime \prime}=\eta_{1}^{\prime \prime \prime}=$ $1.5, \delta_{1}=\delta_{1}^{\prime}=\delta_{1}^{\prime \prime}=1$ for period $t+1, t=1,2$.

\begin{tabular}{lllllll}
\hline $\mathrm{DMU}$ & $\overline{\mathrm{EC}}^{(1,2)}$ & $\overline{\mathrm{TC}}^{(1,2)}$ & $\mathrm{DSML}^{(1,2)}$ & $\overline{\mathrm{EC}}^{(2,3)}$ & $\overline{\mathrm{TC}}^{(2,3)}$ & $\mathrm{DSML}^{(2,3)}$ \\
\hline 1 & 1 & 1.0371 & 1.0371 & 0.9653 & 1.0059 & 0.9710 \\
2 & 0.9740 & 1.0464 & 1.0192 & 1.0164 & 1.0164 & 1.0331 \\
3 & 0.8656 & 1.0401 & 0.9003 & 1.1025 & 1.0669 & 1.1763 \\
4 & 0.9088 & 1.0512 & 0.9553 & 0.9916 & 1.0273 & 1.0186 \\
5 & 1 & 1.0850 & 1.0850 & 0.8571 & 1.0337 & 0.8861 \\
6 & 0.8747 & 1.0516 & 0.9198 & 1.0157 & 1.0153 & 1.0313 \\
7 & 0.9499 & 1.0371 & 0.9852 & 1.0057 & 1.0415 & 1.0475 \\
8 & 1.0915 & 1.0391 & 1.1341 & 0.9749 & 1.0114 & 0.9860 \\
9 & 1.0708 & 1.0558 & 1.1305 & 0.9495 & 1.0007 & 0.9501 \\
10 & 1 & 1.0994 & 1.0994 & 0.9198 & 1.0081 & 0.9272 \\
11 & 0.8630 & 1.0303 & 0.8892 & 1.0623 & 1.0276 & 1.0916 \\
12 & 0.9730 & 1.0062 & 0.9790 & 0.8725 & 1.0328 & 0.9011 \\
13 & 1.0111 & 1.0800 & 1.0920 & 1 & 1.0289 & 1.0289 \\
14 & 0.9845 & 1.0095 & 0.9938 & 1.0128 & 1.0087 & 1.0216 \\
15 & 0.9995 & 1.0263 & 1.0258 & 0.9812 & 1.0191 & 0.9999 \\
16 & 0.9462 & 1.0271 & 0.9718 & 0.9956 & 1.0211 & 1.0166 \\
17 & 1 & 1.1145 & 1.1145 & 0.9787 & 1.0060 & 0.9846 \\
18 & 0.9600 & 1.0066 & 0.9663 & 1.0395 & 1.0724 & 1.1148 \\
19 & 1.0437 & 1.0167 & 1.0611 & 0.9830 & 1.0207 & 1.0033 \\
20 & 1 & 1.1038 & 1.1038 & 1 & 1.0001 & 0.9927 \\
21 & 1 & 1.0198 & 1.0198 & 0.9365 & 1.0079 & 0.9439 \\
22 & 0.9441 & 1.01099 & 0.9545 & 1.0524 & 1.0842 & 1.1411 \\
23 & 0.9185 & 1.0448 & 0.9596 & 0.9528 & 1.0472 & 0.9977 \\
24 & 1.0615 & 1.0509 & 1.1155 & 1.0000 & 1.0300 & 1.0300 \\
25 & 1.1395 & 1.0667 & 1.2155 & 1.0000 & 1.0119 & 1.0119 \\
26 & 1.0033 & 1.0183 & 1.0217 & 1.0000 & 1.0148 & 1.0148 \\
27 & 1.0919 & 1.0869 & 1.1868 & 0.8704 & 1.0090 & 0.8782 \\
28 & 1.0044 & 1.0837 & 1.0885 & 0.8730 & 1.0322 & 0.9012 \\
29 & 0.9405 & 1.0794 & 1.0152 & 0.9699 & 1.0377 & 1.0064 \\
30 & 1 & 1.0360 & 1.0360 & 0.9434 & 1.0010 & 0.9444 \\
\hline & & & & & &
\end{tabular}

Consider the synthetic dataset of 30 DMUs in Tables 4 and 5 . We apply model (M5) ${ }_{a, b}$ for $a, b \in\{0,1\}$, and computed DSMLPI. The outcomes are recorded in Table 7.

In Table 7, columns 4 and 7 show the DSML change; 11 units show productivity regress between periods $t=1 \& 2$, whereas this number increases to 14 in $t=2 \& 3$. The values of $\overline{\mathrm{EC}}$ in columns 2 and 5 in Table 7 are equal or lower than those of EC in columns 2 and 5 in Table 6 . This indicates that certain DMUs are at a distance away from the efficient frontier in period $t+1$ compared to $t$, and this gap is more prominent in sequential frontier than contemporaneous frontier. Also, $\overline{\mathrm{TC}}$ values are always one or more than one in columns 3 and 6 in Table 7, while TC values can be less than one as observed in columns 3 and 6 in Table 6 , indicating that technical regress is not observed in DSMLPI. The behavior of technical change in DSMLPI can also be observed from Figure 5. As already stated this feature provides a significant advantage to DSMLPI over DMLPI.

\section{EMPIRICAL STUDY}

To demonstrate the practical aspect of the proposed indexes, we consider the annual data for 39 Indian commercial, including both public and private banks from 2008 to 2019. Fukuyama and Weber [29,31], Tavana 


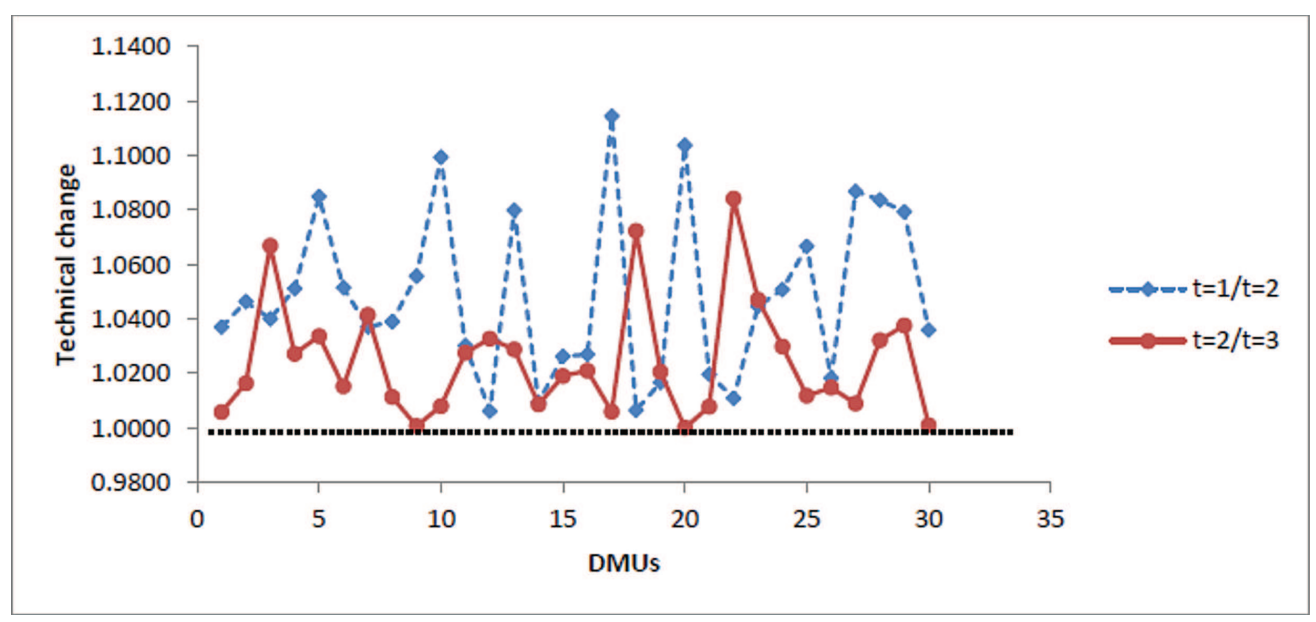

FiguRE 5. The technical change in DSMLPI in two consecutive periods $t=1 \& 2$ and $t=2 \& 3$ on the synthetic data of 30 DMUs.

[67], Henriques [34] advocated to apply a two-stage network structure in the banking industry. We follow in their footsteps to consider a two-stage dynamic network production process of an Indian bank. Figure 6 provides the underlying design in which the production process of a bank within each period has two distinct divisions: (i) operations and (ii) profitability. These divisions are linked vertically with intermediate products and horizontally by carryovers that link two distinct periods. Table 8 explains the inputs, outputs, intermediate links, and carryovers variables in the present analysis.

In division 1, we assume that a bank consumes four inputs (labor, fixed assets, borrowings, and operational expenses) to produce four outputs (operating income, deposits, investments, and loans), which serve as an intermediate input for division 2.

Borrowings include interbank borrowings and borrowings from the Reserve bank of India (RBI) and borrowings from outside India. The treatment of deposits as an intermediate product addresses the famous "deposit dilemma" in the banking efficiency literature due to disagreement between the intermediation and production approaches.

Here, we neither treat deposits as an input as proposed in the intermediation approach nor as an output as advocated in the production approach, but treat deposits as an intermediate product in lines suggested by Holod and Lewis [36]. We further refer to $[30,39,67]$ for detailed reasons for including these inputs and intermediates in our present study.

In division 2, we assume that a bank utilizes the income generated by division 1 as inputs to maximize returns on assets and net profit and minimize non-performing assets (NPA). To link the network structure of two periods, we follow Fukuyama and Weber [30] and use capital reserves and unused assets of the previous period as the desirable carryovers. The unused assets are measured by the total assets minus the sum of required reserves, capital, loans, and investment.

Some of the features, like return on assets and net profit, can take negative values. We apply the methodologies of Sections 4 and 5 to obtain the DMLPI and DSMLPI and their components efficiency change (EC \& $\overline{\mathrm{EC}}$ ), and technical change (TC \& $\overline{\mathrm{TC}}$ ). Due to the compatibility issue of CRS with negative data, the productivity change discussed here is independent of the scale efficiency change factor. 


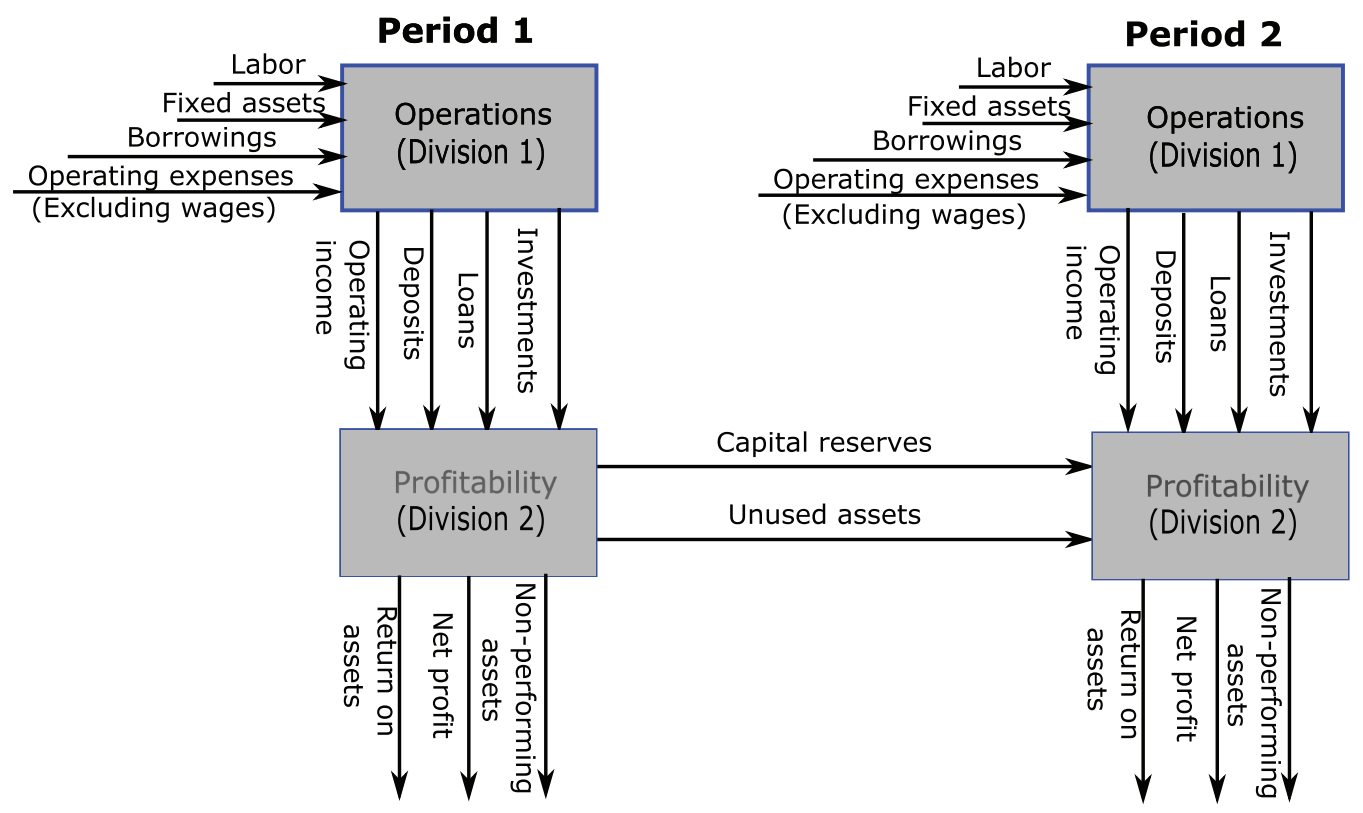

FIGURE 6. A dynamic network structure of a banking unit; the consecutive periods are connected horizontally through desirable and undesirable carryover activities, and the two divisions are connected vertically through intermediate products.

TABLE 8. Inputs, outputs, intermediate products and carryover variables applied in the empirical analysis.

\begin{tabular}{|c|c|}
\hline Inputs of division 1 & $\begin{array}{l}\text { 1. Labor } \\
\text { 2. Fixed assets } \\
\text { 3. Borrowings } \\
\text { 4. Operating expenses (excluding wages) }\end{array}$ \\
\hline Intermediates between divisions 1 and 2 & $\begin{array}{l}\text { 1. Operating income } \\
\text { 2. Deposits } \\
\text { 3. Loans } \\
\text { 4. Investments }\end{array}$ \\
\hline Desirable carryovers in division 2 & $\begin{array}{l}\text { 1. Capital reserves } \\
\text { 2. Unused assets }\end{array}$ \\
\hline Desirable outputs of division 2 & $\begin{array}{l}\text { 1. Return on assets } \\
\text { 2. Net profit }\end{array}$ \\
\hline Undesirable outputs of division 2 & 1. Non-performing assets (NPA) \\
\hline
\end{tabular}

\subsection{Data}

We collect the data of 39 Indian commercial public and private sector banks over the period 2008 to 2019 from various issues of Statistical Tables Relating to Banks in India (an annual publication of the RBI). The current price figures of all variables (except labor and return on assets) are deflated by the implicit price deflator of gross domestic product (GDP) at factor cost. Following Denizer et al. [17], we normalize the input, output, carryover, and intermediate variables of a bank by the number of bank branches. We assume that all banks 
TABLE 9. Summary statistics of variables in the entire period of study; the unit of measurement of all variables (except Labor and Return on assets) is INR in lakhs.

\begin{tabular}{llllllll}
\hline & Mean & Std. dev. & Kurtosis & Skewness & Median & Max & Min \\
\hline Labor & 11.88 & 5.76 & 3.69 & 2.01 & 9.82 & 31.18 & 6.58 \\
Borrowings & 785.51 & 1230.88 & 6.69 & 2.54 & 373.03 & 5454.77 & 2.00 \\
Fixed assets & 78.75 & 63.93 & 7.63 & 2.33 & 61.07 & 341.95 & 14.11 \\
Operating expenses & 154.13 & 102.54 & 2.85 & 1.88 & 115.05 & 484.55 & 66.54 \\
Deposits & 7010.43 & 3245.41 & 4.46 & 1.65 & 6141.09 & 18996.89 & 2412.79 \\
Investments & 2367.14 & 1387.85 & 4.21 & 1.89 & 1962.49 & 7401.84 & 796.03 \\
Loans & 4932.59 & 2941.15 & 4.19 & 1.69 & 4056.17 & 15281.93 & 1215.34 \\
Operating income & 776.07 & 438.59 & 3.19 & 1.77 & 638.38 & 2266.84 & 277.12 \\
Unused assets & 718.68 & 561.47 & 3.85 & 1.74 & 507.69 & 2639.13 & 102.47 \\
Capital reserves & 39.93 & 37.92 & 1.13 & 1.25 & 23.67 & 150.49 & 2.16 \\
Net profit & 55.01 & 84.58 & 2.52 & 0.95 & 44.44 & 290.08 & -135.61 \\
Return on assets & 0.59 & 0.77 & 1.43 & -0.59 & 0.64 & 1.89 & -1.50 \\
NPA & 119.25 & 93.22 & 4.58 & 1.63 & 110.22 & 459.81 & 8.10 \\
\hline
\end{tabular}

under consideration are homogeneous because they all undertake similar activities using the same inputs to produce the same outputs. Table 9 presents the summary statistics of all the variables used in the empirical illustration.

\subsection{Results}

Model (M4) $a_{a, b}$ is solved for $\xi=\xi^{\prime}=\xi^{\prime \prime \prime}=3, \pi=\pi^{\prime}=1$, for period $t$ and $t+1$ while model (M5) $)_{a, b}$ is solved setting $\eta_{1}=\eta_{1}^{\prime}=\eta_{1}^{\prime \prime \prime}=3, \delta_{1}=\delta_{1}^{\prime}=1$, for period $t$ and $\eta_{1}=\eta_{1}^{\prime}=\eta_{1}^{\prime \prime \prime}=1.5, \delta_{1}=\delta_{1}^{\prime}=1$, for period $t+1$. The results are shown in Tables 10-15, where IFSC codes are used for naming banks. In our analysis, a number greater than one depicts an increase while less than one indicate decrease; value equals 1 depicts no change.

Table 10 presents the efficiency change for each bank and average efficiency change for the period 2008 to 2019, where the average is computed, taking the geometric mean of efficiency changes. UTBI exhibited efficiency change progress in the initial years of study and settled down to no efficiency change in the subsequent years. Four banks (NTBL, RATN, HDFC, ICIC) depict EC $=1$ in the entire period indicating these units record no efficiency change. Five banks (IDIB, CSBK, CIUB, UTIB, KKBK) have exhibited EC $\geq 1$ in ten out of eleven periods of analysis showing more or less a consistent performance in efficiency change by them. A few other banks (BARB, BAID, UCBA, DLXB, TMBL, IBKL, DCBL) have EC $\geq 1$ on nine out of eleven instances. On the other hand, the largest public sector bank SBIN is inconsistent in efficiency performance with a mix of up and down of EC-values about one. We observe periods of progress as well as periods of regress in efficiency in the other banking units. Six banking units (ALLA, CNRB, IOBA, ORBC, SYNB, JAKA) have shown progress in efficiency change in the recent two periods 2017/18 and 2018/19.

The efficiency change, computed by DSMLPI solving model (M5) ${ }_{a, b}$, is reported in Table 11. One unit (NTBL) shows $\overline{\mathrm{EC}}=1$ throughout the period indicating its consistency in maintaining efficiency. Another unit (HDFC) registers a consistent performance in terms of efficiency score for almost all, especially in recent times, except for one year, 2008/09. ICIC bank attains $\overline{\mathrm{EC}} \geq 1$ in eight periods out of eleven. Twelve banking units have $\overline{\mathrm{EC}}<1$ in the whole period of study, including the largest public bank SBIN.

Compared to the number of units with EC $>1$, we observe this number is relatively low when it comes to $\overline{\mathrm{EC}}$. The EC and $\overline{\mathrm{EC}}$ measures shift in a DMU towards the efficient frontier composed by the production technology of period $t$ utilizing the data in period $t+1$. The convergence of a DMU towards an efficient frontier happens if either the PPS remains unchanged at $t+1$ or expands but at a relatively lower rate than the rate at which the input-output bundle of a unit at $t+1$ comes more proximate to the efficient frontier at $t$. If the PPS at 
TABLE 10. Efficiency change (EC) of banks over the period 2008-2019 by model (M4) ${ }_{a, b}$.

\begin{tabular}{|c|c|c|c|c|c|c|c|c|c|c|c|}
\hline DMU & $2008 / 09$ & $2009 / 10$ & $2010 / 11$ & $2011 / 12$ & $2012 / 13$ & 2013/14 & $2014 / 15$ & $2015 / 16$ & $2016 / 17$ & $2017 / 18$ & $2018 / 19$ \\
\hline SBIN & 0.9995 & 1 & 1 & 0.9907 & 1.0016 & 0.9943 & 1.0118 & 1.0019 & 0.9938 & 1.0062 & 0.9981 \\
\hline ALLA & 0.9979 & 1.0019 & 0.9988 & 1.0012 & 0.9930 & 0.9925 & 1.0080 & 1.0066 & 0.9881 & 1.0039 & 1.0063 \\
\hline ANDB & 0.9966 & 1 & 0.9996 & 0.9983 & 0.9999 & 1.0022 & 1 & 1 & 1 & 0.9964 & 1.0009 \\
\hline BARB & 0.9985 & 1.0015 & 1 & 1 & 1 & 1 & 1 & 1 & 1 & 0.9728 & 1.0279 \\
\hline BAID & 1 & 1 & 0.9946 & 0.9966 & 1.0089 & 1 & 1 & 1 & 1 & 1 & 1 \\
\hline MAHB & 0.9935 & 1 & 0.9962 & 1.0037 & 1.0001 & 0.9948 & 1.0053 & 0.9989 & 1.0011 & 0.9977 & 0.9998 \\
\hline CNRB & 1 & 1 & 1 & 0.99343 & 1.0058 & 1.0008 & 1 & 0.9888 & 0.9966 & 1.0112 & 1.0035 \\
\hline CBIN & 1 & 1 & 0.9926 & 1 & 1.0075 & 0.9834 & 1.0169 & 0.9939 & 1.0061 & 0.9964 & 1.0012 \\
\hline CORP & 1 & 1 & 0.9970 & 1.0018 & 0.9945 & 1.0068 & 1 & 0.9923 & 1.0049 & 0.9930 & 1.0021 \\
\hline BKDN & 0.9959 & 0.9970 & 1.0048 & 1.0004 & 1 & 0.9977 & 1.0022 & 0.9903 & 1.0084 & 0.9994 & 1.0012 \\
\hline IDIB & 1 & 1 & 1 & 1 & 0.998 & 1.002 & 1 & 1 & 1 & 1 & 1 \\
\hline IOBA & 0.9992 & 0.9878 & 0.9995 & 1.0128 & 0.9854 & 0.9997 & 1.0108 & 0.9837 & 0.9999 & 1.0169 & 1.0042 \\
\hline ORBC & 1.0053 & 1 & 0.9934 & 0.9969 & 0.9989 & 0.9954 & 1.0047 & 1.0003 & 0.9919 & 1.0074 & 1.0083 \\
\hline PSIB & 0.9968 & 1 & 1 & 0.9994 & 1.0006 & 1 & 1 & 1 & 1 & 1 & 1 \\
\hline PUNB & 1.0039 & 0.9941 & 0.9993 & 0.9916 & 1.0164 & 0.9689 & 1.0177 & 1.0141 & 0.9840 & 1.0027 & 0.9968 \\
\hline SYNB & 0.9927 & 1 & 0.998 & 1.0020 & 0.9963 & 1.0036 & 0.9987 & 1.0015 & 0.9967 & 1.0006 & 1.0015 \\
\hline UCBA & 0.9935 & 0.9973 & 1.0059 & 0.9926 & 1.0033 & 1.0042 & 1 & 1 & 1 & 1 & 1 \\
\hline UBIN & 0.9927 & 0.9944 & 1.0064 & 0.9886 & 1.0066 & 0.9931 & 1.0034 & 1.0038 & 0.9942 & 1.0115 & 0.9972 \\
\hline UTBI & 1.0020 & 1.0008 & 1 & 1 & 1 & 1 & 1 & 1 & 1 & 1 & 1 \\
\hline VIJB & 0.9986 & 0.9933 & 1.0028 & 1.0023 & 1.0014 & 0.9992 & 0.9939 & 0.9984 & 1.0058 & 1.0041 & 0.9951 \\
\hline CSBK & 0.9991 & 1 & 1 & 1 & 1 & 1 & 1 & 1 & 1 & 1 & 1 \\
\hline CIUB & 0.9997 & 1.0002 & 1 & 1 & 1 & 1 & 1 & 1 & 1 & 1 & 1 \\
\hline DLXB & 1.0001 & 0.9986 & 1.0013 & 0.9902 & 1.0091 & 1.0009 & 1 & 1 & 1 & 1 & 1 \\
\hline FDRL & 0.9977 & 0.9911 & 1.0066 & 0.9986 & 1.0038 & 1 & 1 & 0.9969 & 1.0028 & 0.9969 & 1.0027 \\
\hline JAKA & 0.9975 & 0.9964 & 1.0021 & 1.0016 & 1 & 1 & 0.9972 & 0.9925 & 1.0073 & 1.0029 & 1.0001 \\
\hline KARB & 1.0012 & 1 & 0.9959 & 0.9998 & 1.0043 & 0.9987 & 1.0013 & 0.9953 & 1.0048 & 0.9993 & 0.9951 \\
\hline KVBL & 0.9999 & 1 & 1 & 0.9995 & 0.9975 & 1.0030 & 0.9950 & 1.0050 & 0.9988 & 0.9943 & 1.0068 \\
\hline LAVB & 0.9982 & 0.9972 & 1.0037 & 0.9922 & 1.0026 & 1.0035 & 0.9992 & 1.0027 & 1 & 1 & 1 \\
\hline NTBL & 1 & 1 & 1 & 1 & 1 & 1 & 1 & 1 & 1 & 1 & 1 \\
\hline RATN & 1 & 1 & 1 & 1 & 1 & 1 & 1 & 1 & 1 & 1 & 1 \\
\hline SIBL & 0.9970 & 1.0004 & 1 & 1 & 1 & 1 & 1 & 1 & 0.9997 & 0.9972 & 1.0025 \\
\hline TMBL & 0.9998 & 1 & 1 & 1 & 1 & 0.9993 & 1.0007 & 1 & 1 & 1 & 1 \\
\hline UTIB & 1 & 1 & 1 & 1 & 1 & 1 & 1 & 1 & 1 & 0.9720 & 1.0288 \\
\hline HDFC & 1 & 1 & 1 & 1 & 1 & 1 & 1 & 1 & 1 & 1 & 1 \\
\hline ICIC & 1 & 1 & 1 & 1 & 1 & 1 & 1 & 1 & 1 & 1 & 1 \\
\hline INDB & 0.9672 & 1.0143 & 1.0028 & 1.0023 & 1 & 0.9992 & 1.0008 & 1 & 1 & 1 & 0.9997 \\
\hline DCBL & 1.0065 & 0.9718 & 1.0290 & 1 & 1 & 0.9939 & 1.0061 & 1 & 1 & 1 & 1 \\
\hline IBKL & 1 & 0.9817 & 1.0187 & 1 & 1 & 0.9635 & 1.0379 & 1 & 1 & 1 & 1 \\
\hline KKBK & 0.9804 & 1.0166 & 1 & 1 & 1 & 1 & 1 & 1 & 1 & 1 & 1 \\
\hline Average & 0.9977 & 1 & 1.0012 & 0.9989 & 1.0009 & 0.9974 & 1.0028 & 0.9991 & 0.9996 & 0.9995 & 1.0020 \\
\hline $\begin{array}{l}\text { Number of } \\
\text { units with } \\
\text { EC }>1\end{array}$ & 6 & 7 & 11 & 9 & 14 & 10 & 14 & 8 & 8 & 10 & 15 \\
\hline
\end{tabular}


TABLE 11. Efficiency change $(\overline{\mathrm{EC}})$ in banks over the period $2008-2019$ by model $(\mathrm{M} 5)_{a, b}$.

\begin{tabular}{|c|c|c|c|c|c|c|c|c|c|c|c|}
\hline DMU & 2008/09 & $2009 / 10$ & $2010 / 11$ & $2011 / 12$ & $2012 / 13$ & $2013 / 14$ & $2014 / 15$ & $2015 / 16$ & $2016 / 17$ & $2017 / 18$ & $2018 / 19$ \\
\hline SBIN & 0.9758 & 0.9894 & 0.9935 & 0.9819 & 0.9853 & 0.9859 & 0.9985 & 0.9811 & 0.9850 & 0.9849 & 0.9544 \\
\hline ALLA & 0.9885 & 0.9921 & 0.9927 & 0.9934 & 0.9973 & 0.9904 & 0.9973 & 0.9923 & 0.9880 & 0.9952 & 0.9917 \\
\hline ANDB & 0.9923 & 0.9991 & 0.9973 & 0.9968 & 0.9992 & 0.9960 & 0.9987 & 0.9974 & 0.9915 & 0.9956 & 0.9907 \\
\hline BARB & 0.9971 & 1.0063 & 1 & 1 & 1 & 1 & 1 & 0.9867 & 0.9891 & 0.9678 & 0.9761 \\
\hline BAID & 1 & 0.9996 & 0.9951 & 0.9864 & 1.0081 & 1.0005 & 0.9980 & 1.0174 & 0.9701 & 0.9835 & 0.9826 \\
\hline MAHB & 0.9885 & 0.9915 & 0.9939 & 0.9930 & 0.9944 & 0.9877 & 1.0020 & 0.9929 & 0.9935 & 0.9977 & 0.9885 \\
\hline CNRB & 1 & 0.9865 & 0.9985 & 0.9861 & 0.9956 & 1.0078 & 0.9913 & 0.9891 & 0.9816 & 0.9895 & 0.9862 \\
\hline CBIN & 0.9983 & 0.9942 & 0.9870 & 0.9940 & 0.9966 & 0.9879 & 0.9942 & 1.0021 & 0.9955 & 0.9993 & 0.9977 \\
\hline CORP & 1 & 1 & 0.9984 & 0.9935 & 0.9936 & 0.9976 & 0.9987 & 0.9873 & 0.9964 & 0.9869 & 0.9955 \\
\hline BKDN & 0.9918 & 0.9953 & 0.9961 & 0.9936 & 0.9926 & 0.9921 & 0.9980 & 0.9887 & 0.9948 & 0.9981 & 0.9983 \\
\hline IDIB & 1 & 0.9994 & 0.9943 & 0.9899 & 1.0000 & 1.0013 & 0.9980 & 0.9960 & 0.9811 & 0.9951 & 0.9935 \\
\hline IOBA & 0.9855 & 0.9758 & 0.9856 & 0.9943 & 0.9925 & 0.9921 & 0.9887 & 0.9768 & 0.9972 & 0.9990 & 0.9979 \\
\hline ORBC & 0.9963 & 1 & 0.9829 & 0.9938 & 0.9904 & 0.9927 & 0.9949 & 0.9909 & 0.9803 & 0.9998 & 0.9855 \\
\hline PSIB & 0.9938 & 1 & 1 & 1 & 1 & 1 & 1 & 0.9977 & 0.9947 & 0.9980 & 0.9990 \\
\hline PUNB & 1.0028 & 0.9780 & 0.9837 & 0.9848 & 1.0143 & 0.9713 & 0.9887 & 0.9753 & 0.9924 & 0.9782 & 0.9948 \\
\hline SYNB & 0.9855 & 0.9891 & 0.9903 & 0.9865 & 0.9905 & 0.9950 & 0.9945 & 0.9937 & 0.9913 & 0.9893 & 0.9897 \\
\hline UCBA & 0.9859 & 0.9869 & 0.9949 & 0.9895 & 0.9948 & 0.9967 & 0.9971 & 0.9895 & 0.9946 & 0.9943 & 0.9951 \\
\hline UBIN & 0.9856 & 0.9866 & 0.9881 & 0.9841 & 0.9938 & 0.9900 & 0.9899 & 0.9861 & 0.9819 & 0.9861 & 0.9832 \\
\hline UTBI & 1.0009 & 1.0000 & 1 & 0.9990 & 1.0000 & 0.9976 & 1.0014 & 0.9979 & 0.9975 & 0.9958 & 0.9988 \\
\hline VIJB & 0.9923 & 0.9930 & 0.9953 & 0.9889 & 0.9922 & 0.9965 & 0.9922 & 0.9907 & 0.9872 & 0.9973 & 0.9998 \\
\hline CSBK & 0.9983 & 0.9991 & 0.9964 & 1.0021 & 0.9974 & 1.0014 & 0.9999 & 0.9998 & 0.9998 & 0.9998 & 0.9998 \\
\hline CIUB & 0.9990 & 0.9992 & 0.9960 & 0.9956 & 0.9965 & 0.9997 & 1.0001 & 0.9998 & 0.9959 & 0.9897 & 1.0031 \\
\hline DLXB & 1.0001 & 0.9969 & 0.9873 & 0.9743 & 1.0089 & 0.9965 & 0.9968 & 0.9989 & 0.9997 & 0.9951 & 0.9998 \\
\hline FDRL & 0.9939 & 0.9888 & 0.9929 & 0.9865 & 0.9953 & 0.9950 & 0.9977 & 0.9960 & 0.9849 & 0.9947 & 0.9919 \\
\hline JAKA & 0.9881 & 0.9993 & 0.9951 & 1.0002 & 1.0006 & 0.9925 & 0.9906 & 0.9944 & 0.9994 & 0.9958 & 0.9920 \\
\hline KARB & 1.0012 & 0.9952 & 0.9896 & 0.9945 & 0.9924 & 0.9908 & 1.0006 & 0.9967 & 0.9984 & 0.9981 & 0.9853 \\
\hline KVBL & 0.9995 & 1.0002 & 1.0000 & 0.9782 & 0.9862 & 0.9846 & 0.9923 & 0.9998 & 0.9946 & 0.9932 & 0.9980 \\
\hline LAVB & 0.9966 & 0.9934 & 0.9873 & 0.9967 & 0.9969 & 0.9980 & 0.9976 & 0.9951 & 0.9867 & 0.9822 & 1.0071 \\
\hline NTBL & 1 & 1 & 1 & 1 & 1 & 1 & 1 & 1 & 1 & 1 & 1 \\
\hline RATN & 1 & 1.0000 & 0.9995 & 0.9884 & 0.9988 & 0.9877 & 0.9973 & 0.9960 & 0.9803 & 0.9953 & 0.98774 \\
\hline SIBL & 0.9946 & 0.9989 & 0.9990 & 0.9965 & 0.9973 & 0.9970 & 0.9970 & 0.9964 & 0.9924 & 0.9865 & 0.9872 \\
\hline TMBL & 0.9989 & 0.9988 & 0.9997 & 0.9922 & 1.0042 & 0.9964 & 1.0014 & 0.9968 & 0.9985 & 0.9972 & 0.9978 \\
\hline UTIB & 1 & 1 & 1 & 1 & 0.9908 & 0.9859 & 0.9961 & 0.9756 & 0.9528 & 0.9764 & 0.9768 \\
\hline HDFC & 0.9691 & 1.0007 & 1 & 1 & 1 & 1 & 1 & 1 & 1 & 1 & 1.0090 \\
\hline ICIC & 1 & 1 & 1 & 1 & 0.9894 & 1.0065 & 0.9955 & 1.0064 & 1 & 1 & 0.9725 \\
\hline INDB & 0.9065 & 0.9998 & 1.0085 & 0.9925 & 0.9897 & 0.9920 & 0.9987 & 0.9920 & 0.9995 & 0.9888 & 0.9751 \\
\hline DCBL & 0.9884 & 0.9636 & 0.9838 & 0.9679 & 0.9819 & 0.9916 & 0.9812 & 0.9912 & 0.9954 & 0.9925 & 0.9914 \\
\hline IBKL & 0.9180 & 0.9845 & 0.9922 & 0.9653 & 0.9937 & 0.9810 & 1.0215 & 0.9873 & 0.9824 & 0.9847 & 0.9852 \\
\hline KKBK & 0.9239 & 1.0286 & 1 & 1 & 0.9931 & 0.9820 & 1.0105 & 0.9819 & 0.9858 & 0.9928 & 0.9935 \\
\hline Average & 0.9879 & 0.9951 & 0.9947 & 0.9913 & 0.9960 & 0.9938 & 0.9973 & 0.9931 & 0.9905 & 0.9921 & 0.9910 \\
\hline $\begin{array}{l}\text { Number of } \\
\text { units with } \\
\overline{\mathrm{EC}}>1\end{array}$ & 4 & 4 & 1 & 2 & 7 & 5 & 7 & 3 & 0 & 0 & 4 \\
\hline
\end{tabular}




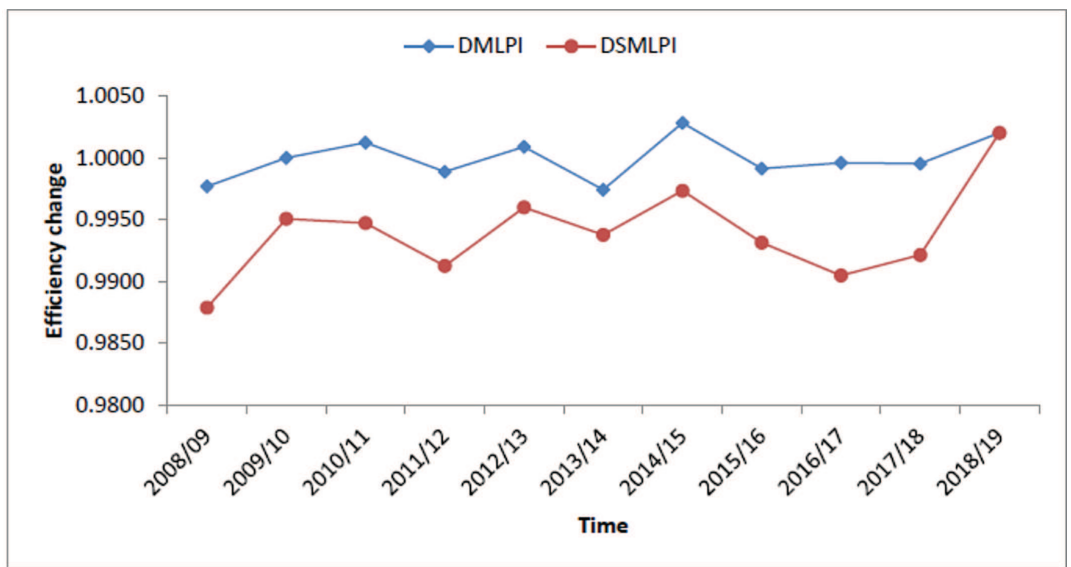

(a)

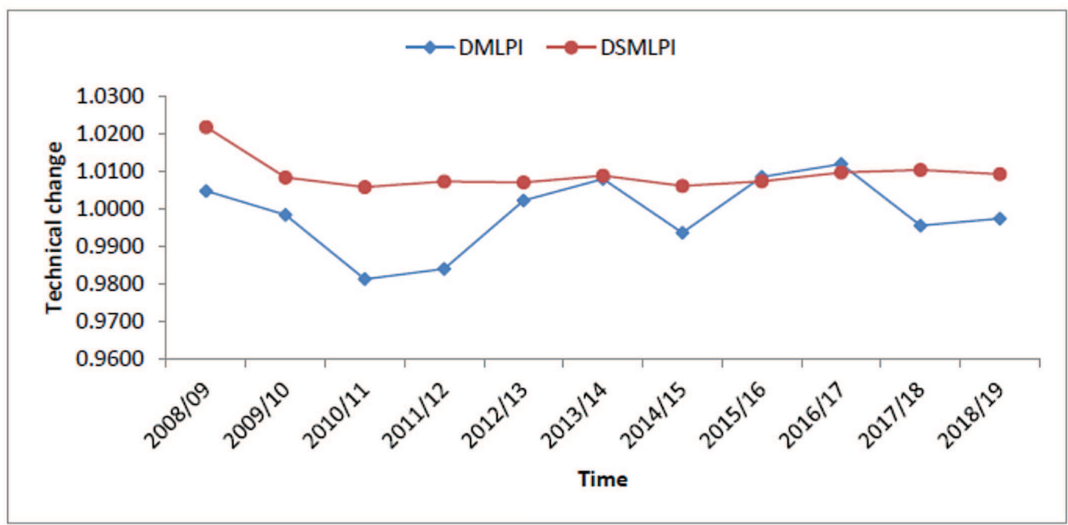

(b)

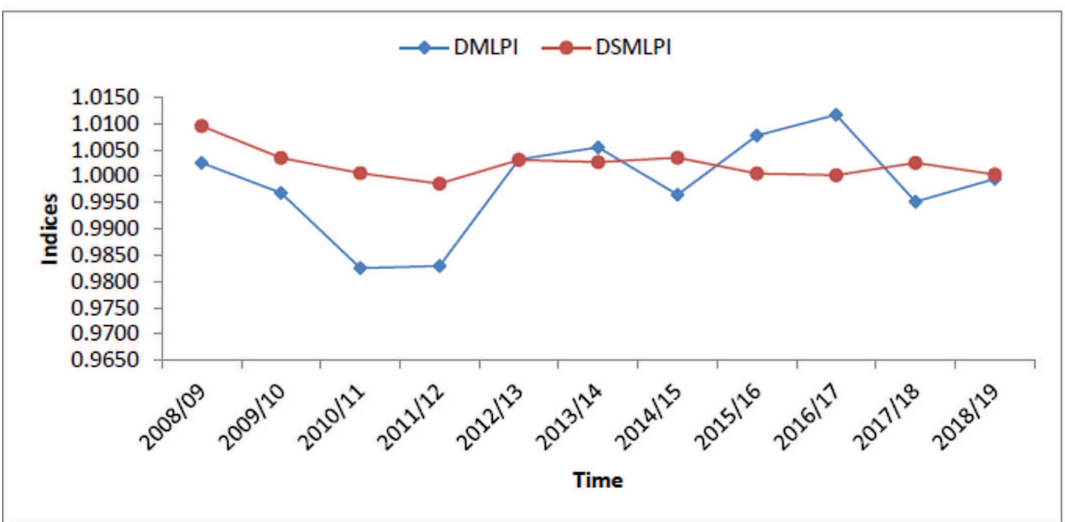

(c)

FigURE 7. Average DMLPI, DSMLPI and their components for 39 Indian nationalized banks from 2008 to 2019. (a) Efficiency change. (b) Technical change. (c) Productivity indices, liberated from scale change. 
TABLE 12 . Technical change (TC) in banks over the period 2008-2019 by model (M4) $)_{a, b}$.

\begin{tabular}{|c|c|c|c|c|c|c|c|c|c|c|c|}
\hline Banks & 2008/09 & $2009 / 10$ & $2010 / 11$ & $2011 / 12$ & $2012 / 13$ & $2013 / 14$ & $2014 / 15$ & $2015 / 16$ & $2016 / 17$ & $2017 / 18$ & $2018 / 19$ \\
\hline SBIN & 1.0016 & 1.0004 & 0.9888 & 0.9950 & 1.0020 & 1.0063 & 1.0021 & 0.9898 & 1.0062 & 0.9988 & 0.9854 \\
\hline ALLA & 0.9993 & 1.0052 & 0.9926 & 0.9985 & 1.0006 & 1.0052 & 0.9935 & 1.0430 & 0.9941 & 0.9937 & 1.0056 \\
\hline ANDB & 1.0010 & 1.0100 & 0.9858 & 1.0020 & 1.0025 & 0.9947 & 1.0038 & 0.9987 & 1.0059 & 0.9915 & 0.9991 \\
\hline BARB & 0.9992 & 1.0122 & 0.9947 & 0.9787 & 1.0422 & 1.0815 & 1.0237 & 1.0631 & 1.0235 & 0.9533 & 1.0028 \\
\hline BAID & 1.0810 & 0.9821 & 0.9925 & 0.9743 & 1.0118 & 1.1314 & 0.9302 & 1.2150 & 1.0169 & 0.9926 & 1.0113 \\
\hline MAHB & 1.0005 & 1.0018 & 0.9905 & 1.0052 & 0.9955 & 0.9989 & 1.0001 & 0.9880 & 1.0093 & 0.9901 & 0.9998 \\
\hline CNRB & 1.0478 & 0.9725 & 0.9787 & 0.9148 & 1.0071 & 1.1058 & 0.8955 & 0.9943 & 1.0082 & 0.9860 & 1.0043 \\
\hline CBIN & 0.9984 & 1.0057 & 0.9920 & 1.0014 & 1.0019 & 1.0107 & 0.9836 & 1.0202 & 1.0393 & 0.9638 & 1.0014 \\
\hline CORP & 1.0026 & 0.9952 & 0.9938 & 1.0024 & 1.0013 & 0.9931 & 1.0053 & 0.9922 & 1.0130 & 0.9902 & 1.0002 \\
\hline BKDN & 1.0005 & 1.0001 & 0.9971 & 1.0011 & 1.0145 & 0.9940 & 1.0075 & 0.9895 & 0.9983 & 0.9986 & 1.0011 \\
\hline IDIB & 1.0364 & 0.9644 & 0.9675 & 0.9804 & 1.0011 & 1.0394 & 0.9586 & 1.0077 & 1.0113 & 0.9886 & 1.0074 \\
\hline IOBA & 1.0338 & 0.9663 & 0.9949 & 0.9885 & 1.0094 & 1.0196 & 0.9781 & 1.0331 & 0.9994 & 0.9847 & 1.0044 \\
\hline ORBC & 1.0020 & 0.9643 & 0.9905 & 0.9951 & 1.0016 & 1.0110 & 0.9853 & 1.0309 & 1.0185 & 0.9849 & 1.0040 \\
\hline PSIB & 1.0032 & 1.0047 & 0.9930 & 0.9815 & 0.9926 & 1.1766 & 0.8900 & 1.0023 & 0.9975 & 0.9981 & 1.0023 \\
\hline PUNB & 1.0033 & 1.0025 & 0.9930 & 1.0005 & 1.0074 & 1.0044 & 0.9923 & 1.0056 & 1.0088 & 0.9765 & 0.9999 \\
\hline SYNB & 1.0008 & 0.9961 & 0.9964 & 1.0046 & 1.0047 & 0.9964 & 1.0033 & 0.9943 & 0.9960 & 0.9988 & 0.9988 \\
\hline UCBA & 1.0009 & 1.0047 & 0.9991 & 0.9825 & 1.0019 & 0.9977 & 0.9995 & 1.0390 & 0.9878 & 1.0043 & 1.0005 \\
\hline UBIN & 1.0016 & 1.0016 & 0.9938 & 1.0052 & 0.9974 & 1.0076 & 0.9959 & 0.9895 & 1.0032 & 0.9903 & 0.9922 \\
\hline UTBI & 1.0004 & 1.0232 & 0.9466 & 0.9297 & 0.9437 & 0.9878 & 0.9980 & 1.0202 & 0.9966 & 0.9827 & 1.0005 \\
\hline VIJB & 1.0010 & 0.9940 & 0.9931 & 1.0017 & 0.9964 & 1.0023 & 1.0022 & 0.9949 & 1.0001 & 0.9893 & 1.0014 \\
\hline CSBK & 1.0001 & 0.9954 & 0.9981 & 1.0030 & 0.9961 & 0.9976 & 1.0003 & 0.9959 & 1.0028 & 0.9958 & 1.0011 \\
\hline CIUB & 1.0002 & 1.0007 & 0.9957 & 1.0022 & 1.0052 & 0.9903 & 1.0039 & 0.9937 & 1.0021 & 1.0030 & 1.0054 \\
\hline DLXB & 1.0000 & 0.9995 & 0.9993 & 1.0035 & 1.0000 & 1.0015 & 1.0010 & 1.0169 & 0.9974 & 0.9868 & 1.0029 \\
\hline FDRL & 1.0024 & 1.0037 & 0.9985 & 0.9989 & 1.0014 & 1.0005 & 0.9994 & 0.9946 & 0.9995 & 0.9984 & 1.0002 \\
\hline JAKA & 1.0022 & 1.0041 & 1.0000 & 1.0224 & 0.9863 & 0.9914 & 0.9812 & 0.9882 & 1.0067 & 0.9975 & 0.9997 \\
\hline KARB & 1.0001 & 0.9958 & 0.9963 & 1.0033 & 1.0023 & 0.9979 & 1.0022 & 0.9900 & 1.0001 & 0.9922 & 1.0012 \\
\hline KVBL & 1.0010 & 1.0061 & 0.9945 & 0.9930 & 0.9978 & 0.9949 & 0.9934 & 1.0014 & 0.9968 & 0.9903 & 1.0011 \\
\hline LAVB & 1.0004 & 1.0007 & 0.9964 & 0.9994 & 1.0021 & 0.9984 & 1.0034 & 0.9999 & 1.0029 & 0.9892 & 0.9947 \\
\hline NTBL & 1.0040 & 1.0032 & 0.9831 & 1.0419 & 0.9622 & 1.0002 & 1.0045 & 0.9755 & 1.0196 & 0.9994 & 0.9793 \\
\hline RATN & 1.0622 & 0.9754 & 0.9966 & 1.0054 & 0.9894 & 1.0008 & 0.9982 & 0.9902 & 1.0118 & 0.9989 & 1.0037 \\
\hline SIBL & 1.0002 & 1.0018 & 0.9989 & 0.9989 & 1.0027 & 0.9929 & 1.0050 & 0.9908 & 0.9977 & 0.9967 & 0.9986 \\
\hline TMBL & 1.0002 & 1.0005 & 0.9963 & 1.0078 & 1.0204 & 0.9739 & 1.0100 & 0.9949 & 0.9997 & 1.0000 & 1.0024 \\
\hline UTIB & 1.0008 & 1.0178 & 0.9240 & 0.9336 & 1.0313 & 0.9557 & 1.0617 & 0.9675 & 1.0029 & 0.9911 & 0.9899 \\
\hline HDFC & 0.9502 & 1.0225 & 0.9799 & 0.9351 & 1.0106 & 1.0214 & 0.9919 & 1.0057 & 1.0114 & 1.0858 & 0.9704 \\
\hline ICIC & 0.9817 & 0.9710 & 0.7314 & 0.8269 & 1.0500 & 0.9559 & 1.0252 & 1.1438 & 1.1631 & 1.0480 & 1.0068 \\
\hline INDB & 0.9789 & 1.0043 & 0.9844 & 0.9819 & 0.9912 & 0.9993 & 1.0367 & 0.9651 & 1.0141 & 1.0002 & 0.9941 \\
\hline DCBL & 1.0129 & 1.0058 & 0.9965 & 0.9858 & 1.0016 & 0.9753 & 0.9913 & 0.9739 & 1.0371 & 0.9686 & 1.0004 \\
\hline IBKL & 0.9775 & 1.0036 & 0.9823 & 0.8739 & 1.0263 & 1.0106 & 1.0157 & 0.9824 & 1.0660 & 1.0422 & 0.9289 \\
\hline KKBK & 1.0078 & 1.0264 & 0.9886 & 1.0527 & 0.9832 & 0.9278 & 0.9992 & 0.9897 & 1.0192 & 0.9968 & 1.0013 \\
\hline Average & 1.0049 & 0.9985 & 0.9813 & 0.9840 & 1.0023 & 1.0081 & 0.9937 & 1.0086 & 1.0121 & 0.9956 & 0.9975 \\
\hline $\begin{array}{l}\text { Number of } \\
\text { units with } \\
\text { TC }>1\end{array}$ & 32 & 26 & 1 & 18 & 27 & 19 & 20 & 15 & 27 & 7 & 25 \\
\hline
\end{tabular}

$t+1$ contracts, a unit can achieve the efficient frontier at $t$ without doing anything; it is one of the drawbacks of DMLPI. As $P_{1}^{t} \subseteq \overline{P^{t}}$, a large number of units can achieve the efficient frontier at $t$ for DMLPI compared to DSMLPI, and hence, EC $\geq \overline{\text { EC }}$. We can observe the average efficiency changes for the banks over 2008-2019 through Figure $7 \mathrm{c}$, which shows that $\overline{\mathrm{EC}}$ lies below EC. 
Tables 12 and 13 present the technical change in the banks from period $t$ to $t+1$. We observe that spurious technical regress is likely to appear in the DMLPI approach. The average values in (Tab. 12) depict five periods with technical advancement and six periods of technical regress. The periods from 2012-14 and 2015-17 emerged as periods when the banking units show technical progress on average. On average, the Indian banking sector achieved a positive technical growth of $1.83 \%$ in 2012/13 and 1.5\% in 2015/16. Compared to 2016/17, the Indian banking units, on average, suffer a decline of $1.65 \%$ in 2017-19 due to technical regress. In 2018/19, the average TC has shown a marginal improvement compared to 2017/18; out of 39 units, almost 25 banks recorded an improvement in their TC values. Moreover, in the most recent three years 2016-19 of the study, only CIUB, and ICIC units recorded TC $>1$.

The estimates of technical change obtained by DSMLPI (model (M5) ${ }_{a, b}$ ) rules out any possibility of technical regress. The same is evident from Table 13 when $\overline{\mathrm{TC}}>1$ for all 39 banks.

Tables 14 and 15 display productivity changes in banks by DMLPI and DSMLPI approaches, respectively. From Table 14, we observe that the average productivity gains in five periods and loss in six periods. It is noticeable that the periods $2012-14$ and $2015-17$ showing productivity growth also showed technical progress in Table 12. Compared to year 2011-12, the productivity change records $2.03 \%$ increase in 2012-13 while this increase is $1.13 \%$ in 2015-16 compared to its previous year. The period 2017-19 has seen a fall in productivity, a phenomena that we observed in technical change also, and the decline on average is $1.424 \%$ as compared to 2016-17. At the same time, a marginal improvement is noticed in 2018-19 compared to 2017-18.

The DSMLPI, on average, exhibits progress in productivity in almost all periods. Considering all the banks and all periods together, from Table 14, we found 204 instances of productivity increase and 225 instances of productivity decline showing $48 \%$ growth in productivity change. On the other hand, from Table 15 , these numbers are respectively 251 and 178, giving $59 \%$ increase in productivity by the DSMLPI approach.

Figures $7 \mathrm{c}, 7 \mathrm{~b}$, and $7 \mathrm{a}$ illustrate the average efficiency change, technical change, and productivity change, respectively over the period 2008 to 2019 measured by DMLPI and DSMLPI. The following are a few interesting facts noted:

(i) The trends in productivity change and technical change by DMLPI are very similar.

(ii) The movement trends in efficiency change are often opposite of the productivity change by DMLPI. For example, periods 2008-11 and 2013-15 experience an upward increase in efficiency change, while productivity change declines in the same periods.

(iii) The trending behavior of two indexes for efficiency change is similar except in 2010-11 and 2016-17.

(iv) The technical change and productivity change by DMLPI are volatile compared to their respective relatively stable counterparts by DSMLPI.

Table 16 presents the correlation coefficients between the DMLPI, DSMLPI, and their components. Columns (1)-(3) depict that there is a noticeable difference between the two productivity indexes and their components EC and $\overline{\mathrm{EC}}$, and TC and $\overline{\mathrm{TC}}$ in the period of study. Column (4) shows that the correlation between EC and DMLPI is quite weak and almost always less than 0.5 except once. Column (5) establishes a very high positive correlation between TC and DMLPI in all the periods. This trend has also been observed in Figures 7b and 7a. Our observations support our belief that it is the technical change instead of efficiency change that acts as the main driver in computing DMLPI. In other words, technical change plays a vital role in assessing productivity change when measured relative to the two consecutive periods. But, columns (6) and (7) do not give a clear indication as to which among $\overline{\mathrm{EC}}$ or $\overline{\mathrm{TC}}$ contributing more in DSMLPI. The correlation ( $\overline{\mathrm{EC}}, \mathrm{DSMLPI})$ is higher than that of (TC, DSMLPI) on six instances, while the two are almost equal in periods 2009-10 and 2013-14. Thus, both $\overline{\mathrm{EC}}$ and $\overline{\mathrm{TC}}$ are equally participating in DSMLPI. However, it appears that $\overline{\mathrm{EC}}$ is occasionally a primary impact factor in productivity change when measured considering the accumulated information from the past several years.

To explore the possible factors that might influence the productivity change and its components, we apply the panel data regression over 468 observations including 39 (banks) cross-sectional units over a time series length of 12 years (2008-2019) with 13 features. Table 17 reports the estimates of coefficients by the regression model; the 
TABLE 13. Technical change ( $\overline{\mathrm{TC}})$ of banks in the period $2008-2019$ by model (M5) ${ }_{a, b}$.

\begin{tabular}{|c|c|c|c|c|c|c|c|c|c|c|c|}
\hline Banks & 2008/09 & $2009 / 10$ & 2010/11 & 2011/12 & 2012/13 & 2013/14 & $2014 / 15$ & $2015 / 16$ & $2016 / 17$ & $2017 / 18$ & $2018 / 19$ \\
\hline SBIN & 1.0265 & 1.0072 & 1.0064 & 1.0100 & 1.0126 & 1.0140 & 1.0114 & 1.0169 & 1.0144 & 1.0124 & 1.0223 \\
\hline ALLA & 1.0069 & 1.0081 & 1.0050 & 1.0057 & 1.0056 & 1.0081 & 1.0071 & 1.0098 & 1.0116 & 1.0088 & 1.0078 \\
\hline ANDB & 1.0038 & 1.0046 & 1.0030 & 1.0055 & 1.0026 & 1.0024 & 1.0025 & 1.0083 & 1.0080 & 1.0064 & 1.0066 \\
\hline BARB & 1.0042 & 1.0097 & 1.0030 & & & & & & & 1.0174 & 1.0225 \\
\hline BAID & 1.0853 & 1.0094 & 1.0030 & 1.0084 & 1.0070 & 1.0146 & 1.0009 & 1.0223 & 1.0135 & 1.0172 & 1.0190 \\
\hline & 1.0032 & 1.0056 & 1.0065 & 1.0066 & 1.0063 & & 1.0064 & 1.0086 & & 1.0074 & 1.0063 \\
\hline CNRB & 1.0556 & 1.0082 & 1.0055 & 1.0075 & 1.0091 & 1.0087 & 1.0027 & 1.0109 & 1.0128 & & 1.0130 \\
\hline CBIN & 1.0016 & 1.0029 & 1.0058 & & 1.0061 & & & & & & \\
\hline CORP & 1.0078 & 1.0048 & 1.0004 & 1.0073 & 1.0047 & 1.0044 & 1.0033 & 1.0066 & 1.0090 & 1.0078 & 1.0083 \\
\hline BKDN & 1.0032 & 1.0048 & 1.0046 & 1.0048 & 1.0059 & 1.0070 & 60 & 1.0073 & 0075 & & 037 \\
\hline IDIB & & 1.0012 & 1.0024 & & & & & & & & \\
\hline IOBA & 1.0496 & 1.01 & 1.01 & & 1.00 & & & & & & \\
\hline ORBC & 1.0088 & 1.0038 & 1.0043 & 1.0079 & 1.0081 & & & 1.00 & 1.0110 & 1.0106 & 1.0091 \\
\hline PSIB & 1.0062 & 1.0062 & 1.0033 & 1.00 & 1.00 & 1.03 & 30 & 1.00 & & & 022 \\
\hline & 1.0061 & 1.0103 & & & & 1.0 & & & & & \\
\hline SYNB & 1.0055 & 1.0044 & 1.0073 & 1.0098 & 1.0105 & 1.0088 & 1.0071 & 1.00 & 1.0062 & 69 & .0092 \\
\hline UCBA & 1.0062 & & & & & & & & & & 1.0060 \\
\hline UBIN & 1.0061 & 1.0092 & 1.01 & 1.0122 & & 1.0119 & 1.0 & 54 & & & . 0154 \\
\hline UTBI & 1.0023 & 1.0198 & 1.0024 & 1.0002 & 1.0005 & 1.0014 & 1.0 & 1.0 & & & \\
\hline VIJB & 1.0073 & 1.0050 & 1.0054 & 1.0066 & 1.0080 & 1.0071 & 1.0072 & 1.0089 & 1.0118 & 1.0103 & 1.0055 \\
\hline & & & & & & & & & & & 0002 \\
\hline CIUB & 1.0007 & 1.00 & 1.00 & & & & 1.0 & 1.0 & 1.00 & 043 & 1.0040 \\
\hline DLXB & 1.0001 & 1.0008 & 1.0043 & 1.0117 & 1.0102 & 1.0040 & 1.0037 & 1.0029 & 1.0018 & 1.0022 & 1.0024 \\
\hline FDRL & 1.0061 & 1.0063 & 1.0074 & 1.0091 & 1.0091 & 1.0070 & 1.0054 & 1.0045 & 1.0069 & 1.0086 & 1.0077 \\
\hline & & & & & & & & & & & \\
\hline & 1.0007 & 1.00 & & & & & & 1.00 & & 024 & 1.0053 \\
\hline KVBL & 1.0013 & 1.0030 & 1.0045 & 1.0064 & 1.0115 & 1.0132 & 1.0126 & 1.0084 & 1.0057 & 1.0059 & 1.0052 \\
\hline LAVB & 1.0014 & 1.0037 & 1.0059 & 1.0070 & 1.0051 & 1.0039 & 1.0030 & 1.0034 & 1.0062 & 1.0112 & 1.0081 \\
\hline & 1.0045 & & 1.0001 & & 1.00 & & & & 1.0024 & 1.0000 & 1.0000 \\
\hline & & & & & & & & 1.0039 & 1.0071 & .0078 & 1.0090 \\
\hline SIBL & 1.0016 & 1.0024 & 1.0017 & 1.0020 & 1.0025 & 1.0027 & 1.0029 & 1.0031 & 1.0040 & 1.0074 & 1.0103 \\
\hline TMBL & 1.0008 & 1.0008 & 1.0016 & 1.0026 & 1.0130 & 1.0009 & 1.0010 & 1.0010 & 1.0016 & 1.0019 & 1.0022 \\
\hline & 1.0315 & & & & & & & & 1.0177 & 1.0305 & 1.0277 \\
\hline & & & & & & & & 1.0027 & & .0119 & 1.0060 \\
\hline ICIC & 1.1393 & 1.0251 & 1.0066 & 1.0052 & 1.0024 & 1.0093 & 1.0028 & 1.0050 & 1.0753 & 1.0848 & 1.0437 \\
\hline INDB & 1.0519 & 1.0267 & 1.0226 & 1.0090 & 1.0080 & 1.0099 & 1.0066 & 1.0008 & 1.0010 & 1.0040 & 1.0086 \\
\hline & & & & & & & & & 1.0090 & 1.0079 & 1.0084 \\
\hline & & & & & & & & & & & 1.0157 \\
\hline KKBK & 1.0859 & 1.0341 & 1.0138 & 1.0201 & 1.0031 & 1.0069 & 1.0081 & 1.0045 & 1.0074 & 1.0075 & 1.0070 \\
\hline Average & 1.0219 & 1.0084 & 1.0059 & 1.0074 & 1.0071 & 1.0090 & 1.0062 & 1.0074 & 1.0098 & 1.0105 & 1.0094 \\
\hline
\end{tabular}

associated coefficient estimates the change in the mean response per unit increase in the factor when all other predictors are held constant. It is observed that the two factors viz. deposits and investments significantly affect TC, DMLPI, TC, and DSMLPI at 5\% significance level. Since the coefficients of deposits are positive while that of investment are negative for all four dependent indexes, the technical change and productivity change are favourably impacted by the deposits and see adverse affect by the investments during the period 2008 to 2019. The unused assets and capital reserves depict unfavorable impact on TC and DMLPI. Our findings report a positive influence of the operating income on TC and DSMLPI and operating expenses on $\overline{\mathrm{TC}}$ and DSMLPI. 
TABLE 14. DMLPI of banks showing productivity change in the period 2008-2019.

\begin{tabular}{|c|c|c|c|c|c|c|c|c|c|c|c|}
\hline Banks & 2008/09 & $2009 / 10$ & 2010/11 & $2011 / 12$ & $2012 / 13$ & 2013/14 & $2014 / 15$ & $2015 / 16$ & $2016 / 17$ & $2017 / 18$ & $2018 / 19$ \\
\hline & 1.0012 & 1.0004 & & 0.9857 & 1.0036 & 1.0005 & 1.0139 & 0.9917 & 1.0000 & 1.0050 & 0.9835 \\
\hline ALLA & 0.9971 & 1.0072 & 0.9913 & 0.9997 & 0.9937 & 0.9977 & 1.0014 & 1.0499 & 0.9823 & 0.9976 & 1.0120 \\
\hline ANDB & 0.9976 & 1.0100 & 0.9854 & 1.0003 & 1.0023 & 0.9969 & 1.0038 & 0.9987 & 1.0059 & 0.9880 & 0.9999 \\
\hline BARB & 0.9977 & 1.0137 & 0.9947 & 0.9787 & 1.0422 & 1.0815 & 1.0237 & & 1.0235 & 0.9274 & \\
\hline BAID & 1.0810 & 0.9821 & & 0.9710 & 1.0208 & 1.1314 & & 1.2150 & 1.0169 & .9926 & 1.0113 \\
\hline MAHB & 0.9940 & 1.0018 & 0.9867 & 1.0090 & 0.9956 & 0.9937 & 1.0054 & 0.9869 & 1.0104 & 0.9878 & 0.9996 \\
\hline CNRB & 1.0478 & 0.9725 & 0.9787 & 0.9088 & 1.0129 & 1.1067 & 0.8955 & 0.9831 & 1.0048 & 0.9970 & 1.0078 \\
\hline CBIN & 0.9984 & 1.0057 & 0.98 & 1.0014 & 1.0095 & 0.9939 & 1.0 & 1.0140 & 1.0457 & 0.9604 & 1.0026 \\
\hline CORP & 1.0026 & & & & 0.9958 & 0.9998 & & 0.9845 & 1.0179 & & \\
\hline BKDN & 0.9964 & 0.9972 & 1.0019 & 1.0014 & 1.0145 & 0.9918 & 1.0097 & 0.9799 & 1.0067 & 0.9980 & 1.0023 \\
\hline IDIB & 1.0364 & 0.9644 & 0.9675 & 0.9804 & 0.9991 & 1.0415 & & 1.0077 & 1.0113 & 0.9886 & 1.0074 \\
\hline IOBA & 1.0330 & 0.9545 & 0.9944 & 1.0012 & 0.9947 & 1.0193 & 0.98 & 1.0162 & 0.9992 & 1.0013 & 1.0086 \\
\hline & 1.0073 & 0.9643 & & 0.9921 & 1.0005 & & & & & & \\
\hline PSIB & 1.0000 & 1.0047 & 0.9930 & 0.9808 & 0.9932 & 1.17 & 0.8 & 1.0023 & 0.9975 & & 1.0023 \\
\hline PUNB & 1.0072 & 0.9965 & 0.99 & 0.9921 & 1.0 & 0.9 & & & 0.9926 & & 0.9967 \\
\hline SYNB & 0.9935 & 0.9961 & 0.9944 & 1.0066 & 1.0009 & 1.0000 & 1.0020 & 0.9957 & 0.9928 & 0.9994 & 1.0003 \\
\hline UCBA & 0.9944 & 1.0020 & 1.0050 & 0.9752 & 1.0052 & 1.0018 & & 1.0390 & 0.9878 & & 1.0005 \\
\hline UBIN & 0.9943 & 0.9960 & 1.0002 & 0.9938 & 1.0040 & 1.0007 & & 0.9932 & 0.9974 & & 0.9894 \\
\hline UT & & & & 0.9 & 0.9 & & & & & & 1.0005 \\
\hline VIJB & 0.9996 & 0.9873 & 0.9959 & 1.0040 & 0.9978 & 1.0015 & 0.9961 & 0.9933 & 1.0059 & 0.9933 & 0.9965 \\
\hline CSBK & 0.9991 & 0.9954 & 0.9981 & 1.0030 & 0.9961 & 0.9 & 1.0 & 0.9 & 028 & & 1.0011 \\
\hline & & & & & & & & & & & \\
\hline & & & & & & & & & & & \\
\hline FDRL & 1.0002 & 0.9948 & 1.0051 & 0.9975 & 1.0052 & 1.0005 & 0.9994 & 0.9915 & 1.0024 & 0.9953 & 1.0030 \\
\hline JAKA & 0.9997 & 1.0005 & 1.0021 & 1.0240 & 0.9863 & 0.9914 & 0.9785 & 0.9808 & 1.0140 & 1.0004 & 0.9998 \\
\hline KARB & 1.0013 & & & & & & & & & & 0.9963 \\
\hline & & & & & & & & & & & 1.0079 \\
\hline & 0.9986 & 9979 & 1.0001 & 0.9916 & 1.0047 & 1.0019 & 1.0026 & 1.0026 & 1.0029 & 0.9892 & 0.9947 \\
\hline NTBL & 1.0040 & 1.0032 & 0.9831 & 1.0419 & 0.9622 & 1.0002 & 1.0045 & 0.9755 & 1.0196 & 0.9994 & 0.9793 \\
\hline & 1.0622 & 0.9754 & 0.9966 & & 0.9894 & & 0.9982 & & 1.0118 & & 1.0037 \\
\hline & & & & & & & & & & & 1.0012 \\
\hline TMBL & 1.0000 & 1.0005 & & 1.0078 & 1.0204 & & 1.0107 & 0.9949 & 0.9997 & 1.0000 & 1.0024 \\
\hline UTIB & 1.0008 & 1.0178 & 0.9240 & 0.9336 & 1.0313 & 0.9557 & 1.0617 & 0.9675 & 1.0029 & 0.9634 & 1.0184 \\
\hline HDFC & 0.9502 & 1.0225 & 0.9799 & 0.9351 & 1.0106 & & 0.9919 & 1.0057 & 1.0114 & 1.0858 & 0.9704 \\
\hline & & & & & & & & & & & \\
\hline & & & & & 0.9912 & & 1.0375 & & 1.0141 & 1.0002 & 0.9938 \\
\hline DCBL & 1.0195 & 0.9774 & 1.0254 & 0.9858 & 1.0016 & 0.9694 & 0.9973 & 0.9739 & 1.0371 & 0.9686 & 1.0004 \\
\hline & 0.9775 & 0.9852 & 1.0007 & 0.8739 & 1.0263 & 0.9738 & 1.0541 & 0.9824 & 1.0660 & 1.0422 & 0.9289 \\
\hline KKBK & 0.9881 & 1.0435 & & 1.0527 & 0.9832 & 0.9278 & 0.9992 & 0.9897 & 1.0192 & 0.9968 & 1.0013 \\
\hline Average & 1.0025 & 0.9968 & 0.9825 & 0.9829 & 1.0032 & 1.0055 & 0.9965 & 1.0077 & 1.0117 & 0.9951 & 0.9995 \\
\hline
\end{tabular}

The feature of fixed assets show a negative impact on EC and $\overline{\mathrm{EC}}$ and a positive impact on $\overline{\mathrm{TC}}$. The factors like labor, net profit, return on assets, and NPA are not playing a significant role on the two indexes and their components.

\section{Conclusions And Future Directions of ReSEARCH}

In this study, we introduce an enhanced ML productivity index (MLPI) to address the problem of infeasibility when evaluating cross-period DDFs in the presence of negative data. In the dynamic network framework, 
TABLE 15. DSMLPI of banks over the period 2008 to 2019.

\begin{tabular}{|c|c|c|c|c|c|c|c|c|c|c|c|}
\hline Banks & 2008/09 & $2009 / 10$ & $2010 / 11$ & $2011 / 12$ & $2012 / 13$ & $2013 / 14$ & $2014 / 15$ & $2015 / 16$ & $2016 / 17$ & $2017 / 18$ & $2018 / 19$ \\
\hline SBIN & 1.0017 & 0.9966 & 0.9999 & 0.9917 & 0.9977 & 0.9998 & 1.0099 & 0.9977 & 0.9992 & 0.9970 & 0.9757 \\
\hline ALLA & 0.9954 & 1.0001 & 0.9976 & 0.9991 & 1.0029 & 0.9985 & & & & & \\
\hline ANDB & 0.9961 & 1.0037 & 1.0003 & 1.0022 & 1.0018 & & & & & 1.0020 & 0.9972 \\
\hline BARB & 1.0014 & 1.0160 & 1.0030 & 1.0088 & 1.0104 & 1.0205 & 1.0066 & 1.0015 & 1.0026 & 0.9847 & \\
\hline BAID & 1.0853 & 1.0089 & & 0.9947 & & & & & & 1.0005 & \\
\hline MAHB & 0.9916 & 0.9971 & 1.0003 & 0.9995 & 1.0007 & 0.9956 & 084 & 1.0014 & 1.0038 & 051 & 947 \\
\hline CNRB & 1.0556 & 0.9946 & & & 1.0047 & & & 0.9998 & 42 & 031 & \\
\hline CBIN & 1.0000 & 0.9971 & 0.9927 & 1.0013 & 1.0026 & & 36 & 107 & & 30 & \\
\hline CORP & 1.0078 & 1.0048 & 0.9988 & 1.0008 & 0.9983 & 1.0020 & 021 & 0.9939 & 1.0054 & 946 & 38 \\
\hline BKDN & 0.9950 & 1.0001 & 1.0006 & & & & & & & 37 & \\
\hline IDIB & 1.0370 & 1.0006 & 0.9967 & 0.9947 & 0050 & & & & & 049 & \\
\hline IOBA & & & & & & & & & & & \\
\hline ORBC & 1.0051 & 1.0038 & & 1.0017 & & & & & & & \\
\hline PSIB & 1.0000 & 1.0062 & 1.0033 & 1.0006 & 08 & 1.0 & 1.0 & 0.9 & 1.00 & 011 & 12 \\
\hline PUNB & 1.0089 & & & & & & & & & & \\
\hline SYNB & 0.9909 & 0.9935 & 0.9975 & 0.9961 & 1.0009 & & & & & & \\
\hline UCBA & 0.9921 & 1.0005 & 1.0021 & 0.9980 & 1.0027 & 1.0028 & & 0.9970 & & & \\
\hline & 0.9917 & & & & & & & & & & \\
\hline UTBI & 1.0032 & 1.0198 & 1.0024 & 0.9993 & 1.0005 & 0.9989 & 1.0042 & 1.0022 & 08 & 991 & \\
\hline & 0.9996 & 0.9 & 1.0007 & & & & & & & & \\
\hline CSBK & 0.9988 & 1.0001 & 0.9977 & 1.0032 & & 1.0027 & & & & & \\
\hline CIUB & 0.9998 & 0.9999 & 0.9974 & 0.9985 & 0.9999 & 1.0024 & 1.0015 & 1.0005 & 0.9973 & 0.9939 & \\
\hline DLXB & 1.0001 & & 15 & & & & & & & 73 & \\
\hline FDRL & 0.9999 & 0.9950 & 1.0002 & 0.9955 & .0044 & 1.0020 & 1.0030 & 1.0004 & & 032 & \\
\hline & & & & & & & & & & & \\
\hline KARB & 1.0019 & 0.9964 & 0.9940 & & & & & & & & \\
\hline KVBL & 1.0007 & 1.0032 & 1.0045 & 0.9845 & 0.9976 & & 1.0048 & 1.0082 & 1.0002 & 0.9991 & 1.0032 \\
\hline LAVB & 0.9980 & 0.9971 & 0.9931 & 1.0037 & 1.0020 & 0019 & 1.0006 & 0.9985 & 0.9928 & 0.9932 & \\
\hline NTBL & 1.0045 & 1.0021 & 1.0001 & 1.0050 & 1.0024 & 1.0050 & 1.0061 & 1.0011 & 1.0024 & 1.0000 & 1.0000 \\
\hline & & & & & & & & & & & \\
\hline SIBL & 0.9962 & 1.0013 & 1.0007 & & 0.9999 & & 0.9999 & & & & 0.9974 \\
\hline TMBL & 0.9997 & 0.9995 & 1.0013 & & & & & & & & \\
\hline UTIB & 1.0315 & 1.0300 & 1.0038 & 1.0015 & 0.9935 & 0.9933 & 1.0063 & 0.9763 & 0.9697 & 1.0062 & 1.0039 \\
\hline HDFC & 0.9800 & 1.0046 & 1.0053 & 1.0043 & 1.0085 & 1.0102 & 1.0023 & 1.0027 & 1.0008 & 1.0119 & 1.0151 \\
\hline ICIC & 1.1393 & 1.0251 & 1.0066 & 1.0052 & 0.9918 & 1.0159 & 0.9983 & 1.0115 & & 1.0848 & 1.0150 \\
\hline INDB & 0.9535 & 1.0266 & 1.0313 & 1.0015 & 0.9976 & 1.0018 & 1.0054 & 0.9928 & 1.0004 & 0.9927 & 0.9835 \\
\hline & 1.0267 & & & & & & & & & 1.0004 & 0.9997 \\
\hline IBKL & 1.0017 & 1.0011 & 1.0052 & 0.9816 & 1.0132 & 1.0031 & 1.0355 & 1.0047 & 1.0018 & 1.0018 & 1.0007 \\
\hline KKBK & 1.0033 & 1.0636 & 1.0138 & 1.0201 & 0.9962 & & & & & 1.0003 & 1.0004 \\
\hline Average & 1.0095 & 1.0035 & 1.0006 & 0.9986 & 1.0031 & 1.0027 & 1.0035 & 1.0005 & 1.0002 & 1.0025 & 1.0003 \\
\hline
\end{tabular}

where multiple divisions are connected through intermediate products and multiple periods are linked through carryovers, the paper's significant contribution is an extension of MLPI to the dynamic MLPI (DMLPI) and dynamic sequential MLPI (DSMLPI) involving undesirable outputs and real data values. The proposed indexes capture productivity change subject to efficiency change and technical change independent of scale change. The sequential technique considers the past information of the data and eliminates the chance of detecting technical regress and inconsistency. To demonstrate the usefulness of the suggested indexes, we compare the findings from DMLPI and DSMLPI using data from 39 Indian commercial banks from 2008 to 2019. We discovered that the DSMLPI is a superior indicator for detecting efficiency changes than the DMLPI. The 
TABLE 16. Correlation coefficients between indexes and their components over the period 2008 to 2019 .

\begin{tabular}{|c|c|c|c|c|c|c|c|}
\hline & $\begin{array}{l}(\mathrm{EC}, \overline{\mathrm{EC}}) \\
(1)\end{array}$ & $\begin{array}{l}(\mathrm{TC}, \overline{\mathrm{TC}}) \\
(2)\end{array}$ & $\begin{array}{l}\text { (DMLPI, DSMLPI) } \\
(3)\end{array}$ & $\begin{array}{l}\text { (EC, DMLPI) } \\
(4)\end{array}$ & $\begin{array}{l}\text { (TC, DMLPI) } \\
(5)\end{array}$ & $\begin{array}{l}(\overline{\mathrm{EC}}, \mathrm{DSMLPI}) \\
(6)\end{array}$ & $\begin{array}{l}(\overline{\mathrm{TC}}, \mathrm{DSMLPI}) \\
(7)\end{array}$ \\
\hline 2008/09 & 0.72 & 0.26 & 0.58 & 0.44 & 0.96 & 0.34 & 0.72 \\
\hline $2009 / 10$ & 0.82 & 0.23 & 0.54 & 0.53 & 0.92 & 0.80 & 0.71 \\
\hline $2010 / 11$ & -0.17 & 0.00 & -0.18 & 0.19 & 0.99 & 0.75 & 0.53 \\
\hline $2011 / 12$ & 0.31 & 0.07 & 0.24 & 0.10 & 0.99 & 0.85 & -0.12 \\
\hline $2012 / 13$ & 0.49 & 0.30 & 0.26 & 0.27 & 0.96 & 0.73 & 0.43 \\
\hline $2013 / 14$ & 0.64 & 0.54 & 0.71 & 0.20 & 0.98 & 0.66 & 0.67 \\
\hline $2014 / 15$ & 0.33 & 0.23 & 0.44 & 0.29 & 0.97 & 0.82 & 0.38 \\
\hline $2015 / 16$ & 0.03 & 0.39 & 0.71 & 0.15 & 0.99 & 0.78 & 0.41 \\
\hline $2016 / 17$ & 0.21 & 0.84 & 0.74 & 0.21 & 0.99 & 0.57 & 0.74 \\
\hline $2017 / 18$ & 0.50 & 0.36 & 0.48 & 0.45 & 0.95 & 0.38 & 0.85 \\
\hline 2018/19 & -0.27 & -0.08 & 0.02 & 0.47 & 0.90 & 0.62 & 0.08 \\
\hline
\end{tabular}

TABLe 17. Coefficients ( $p$-value) of the panel data regression.

\begin{tabular}{lllllll}
\hline \multirow{2}{*}{ Predictors } & \multicolumn{5}{c}{ Dependent variables } \\
\cline { 2 - 7 } Labor & EC & TC & DMLPI & $\overline{\text { EC }}$ & $\overline{\text { TC }}$ & DSMLPI \\
& -7.37 & 33.52 & 26.02 & -8.75 & 14.77 & 5.08 \\
& $(-0.1977)$ & $(-0.1794)$ & $(-0.3043)$ & $(-0.2707)$ & $(-0.0871)$ & $(-0.6253)$ \\
\hline Borrowings & 0.037 & -0.073 & -0.036 & -0.093 & -0.012 & -0.114 \\
& $(-0.1391)$ & $(-0.5063)$ & $(-0.744)$ & $(-0.0082)$ & $(-0.7587)$ & $(-0.0134)$ \\
\hline Fixed assets & -0.982 & 1.9 & 0.928 & -2.537 & 3.361 & 0.63 \\
& $(-0.0059)$ & $(-0.2201)$ & $(-0.5551)$ & $(0)$ & $(0)$ & $(-0.3292)$ \\
\hline Operating expenses & 1.102 & 1.086 & 2.199 & 0.157 & 2.314 & 2.432 \\
& $(-0.0565)$ & $(-0.6661)$ & $(-0.3896)$ & $(-0.8442)$ & $(-0.0081)$ & $(-0.021)$ \\
\hline Deposits & 0.0002 & 0.189 & 0.19 & 0.005 & 0.04 & 0.046 \\
& $(-0.9784)$ & $(0)$ & $(0)$ & $(-0.6387)$ & $(-0.0011)$ & $(-0.0018)$ \\
\hline Investments & 0.062 & -0.859 & -0.798 & 0.028 & -0.297 & -0.264 \\
& $(-0.0614)$ & $(0)$ & $(0)$ & $(-0.5446)$ & $(0)$ & $(0)$ \\
\hline Loans & 0.014 & -0.007 & 0.007 & 0.015 & -0.031 & -0.016 \\
& $(-0.3182)$ & $(-0.9091)$ & $(-0.9153)$ & $(-0.4528)$ & $(-0.144)$ & $(-0.5248)$ \\
\hline Operating income & -0.363 & 1.717 & 1.355 & 0.21 & 0.503 & 0.737 \\
& $(-0.0521)$ & $(-0.0353)$ & $(-0.1014)$ & $(-0.4183)$ & $(-0.074)$ & $(-0.0303)$ \\
\hline Unused assets & -0.179 & -1.198 & -1.376 & -0.189 & 0.03 & -0.165 \\
& $(-0.0006)$ & $(0)$ & $(0)$ & $(-0.009)$ & $(-0.7063)$ & $(-0.082)$ \\
\hline Capital reserves & -0.504 & -19.273 & -19.77 & 0.043 & -1.36 & -1.231 \\
& $(-0.4258)$ & $(0)$ & $(0)$ & $(-0.9612)$ & $(-0.1545)$ & $(-0.2853)$ \\
\hline Net profit & -0.007 & -4.707 & -4.711 & 0.765 & 0.005 & 0.762 \\
& $(-0.9929)$ & $(-0.1419)$ & $(-0.1477)$ & $(-0.4529)$ & $(-0.9966)$ & $(-0.5683)$ \\
\hline Return on assets & -35.82 & 206.3 & 170.99 & -70.12 & 103.03 & 30.9 \\
& $(-0.462)$ & $(-0.3319)$ & $(-0.4282)$ & $(-0.3002)$ & $(-0.1611)$ & $(-0.7274)$ \\
\hline NPA & 0.304 & 1.128 & 1.429 & -0.034 & 0.42 & 0.376 \\
& $(-0.1686)$ & $(-0.2409)$ & $(-0.1435)$ & $(-0.9114)$ & $(-0.2064)$ & $(-0.3481)$ \\
\hline
\end{tabular}


discrepancies in estimations are attributable to the use of different postulates when constructing these indices. The empirical findings clearly reveal that productivity change measured by DMLPI is predominantly driven by technical change, however when measured by DSMLPI, both efficiency and technical change contributed to the productivity development of Indian banks. Our method is general in that it can handle network dynamic structures in series including any real data with both desirable and undesirable characteristics. There is currently no approach that can be utilised to compare the findings of our proposed method described in this research, to the best of our knowledge.

Extending the current research to a parallel network structure or more complicated network structures with a feedback mechanism has the potential to be fruitful in the future. Lin and Liu [47] supplied direction vector characterizations, resulting in a plausible super-efficiency DDF model. Lozano and Soltani [50] suggested utilising a multi-directional distance function approach to analyse efficiency. The two research papers provide motivation for developing new direction vectors for computing MLPI. The new directions could shorten the projections of DMUs on the efficient frontier and possibly project them to the strong efficient frontier. For measuring MLPI, Arabi et al. [5] suggested a slacks-based measure (SBM) technique. Integrating the SBM and DDF techniques to compute MLPI in a dynamic DEA network system may yield some interesting results.

Acknowledgements. We would like to thank the editor and the anonymous referees for their valuable suggestions which helped us to improve the quality of the paper substantially. The authors are responsible for any remaining errors.

\section{REFERENCES}

[1] A.I. Ali and L.M. Seiford, Translation invariance in data envelopment analysis. Oper. Res. Lett. 9 (1990) $403-405$.

[2] J. Aparicio, J.T. Pastor and J.L. Zofio, On the inconsistency of the Malmquist-Luenberger index. Eur. J. Oper. Res. 229 (2013) 738-742.

[3] J. Aparicio, J.T. Pastor and F. Vidal, The directional distance function and the translation invariance property. Omega $\mathbf{5 8}$ (2016) $1-3$.

[4] J. Aparicio, J. Barbero, M. Kapelko, J.T. Pastor and J.L. Zofío, Testing the consistency and feasibility of the standard Malmquist-Luenberger index: environmental productivity in world air emissions. J. Environ. Manage. 196 (2017) 148-160.

[5] B. Arabi, S. Munisamy and A. Emrouznejad, A new slacks-based measure of Malmquist-Luenberger index in the presence of undesirable outputs. Omega 51 (2015) 29-37.

[6] N.K. Avkiran, An illustration of dynamic network DEA in commercial banking including robustness tests. Omega 55 (2015) $141-150$.

[7] W. Briec and K. Kerstens, Infeasibility and directional distance functions with application to the determinateness of the luenberger productivity indicator. J. Optim. Theory App. 141 (2009) 55.

[8] W. Briec and K. Kerstens, The luenberger productivity indicator: an economic specification leading to infeasibilities. Econ. Modell. 26 (2009) 597-600.

[9] D.W. Caves, L.R. Christensen and W.E. Diewert, The economic theory of index numbers and the measurement of input, output, and productivity. Econ. J. Econ. Soc. 50 (1982) 1393-1414.

[10] Y.-T. Chang, H.K. Park, B. Zou and N. Kafle, Passenger facility charge vs. airport improvement program funds: a dynamic network DEA analysis for US airport financing. Transp. Res. Part E: Logistics Transp. Rev. 88 (2016) 76-93.

[11] A. Charnes, W.W. Cooper, B. Golany, R. Halek, G. Klopp, E. Schmitz and D. Thomas, Two phase data envelopment analysis approaches to policy evaluation and management of army recruiting activities: tradeoffs between joint services and army advertising. In: Center for Cybernetic Studies. University of Texas-Austin Austin, Texas, USA (1986).

[12] Y. Chen, A non-radial Malmquist productivity index with an illustrative application to Chinese major industries. Int. J. Prod. Econ. 83 (2003) 27-35.

[13] K. Chen and J. Zhu, Scale efficiency in two-stage network DEA. J. Oper. Res. Soc. 70 (2019) 101-110.

[14] Y.H. Chung, R. Färe and S. Grosskopf, Productivity and undesirable outputs: a directional distance function approach. J. Environm. Manage. 51 (1997) 229-240.

[15] T.J. Coelli, D.S.P. Rao, C.J. O'Donnell and G.E. Battese, An Introduction to Efficiency and Productivity Analysis. Springer Science \& Business Media (2005).

[16] W.D. Cook, L. Liang and J. Zhu, Measuring performance of two-stage network structures by DEA: a review and future perspective. Omega 38 (2010) 423-430.

[17] C.A. Denizer, M. Dinc and M. Tarimcilar, Financial liberalization and banking efficiency: evidence from Turkey. J. Prod. Anal. 27 (2007) 177-195.

[18] J. Du, Y. Chen and Y. Huang, A modified Malmquist-Luenberger productivity index: assessing environmental productivity performance in China. Eur. J. Oper. Res. 269 (2018) 171-187. 
[19] J. Du, Y. Duan and J. Xu, The infeasible problem of Malmquist-Luenberger index and its application on China's environmental total factor productivity. Ann. Oper. Res. 278 (2019) 235-253.

[20] A. Emrouznejad and E. Thanassoulis, A mathematical model for dynamic efficiency using data envelopment analysis. Appl. Math. Comput. 160 (2005) 363-378.

[21] A. Emrouznejad and E. Thanassoulis, Measurement of productivity index with dynamic DEA. Int. J. Oper. Res. 8 (2010) 247.

[22] A. Emrouznejad and G.-L. Yang, A framework for measuring global Malmquist-Luenberger productivity index with $\mathrm{CO}_{2}$ emissions on Chinese manufacturing industries. Energy 115 (2016) 840-856.

[23] A. Emrouznejad, A.L. Anouze and E. Thanassoulis, A semi-oriented radial measure for measuring the efficiency of decision making units with negative data using DEA. Eur. J. Oper. Res. 200 (2010) 297-304.

[24] G. Falavigna, R. Ippoliti and G.B. Ramello, DEA-based Malmquist productivity indexes for understanding courts reform. Soc.-Econ. Planning Sci. 62 (2018) 31-43.

[25] R. Färe and S. Grosskopf, Intertemporal production frontiers with dynamic DEA. In: Kluwer Academic, collaboration with R. Briinnlund et al. Boston (1996).

[26] R. Färe, S. Grosskopf and C.A.K. Lovell, Production Frontiers. Cambridge University Press (1994).

[27] R. Färe, S. Grosskopf, M. Norris and Z. Zhang, Productivity growth, technical progress, and efficiency change in industrialized countries. Am. Econ. Rev. 84 (1994) 66-83.

[28] D. Fernández, C. Pozo, R. Folgado, L. Jiménez and G. Guillén-Gosálbez, Productivity and energy efficiency assessment of existing industrial gases facilities via data envelopment analysis and the Malmquist index. Appl. Energy 212 (2018) 15631577.

[29] H. Fukuyama and W.L. Weber, Measuring Japanese bank performance: a dynamic network DEA approach. J. Prod. Anal. 44 (2015) 249-264.

[30] H. Fukuyama and W.L. Weber, Japanese bank productivity, 2007-2012: a dynamic network approach. Pac. Econ. Rev. 22 (2017) 649-676.

[31] H. Fukuyama, R. Matousek and N.G. Tzeremes, A Nerlovian cost inefficiency two-stage DEA model for modeling banks' production process: evidence from the Turkish banking system. Omega 95 (2020) 102198

[32] S. Ghobadi, A generalized DEA model for inputs (outputs) estimation under inter-temporal dependence. RAIRO-Oper. Res. 53 (2019) 1791-1805.

[33] E. Grifell-Tatjé and C.A.K. Lovell, A note on the Malmquist productivity index. Econ. Lett. 47 (1995) $169-175$.

[34] I.C. Henriques, V.A. Sobreiro, H. Kimura and E.B. Mariano, Two-stage DEA in banks: terminological controversies and future directions. Expert Syst. App. 161 (2020) 113-632.

[35] O. Herrera-Restrepo, K. Triantis, J. Trainor, P. Murray-Tuite and P. Edara, A multi-perspective dynamic network performance efficiency measurement of an evacuation: a dynamic network-DEA approach. Omega 60 (2016) 45-59.

[36] D. Holod and H.F. Lewis, Resolving the deposit dilemma: a new DEA bank efficiency model. J. Banking Finance 35 (2011) $2801-2810$.

[37] J. Jablonsky, Ranking of countries in sporting events using two-stage data envelopment analysis models: a case of Summer Olympic Games 2016. Central Eur. J. Oper. Res. 26 (2018) 951-966.

[38] G.R. Jahanshahloo and M. Piri, Data Envelopment Analysis (DEA) with integer and negative inputs and outputs. J. Data Envelopment Anal. Decis. Sci. 2013 (2013) 1-15.

[39] A.R. Jayaraman and P. Bhuyan, Impact of NPA and loan write-offs on the profit efficiency of Indian banks. Decision 47 (2020) $35-48$.

[40] C. Kao, Dynamic data envelopment analysis: a relational analysis. Eur. J. Oper. Res. 227 (2013) 325-330.

[41] C. Kao, Network data envelopment analysis: a review. Eur. J. Oper. Res. 239 (2014) 1-16.

[42] C. Kao, Network Data Envelopment Analysis: Foundations and Extensions. Springer (2017).

[43] S. Kourtzidis, R. Matousek and N.G. Tzeremes, Modelling a multi-period production process: evidence from the Japanese regional banks. Eur. J. Oper. Res. 294 (2021) 327-339.

[44] S. Kumar, Environmentally sensitive productivity growth: a global analysis using Malmquist-Luenberger index. Ecol. Econ. 56 (2006) 280-293.

[45] R. Lin and Z. Chen, Super-efficiency measurement under variable return to scale: an approach based on a new directional distance function. J. Oper. Res. Soc. 66 (2015) 1506-1510.

[46] R. Lin and Z. Chen, A directional distance based super-efficiency DEA model handling negative data. J. Oper. Res. Soc. 68 (2017) 1312-1322.

[47] R. Lin and Y. Liu, Super-efficiency based on the directional distance function in the presence of negative data. Omega 85 (2019) 26-34.

[48] C.A.K. Lovell, The decomposition of malmquist productivity indexes. J. Prod. Anal. 20 (2003) 437-458.

[49] C.A.K. Lovell, J.T. Pastor and J.A. Turner, Measuring macroeconomic performance in the OECD: a comparison of European and non-European countries. Eur. J. Oper. Res. 87 (1995) 507-518.

[50] S. Lozano and N. Soltani, Efficiency assessment using a multidirectional DDF approach. Int. Trans. Oper. Res. 27 (2020) 2064-2080.

[51] S. Malmquist, Index numbers and indifference surfaces. Trabajos de Estadistica y de Investigacion Operativa 4 (1953) $209-242$.

[52] F.B. Mariz, M.R. Almeida and D. Aloise, A review of dynamic data envelopment analysis: state of the art and applications. Int. Trans. Oper. Res. 25 (2018) 469-505. 
[53] R.K. Matin, G.R. Amin and A. Emrouznejad, A modified semi-oriented radial measure for target setting with negative data. Measurement 54 (2014) 152-158.

[54] P. Moreno and S. Lozano, Super SBI Dynamic Network DEA approach to measuring efficiency in the provision of public services. Int. Trans. Oper. Res. 25 (2018) 715-735.

[55] E. Njuki, B.E. Bravo-Ureta and C. J. O'Donnell, Decomposing agricultural productivity growth using a random-parameters stochastic production frontier. Empirical Econ. 57 (2019) 839-860.

[56] D.-H. Oh and A. Heshmati, A sequential Malmquist-Luenberger productivity index: environmentally sensitive productivity growth considering the progressive nature of technology. Energy Econ. 32 (2010) 1345-1355.

[57] K.S. Park and K. Park, Measurement of multiperiod aggregative efficiency. Eur. J. Oper. Res. 193 (2009) $567-580$.

[58] M.C.A.S. Portela and E. Thanassoulis, Malmquist-type indices in the presence of negative data: an application to bank branches. J. Banking Finance 34 (2010) 1472-1483.

[59] M.C.A.S. Portela, E. Thanassoulis and G. Simpson, Negative data in DEA: a directional distance approach applied to bank branches. J. Oper. Res. Soc. 55 (2004) 1111-1121.

[60] S.C. Ray and E. Desli, Productivity growth, technical progress, and efficiency change in industrialized countries: comment. Am. Econ. Rev. 87 (1997) 1033-1039.

[61] R.R. Russell and W. Schworm, Technological inefficiency indexes: a binary taxonomy and a generic theorem. J. Prod. Anal. 49 (2018) 17-23.

[62] H. Scheel, Undesirable outputs in efficiency valuations. Eur. J. Oper. Res. 132 (2001) 400-410.

[63] L.M. Seiford and J. Zhu, Modeling undesirable factors in efficiency evaluation. Eur. J. Oper. Res. 142 (2002) 16-20.

[64] J.A. Sharp, W. Meng and W. Liu, A modified slacks-based measure model for data envelopment analysis with 'natural' negative outputs and inputs. J. Oper. Res. Soc. 58 (2007) 1672-1677.

[65] V. Shestalova, Sequential Malmquist indices of productivity growth: an application to OECD industrial activities. J. Prod. Anal. 19 (2003) 211-226.

[66] R.M. Solow, Technical change and the aggregate production function. Rev. Econ. Stat. 39 (1957) 312-320.

[67] M. Tavana, M. Izadikhah, D. Di Caprio and R.F. Saen, A new dynamic range directional measure for two-stage data envelopment analysis models with negative data. Comput. Ind. Eng. 115 (2018) 427-448.

[68] K. Tone and M. Tsutsui, Dynamic DEA: a slacks-based measure approach. Omega 38 (2010) 145-156.

[69] K. Tone and M. Tsutsui, Dynamic DEA with network structure: a slacks-based measure approach. Omega 42 (2014) $124-131$.

[70] H. Tulkens and P.V. Eeckaut, Non-parametric efficiency, progress and regress measures for panel data: methodological aspects. Eur. J. Oper. Res. 80 (1995) 474-499.

[71] B. Walheer, Malmquist productivity index for multi-output producers: an application to electricity generation plants. Soc.Econ. Plan. Sci. 65 (2019) 76-88.

[72] D.C. Wheelock and P.W. Wilson, Technical progress, inefficiency, and productivity change in us banking, 1984-1993. J. Money Credit Bank. 31 (1999) 212-234.

[73] A. Zanella, A.S. Camanho and T.G. Dias, Undesirable outputs and weighting schemes in composite indicators based on data envelopment analysis. Eur. J. Oper. Res. 245 (2015) 517-530.

[74] Y. Zha, N. Liang, M. Wu and Y. Bian, Efficiency evaluation of banks in China: a dynamic two-stage slacks-based measure approach. Omega 60 (2016) 60-72.

[75] J.L. Zofio, Malmquist productivity index decompositions: a unifying framework. Appl. Econ. 39 (2007) $2371-2387$.

\section{Subscribe to Open (S20) A fair and sustainable open access model}

This journal is currently published in open access under a Subscribe-to-Open model (S2O). S2O is a transformative model that aims to move subscription journals to open access. Open access is the free, immediate, online availability of research articles combined with the rights to use these articles fully in the digital environment. We are thankful to our subscribers and sponsors for making it possible to publish this journal in open access, free of charge for authors.

\section{Please help to maintain this journal in open access!}

Check that your library subscribes to the journal, or make a personal donation to the S2O programme, by contacting subscribers@edpsciences.org

More information, including a list of sponsors and a financial transparency report, available at: https://www. edpsciences.org/en/maths-s2o-programme 